\title{
Investigação do Processo de Desenvolvimento de Software a partir da Modelagem Organizacional, enfatizando regras do negócio.
}

\section{Silvia Inês Dallavalle de Pádua}

Dissertação apresentada à Escola de Engenharia de São Carlos da Universidade de São Paulo, como parte dos requisitos para obtenção do título de Mestre em Engenharia de Produção

ORIENTADOR: Edson Walmir Cazarini

São Carlos

2001 


\section{Dedicatória}

Aos meus pais, que sempre me apoiaram, abdicando dos seus próprios sonhos para que os meus pudessem ser realizados, incentivando e dando forças para continuar o meu caminho. Sem vocês eu nada seria. Obrigada!

Ao Joubert, meu marido, pelo carinho, companheirismo, por compreender minha ausência e sempre acreditar em mim. Agradeço também por me contagiar todos os dias com tantas energias positivas, transformando pequenos instantes em grandes momentos. 
Se procurar bem, você acaba encontrando não a explicação (duvidosa) da vida, mas a poesia (inexplicável) da vida".

Carlos Drummond de Andrade. 


\section{Agradecimentos}

A Deus, pela saúde, disposição e vontade de trabalhar que tenho todos os dias.

Ao professor Dr. Edson Walmir Cazarini, reservo minha gratidão pelo respeito as minhas idéias, pela amizade, apoio e orientação.

À CAPES (Coordenação de Aperfeiçoamento de Pessoal de Ensino Superior), pelo apoio financeiro, fundamental para conclusão desse trabalho.

Ao professor Dr. Renato Vairo Belhot, pela atenção nos momentos de dúvidas.

Aos funcionários do Departamento de Engenharia de Produção da Escola de Engenharia de São Carlos da USP.

Às professoras Dras. Roseli Sanches e Ethel Cristina Chiari da Silva, pela importante contribuição na Banca de Qualificação.

Ao professor Dr. João do Espirito Santo Batista, pelo valioso apoio que tenho recebido desde a graduação até os dias atuais.

Aos professores Drs. Edmundo, Bremer, Cazarini, Renato, e Renata (ICMC), pelos conhecimentos que me foram passados, pela dedicação que fora dada, pelas orientações que me ajudaram a chegar até aqui e que seguirão comigo tanto na vida pessoal quanto profissional.

Aos amigos João, Tales, Fabrícia, Lauro, Fábio, Bispo, Íris, Rosana e Angelita, pela convivência e troca de experiências que com certeza, ajudaram-me a evoluir um pouco mais como ser humano e também como profissional.

A bibliotecária Eleninha, da Biblioteca Central da Escola de Engenharia de São Carlos EESC-USP, pela grande ajuda na correção das referências bibliográficas.

A Biblioteca da Universidade de Ribeirão Preto, na pessoa da Irene e da bibliotecária chefe Antônia Terezinha Marcantonio.

Aos professores Paulo Sprovieri e Osvaldo Takai, da Universidade de Ribeirão PretoUNAERP, pelo incentivo científico na graduação.

Eternamente agradeço aos meus pais pela vida e cuidados que me deram.

Ao Joubert, meu marido, por compreender minha ausência, me incentivando em todos os momentos e por ser essa luz que sempre brilha na minha vida. 


\section{SUMÁRIO}

LISTA DE FIGURAS

III

LISTA DE TABELAS

IV

LISTA DE ABREVIATURAS V

RESUMO

VI

ABSTRACT

VII

1. INTRODUCÃO 1

1.1. MotivaÇÃo do Trabalho

3

1.2. OBJETIVO

1.3. LiMitaÇÕES DO Trabalho

7

1.4. MÉTOdo de PESQUiSa

1.4.1. PERGUNTAS DE PESQUisa

1.4.2. EscolHa do MÉTOdo de PESQUiSA

1.5. ORganizaÇão do Trabalho

2. MODELAGEM ORGANIZACIONAL 11

2.1. CONSIDERAÇÕES INICIAIS

2.2. MODELO ORGANIZACIONAL

2.3. MODELAGEM ORgaNIZACIONAL DE BUBENKO (1993)

2.4. CONSIDERAÇÕES FINAIS

3.1. CONSIDERAÇÕES INICIAIS

3.2. O QUE SÃo REGRAS DO NEGÓCIO?

3.3. REPRESENTAÇÃO DE REGRAS DO NEGÓCIO

3.3.1. A ESTRUTURA ECAA 
3.3.2. ABSTRAÇÕES E REFINAMENTO DE REGRAS DO NEGÓCIO 31

3.3.3. UM MODELO PARA REGRAS DO NEGÓCIO 33

3.3.4. REGRAS DO NEGÓCIO NO AMBIENTE

3.3.5. UM SISTEMA REPOSITÓRIO PARA REGRAS DO NEGÓCIO 39

3.4. REgRAS DO NEGÓCIO NA ORgANIZAÇÃo 39

3.5. Regras do Negócio: AbORdagem de APOIO À decisÃo 43

3.5.1. ARQUITETURA: APOIO À DECISÃO X CICLO DE VIDA DE REGRAS DO NEGÓCIO 44

3.5.2. ESTRUTURA PARA REPRESENTAR O CONHECIMENTO DO DOMÍNIO 49

3.5.3. TAXINOMIA DE REGRAS DO NEGÓCIO 51

3.5.4. UM METAMODELO PARA O AMBIENTE DE REGRAS DO NEGÓCIO

3.5.5. MÉTODO DE EXTRAÇÃO DE REGRAS DO NEGÓCIO BASEADO SAD 55

3.5.6. METODOLOGIA 57

3.6. REgRAS DO NEGóCIO COMO BASELINE DE REQUISITOS

3.7. CONSIDERAÇÕES FINAIS $\quad 64$

4. MODELAGEM ORGANIZACIONAL: UMA NOVA ABORDAGEM

4.1. CONSIDERAÇÕES INICIAIS 66

4.2. AS MUDANÇAS NA ORGANIZAÇÃO

4.3. CONHECIMENTO ORGANIZACIONAL

4.4. O QUE É EKD?

4.5. COMPONENTES DO EKD

4.6. COMO USAR EKD $\quad \mathbf{7 6}$

4.6.1. MOdELO de OBJETIVOS 80

4.6.2. MODELO DE REGRAS DO NEGÓCIO 91

4.6.3. MODELO DE CONCEITOS 96

4.6.4. MODELO DE PROCESSO DO NEGÓCIO 101

4.6.5. MODELO DE ATORES E RECURSOS 107

4.6.6. MODELO DE REQUISITOS E COMPONENTES TÉCNICOS 111

4.6.7. RELACIONAMENTOS ENTRE OS SUBMODELOS 116

4.7. COMPONENTES PARA AUXILIAR A MODELAGEM 118

4.8. UTILIZAÇÃO DA ABORDAGEM EKD

4.9. CONSIDERAÇÕES FINAIS

5. CONCLUSÃO 135

6. REFERÊNCIA BIBLIOGRÁFICA 141 


\section{Lista de Figuras}

Figura 1 - DESENVOLVIMENTO ESTRATÉGICO DE SOFTWARE. 8

FIGURA 2- MODELO ORGANIZACIONAL E SEUS MODELOS RELACIONADOS. _ 21

FigURA 3- ESPECIALIZAÇÃO DE REGRAS DO NEGÓCIO. ___ 32

FIGURA 4- ENCAIXANDO REGRAS DO NEGÓCIO NO AMBIENTE. ___ 38

FigURA 5- COLOCAÇÃO DO CONTEXTO DE REGRAS DO NEGÓCIO. ___ 40

FIGURA 6-CONTEXTO DE REGRAS DO NEGÓCIO. ___ 41

FIGURA 7- ANÁLISE DE SISTEMAS FOCANDO EM REGRAS DO NEGÓCIO. ___ 43

FIGURA 8- ARQUITETURA PARA CICLO DE VIDA DE REGRAS DO NEGÓCIO NO SAD. —_ 46

FIGURA 9- ESTRUTURA DE APOIO À DECISÃO BASEADO-QUESTÃO. _ _ 50

FIGURA 10- TAXINOMIA DE REGRAS DO NEGÓCIO. 53

FIGURA 11 - O AMBIENTE DE REGRAS DO NEGÓCIO. —_ 54

FIGURA 12- AQUISIÇÃO DE REGRAS DO NEGÓCIO. —_ 58

FIGURA 13- EXEMPLO DE ESTÍMULO/RESPOSTA (DISPARADOR). — 58

FiguRA 14- DESENVOLVIMENTO DE REGRAS DO NEGÓCIO. ___ 60

FIGURA 15- EVOLUÇÃO DE REGRAS DO NEGÓCIO. __ 61

FIGURA 16-TAXINOMIA PARA REGRAS DO NEGÓCIO____ 63

FIGURA 17- CONTEÚDO DA ESTRUTURA DO EKD ___ 71

FIGURA 18- UMA VISÃO DA MODELAGEM EKD. 73

FIGURA 19 - TIPOS DE ATIVIDADES ENVOLVIDAS NO PROCESSO EKD. 78

FIGURA 20 - SUBMODELOS QUE COMPÕEM O MODELO ORGANIZACIONAL.___ 80

FIGURA 21 - FRAÇÃO DE UM MODELO DE OBJETIVOS CONTENDO RELACIONAMENTO AND. _ 83

FIGURA 22 - FRAÇÃO DE UM MODELO DE OBJETIVOS CONTENDO RELACIONAMENTO OR. _— 83

FiguRA 23 - NOTAÇÕES DO MODELO DE OBJETIVOS. ___ 84

FIGURA 24 - MATRIZ DE CLASSIFICAÇÃO POR CATEGORIAS.____ 88

FIGURA 25: MATRIZ DE CORRELAÇÃO DE OBJETIVOS.____ 88

FiguRA 26- PARTE DE UM MODELO DE OBJETIVOS DE CASO DE UMA BIBLIOTECA.__ 90

FIGURA 27 - ESTRUTURA DE REGRAS DO NEGÓCIO. —_ 92

FIGURA 28- REGRAS REFEREM-SE A ENTIDADES DO MODELO DE CONCEITOS E SÃO APOIADAS POR PROCESSOS NO MODELO DE PROCESSOS DO NEGÓCIO.___ 94

FIGURA 29- INTERAÇÃO ENTRE O MODELO DE REGRAS DO NEGÓCIO E COMPONENTES DO MODELOS DE OBJETIVOS. ___ 95

FIGURA 30 - EXEMPLO DE RELACIONAMENTO BINÁRIO._____ 97

FIGURA 31 - O CONCEITO DE "CLIENTE" PODE SER ESPECIALIZADO DE FORMAS DIFERENTES.__ 98

FIGURA 32- EXEMPLO DE RELACIONAMENTO PARTOF. ___ 99

FIGURA 33 - NOTAÇÃO PARA MODELAGEM DO MODELO DE CONCEITOS _ 101

FIGURA 34- O PROCESSO VERIFICAÇÃO DO ENDEREÇO DO CLIENTE NÃO É DECOMPOSTO. _ _ 103

FIGURA 35- O PROCESSO VERIFICAÇÃO DE ENDEREÇO É DECOMPOSTO EM QUATRO SUBPROCESSOS.

FiguRA 36- UM EXEMPLO DE MODELO DE PROCESSOS DE NEGÓCIO. ___ 104

Figura 37- NotAÇÃo do MODELO DE ATORES E RECURSOS. ___ _ 110

Figura 38- UM EXEMPLO DE MODELO DE RECURSOS E ATORES DE UMA BIBLIOTECA. __ 111

FiguRA 39 - EXEMPLO DE UM MODELO DE REQUISITOS E COMPONENTES TÉCNICOS. ___ 115

FIGURA 40- RELAÇÕES ENTRE SUBMODELOS_________________ 118 


\section{Lista de Tabelas}

TABELA 1 -PRINCIPAIS CARACTERÍSTICAS DOS COMPONENTES DO MODELO DE OBJETIVOS. ..........................20

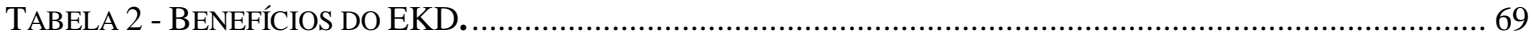

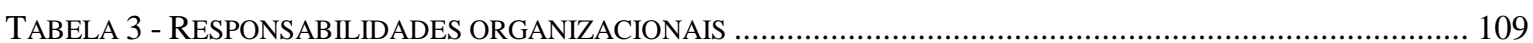




\section{Lista de Abreviaturas}

$\begin{array}{ll}\text { AOO } & \text { Análise Orientada a Objeto } \\ \text { ECA } & \text { Evento, Condição, Então-Ação } \\ \text { ECAA } & \text { Evento, Condição, Então-Ação, Se não-Ação } \\ \text { ELEKTRA } & \text { ELectrical Enterprise Knowledge for TRansforming Applications } \\ \text { EKD } & \text { Enterprise Knowledge Development } \\ \text { LEL } & \text { Language Extended Lexicon } \\ \text { MA } & \text { Modelo de Atores } \\ \text { MAU } & \text { Modelo de Atividades e Uso } \\ \text { MC } & \text { Modelo de Conceitos } \\ \text { MO } & \text { Modelo de Objetivos } \\ \text { MRSI } & \text { Modelo de Requisitos do Sistema de Informação } \\ \text { MSI } & \text { Modelo do Sistema de Informação } \\ \text { NRNF } & \text { Modelo de Requisitos Não-Funcionais } \\ \text { OO } & \text { Orientação a Objeto } \\ \text { Relação ISA } & \text { Generalização } \\ \text { SAD } & \text { Sistemas de Apoio à Decisão } \\ \text { SD } & \text { Modelo de Dependências Estratégicas } \\ \text { SR } & \text { Modelo de Razões Estratégicas } \\ \text { ECOM } & \text { European Electricity Company } \\ \text { EU } & \text { European Union } \\ \text { PPC } & \text { Public Power Corporation }\end{array}$




\section{Resumo}

PÁDUA, S.I.D. (2000). Investigação do processo de desenvolvimento de Software a partir da Modelagem Organizacional, enfatizando regras do negócio. São Carlos. 145 p. Dissertação (Mestrado) - Escola de Engenharia de São Carlos, Universidade de São Paulo.

A preocupação da Engenharia de Software esteve por muito tempo relacionada a aspectos da funcionalidade do sistema, ou seja, com "o que" e "como" fazer e não com o "por que" fazer. Tais aspectos, envolvidos nos processos existentes, buscam a definição das propriedades desejadas, em lugar de observarem a informação de uma forma mais ampla, começando com as necessidades do próprio negócio, ou dos objetivos dos sistemas nele embutidos. As técnicas de análise estruturadas, diagrama de fluxo de dados e modelagem entidade e relacionamento modelam importantes conceitos para o desenvolvimento de sistemas, mas não buscam por soluções alternativas inovadoras aos problemas da organização. É comum encontrar situações onde o sistema não satisfaz às reais necessidades do negócio, embora esteja tecnicamente correto. $\mathrm{O}$ entendimento dos aspectos sociais, organizacionais, técnicos, jurídicos e econômicos é essencial para a realização de um bom trabalho de engenharia de requisitos. Nesse sentido, a modelagem organizacional facilita a compreensão do ambiente empresarial e é reconhecida como uma atividade valiosa pela engenharia de requisitos. O modelo organizacional representa o "mundo" onde se aplicam as regras do negócio. O entendimento das regras do negócio é muito importante para a organização ser flexível em um ambiente de crescente competitividade. Com a necessidade de se ter a modelagem dos aspectos relativos à organização para que o sistema atenda as suas reais necessidades, o presente trabalho tem como objetivo investigar o processo de desenvolvimento de software buscando conhecer técnicas ou métodos que atendem aos requisitos organizacionais, enfatizando o uso de regras do negócio com a finalidade de obter a especificação de requisitos.

Palavras-chaves: Modelagem Organizacional, Regras do Negócio, Desenvolvimento de Software, Engenharia de Requisitos, UML e Use Case. 


\section{Abstract}

PÁDUA, S.I.D. Investigation of the process in Software Development based on Enterprise Modeling, emphasizing business rules. São Carlos, 114p. Dissertação (Mestrado) - Escola de Engenharia de São Carlos, Universidade de São Paulo.

The Software Engineering's focus were for a long time related to system's functionality aspects, or with "what" and "how" to do, and not with "why" to do. Those aspects in the existents process are looking for the definition of the desired proprieties instead observe the information in a more large aspect, beginning with the business needs itself or the systems goals inserted in it. The structure analysis techniques, flux data diagram, and relationship and entity modeling form important concepts for systems development but do not search for innovating alternatives solutions for organization 's problems. It is very common to find situations were the system does not satisfy the real business needs, thought it is technically correct. The comprehension of social, organizational, technical, juridical and economics aspects are essential for a good realization of requirements in engineering work. In that way the enterprise modeling makes the business environment comprehension easier and is recognized as a value activity by the Requirements Engineering. The Enterprise model represents the "world" where the business rules are applied. The comprehension of the business rules is very important so the organization can be flexible in a growing competitive environment. With the necessity to have a modeling of the relative aspects to the organization so the system can accomplish the real needs, this present research has the objective to investigate a software development process trying to find techniques or methods that answer the enterprise's requirement, emphasizing the use of business rules to obtain the specifics requirements

Keywords: Enterprise Modeling, Business Rules, Software Development, Requirements Engineering, UML and Use Case. 


\section{Introdução}

Nas últimas décadas os sistemas computacionais foram difundidos em quase todos os setores, buscando uma ampla melhoria da qualidade e rapidez dos serviços e produtos oferecidos pelas organizações a seus clientes e usuários. Para acompanhar essa demanda, houve um desenvolvimento desordenado de software, chamado por PRESSMAN (1994) como Crise do Software ou Doença do Software. Isso ocorreu porque os desenvolvedores não estavam, como ainda não estão, preparados o suficiente, principalmente para tratar, sistematicamente, com os sistemas complexos e de grande porte que, em grande escala, entram na vida pessoal, governamental e comercial. As técnicas de desenvolvimento de software, quando aplicadas, não eram apropriadas para esses tipos de sistemas. Por isso, surgiram problemas que até hoje se perpetuam, tais como: estimativas de custo e cronogramas mal estipulados, dados duplicados e sem controle, regras do negócio diferenciadas para um mesmo assunto dentro da empresa e baixa qualidade no desenvolvimento de serviços e produtos.

A Engenharia de Software surgiu com o propósito de resolver os problemas da Crise do Software, tendo como princípio obter softwares mais confiáveis, eficientes e passíveis de certificação. A engenharia de software abrange, segundo PRESSMAN (1994), um conjunto de três elementos fundamentais: métodos, ferramentas e procedimentos. Os métodos trazem os detalhes de como fazer para construir o software, incluindo tarefas como planejamento, estimativa de projeto, análise de requisitos de software e de sistema até codificação. As ferramentas dão apoio automatizado aos métodos. Os procedimentos possibilitam o desenvolvimento racional e oportuno do software, definindo a seqüência em que os métodos serão aplicados e os produtos que se exigem que sejam entregues; assim como os controles para assegurar a qualidade e coordenar as mudanças.

O processo de engenharia de software se inicia, na maioria das vezes, com a necessidade de automatizar processos manuais, visando o aumento da produtividade e eficiência. Ao iniciar um processo de engenharia de software é importante definir os requisitos do ambiente, fase essa considerada a mais trabalhosa de todos os estágios de desenvolvimento. Muitos dos problemas oriundos de sistemas mal desenvolvidos são causados por falhas na fase de análise, resultando na produção de um sistema que não satisfaz às necessidades do cliente. Como conseqüência, diversas tarefas do ciclo de desenvolvimento de software devem ser refeitas, o que eleva o seu custo. Segundo KOTONYA \& SOMMERVILLE (1996), o modelo só será completo se o ambiente onde o sistema interage também for modelado, caso contrário, os requisitos modelados não refletirão a atual necessidade. PRESSMAN (1994) explica que mesmo o sistema sendo bem projetado ou 
codificado, se a análise e especificação de requisitos forem pobres, o cliente ficará desapontado e levará o fracasso ao desenvolvedor. Nesse contexto, a Engenharia de Requisitos surge na tentativa de prover um modelo claro, consistente, preciso e exato do problema a ser resolvido. Para isso, é necessário o entendimento dos aspectos sociais, organizacionais, técnicos, econômicos e jurídicos envolvidos no ambiente onde o sistema será inserido. Em geral, a captura e entendimento dos requisitos não são uma tarefa simples, por se tratar muitas vezes de problemas ainda abstratos para o cliente.

Segundo ALENCAR (1999) e ROLLAND ${ }^{\text {a }}$ et al (1999), a preocupação da Ciência da Computação esteve por muito tempo extremamente relacionada com aspectos da funcionalidade do sistema, ou seja, com "o que" e "como" fazer e não com o "por que" fazer, envolvidos nos processos decisórios existentes. Para ALENCAR (1999), as técnicas normalmente utilizadas na administração modelam a estrutura interna da organização, evidenciando suas funções, dados e estratégias, tendo hoje como inovadora a modelagem de processos. Muitas organizações têm reconhecido que para ser flexível em um ambiente de crescente competitividade, é importante ter um claro entendimento das regras do negócio da organização. O entendimento dos aspectos sociais, organizacionais, técnicos, jurídicos e econômicos é essencial para a realização de um bom trabalho de engenharia de requisitos. A grande maioria das técnicas atualmente utilizadas está preocupada com a definição das propriedades desejadas, em lugar de observar a informação de uma forma mais ampla, a começar das necessidades do próprio negócio, ou dos objetivos dos sistemas nele embutidos. As técnicas de análise estruturadas, diagrama de fluxo de dados e modelagem de entidade-relacionamento modelam importantes conceitos para o desenvolvimento de sistemas, mas pouco ajudam na busca por soluções alternativas e inovadoras aos problemas da organização. Nota-se que é comum encontrar situações onde muitos sistemas não satisfazem as reais necessidades do negócio, embora estejam tecnicamente corretos. TAURION (1999) afirma que sem mudanças na maneira de pensar e de usar a tecnologia dentro da empresa para adicionar valor ao negócio, será difícil justificar os investimentos na Tecnologia da Informação. Na busca pelo aumento da rentabilidade e produtividade, não se pode esperar que os computadores por si só transformem uma empresa ineficiente em uma moderna e ágil organização.

Segundo ACHOUR et al. (1999), para desenvolver um sistema com qualidade é necessário requisitos de qualidade, por isso a engenharia de requisitos representa uma importante fase de um projeto de desenvolvimento de software. A engenharia de requisitos é um processo cooperativo e de aprendizagem interativa. Como um processo de aprendizagem interativa, na fase de engenharia de requisitos são realizados: a elicitação, a validação, a revisão e a especificação. Além disso, como um processo cooperativo, a elicitação de requisitos envolve múltiplos 
stakeholders $^{1}$ os quais visam à comunicação e entendimento entre usuários, clientes, especialistas no domínio, gerentes de projeto, entre outros. Muitos desses stakeholders não têm nenhuma habilidade de engenharia de requisitos. Eles não sabem como realizar a análise dos requisitos e as linguagens de especificação não fazem parte do seu vocabulário. Existe um vazio entre o usuário, que tem as necessidades mas não sabe como especificá-las como requisitos; e engenheiro de requisitos que sabe especificar requisitos, mas não conhece as necessidades. Em reação a essa questão, a engenharia de requisitos vem deslocando o foco de interesse da tecnologia para o usuário.

JACOBSON et al. (1998), explicam que atualmente muitas pessoas desenvolvem software usando os mesmos métodos de 25 anos atrás. Sem atualizar os métodos, não será possível alcançar a meta de desenvolvimento de softwares que são exigidos cada vez maiores e mais complexos pelo mercado. Isso é devido, em parte, ao fato dos computadores terem se tornado mais poderosos a cada ano, levando os usuários a esperarem mais deles. Essa tendência também é influenciada pela expansão do uso da Internet para trocar todos os tipos de informação, desde textos simples até imagens em tempo real.

FURLAN (1997), afirma que apesar da necessidade urgente de transformação para se adequar ao mundo globalizado, as organizações tradicionais, assim como seus métodos antigos de trabalho tendem a mudar muito lentamente. No momento de introdução de novos enfoques, muitas lições têm sido aprendidas. Foi observado que em todos os novos enfoques não existem soluções mágicas que irão resolver todos os problemas e satisfazer todas as necessidades prementes. Uma observação muito importante de FURLAN (1997) é que, praticamente, não existe uma situação onde se possa começar da estaca zero para adotar de imediato os mais modernos enfoques e tecnologias.

\subsection{Motivação do Trabalho}

Dentre as técnicas de análise e projeto de sistemas mais usualmente aplicadas, tem-se a Orientação a Objeto, que é um paradigma iniciado no final dos anos 80, baseada em conceitos aprendidos na infância, como objetos, atributos, classes e membros. Para PRESMAM (1994), esses novos conceitos parecem estranhos, mas são realmente muito naturais. Segundo FURLAN (1998), os conceitos do novo paradigma são justificados pelo fato de que objetos existem na natureza muito antes de haver qualquer tipo de aplicação deles pelo negócio. Equipamentos,

\footnotetext{
${ }^{1} \mathrm{O}$ termo Stakeholder foi introduzido para ter um termo comum para todos os envolvidos no projeto, diretamente ou indiretamente, ou que tenha interesse no resultado do projeto.
} 
pessoas, entre outros, existem por si só e têm características próprias representadas pelos seus atributos e pelo seu comportamento no mundo real. Entre as técnicas orientadas a objetos, a Unified Modeling Language (UML) surge como uma evolução das linguagens para especificação dos conceitos de análise orientada a objeto, é uma linguagem para especificação, construção, visualização e documentação de sistemas de software, unindo à sintaxe gráfica de diversos métodos. Os diagramas que compõem a UML são agrupados em diagramas de estrutura estática (diagramas de classe e diagrama de objetos), diagramas comportamentais (diagrama de use case, de seqüência, de colaboração, de atividade e de estado) e diagramas de implementação (diagramas de componentes e de Deployment ) (JACOBSON et al., 1998). A UML juntamente com o método Unified Process (UP) têm sido muito utilizados por toda a comunidade de orientação a objeto, porém GOTTESDIENER (1999) afirma que a linguagem UML e o método Unified Process não direcionam para regras do negócio e requisitos organizacionais, produzindo falhas na captura das necessidades do negócio. O diagrama use case é o centro da UML por ser considerado um modelo de requisitos, embora não enfatize regras do negócio.

A importância do diagrama use case na Análise Orientada a Objeto é destacada por diversos autores como PRADO (1999), JACOBSON et al (1998), LARMAN (1999), FOWLER \& SCOTT (1997), como sendo de suma relevância para compreender o âmbito do problema a ser modelado. O diagrama é considerado como parte fundamental na Análise Orientada a Objeto e tendo sido incorporado em várias metodologias recentes.

De acordo com SUTCLIFFE et al. (1998) e BUHR (1998), o diagrama de use case é uma especificação de seqüência de eventos, também chamado de cenário. Para SUTCLIFFE et al (1998), cenários exigem muito trabalho para capturar e documentar todo o espaço do domínio, além disso, poucas recomendações concretas existem sobre como deveria ser praticada a engenharia de requisitos baseada em cenários. Não existem passos ou diretrizes a seguir sobre como os problemas podem ser descobertos em cenários, deixando em aberto para o julgamento humano a forma de determinar os requisitos do sistema. Os requisitos são implícitos em modelos use cases e a falta de requisitos explícitos pode levar a falhas na validação. As ferramentas de gerenciamento de requisitos não podem ser integradas com sistemas que suportam Orientação a Objeto por ser inexistente tem o relacionamento semântico entre requisitos e objetos. Há uma diversidade muito grande de requisitos em um sistema e nem todos os requisitos podem ser alocados em use case. O desenvolvimento de use cases não é tão simples como é apresentado na literatura, deve ser realizado em estágios que devem ser refinados e validados.

O diagrama de use case representa uma descrição de um completo curso de eventos iniciados por um usuário do futuro sistema e a interação entre o usuário e o sistema. Não há captura de requisitos nesse diagrama, além de dificultar a adaptabilidade. A fase inicial do projeto de 
orientação a objeto é o pior erro no paradigma. O diagrama use case é tratado por muitos como uma forma de focar o modo como os usuários vêem a operação do sistema, mas na maioria das vezes o sistema ainda não existe e se existe não é satisfatório. Além disso, a visão do usuário está relacionada com os processos existentes, computadorizados ou não, e a tarefa do desenvolvedor é buscar novas soluções e não continuar automatizando modos antiquados de operação. O diagrama use case pode ser utilizado para validar aspectos finais da implementação, para ter certeza que o sistema inclui as rotinas dos típicos cenários usados, mas na tecnologia orientada a objeto ele não pode ser utilizado para captura de requisitos (MEYER, 1997).

Para LEE et al. (1998) e LILLY (2000), a engenharia de requisitos é uma tarefa crítica de qualidade de software. O diagrama use case é a técnica de elicitação mais utilizada nas aplicações industriais devido sua notação simples e especificações em linguagem natural e acessível. São atrativas principalmente para grupos com pouca experiência em especificação formal de requisitos. A simplicidade da use case é sua grande vantagem, mas tem como grande desvantagem o fato de descrever apenas o comportamento parcial. Além disso, não existe uma abordagem sistemática para analisar o ambiente. É necessário que o diagrama de use case permita a detecção de inconsistências, mudanças rápidas e descrições formais. Para LILLY (2000), o diagrama use case tem uma notação muito trivial, não é suficiente para mostrar os limites do sistema. A má definição de limites é provavelmente o problema mais universal em projetos iniciados com o diagrama use case. Quando o limite é confuso, é difícil dizer o que está dentro e o que está fora do sistema.

De acordo com ALENCAR (1999), essas técnicas tradicionalmente aplicadas no desenvolvimento de software tratam aspectos relacionados à funcionalidade do sistema, à descrição de atividades e entidades, às entradas que deverão ser transformadas e às saídas que deverão ser produzidas, porém sem considerarem aspectos mais amplos como: os objetivos da organização, regras do negócio, restrições, aspectos não funcionais relacionados à qualidade, confiabilidade e usabilidade. Essas técnicas não ajudam, portanto, a buscar soluções alternativas aos problemas da organização, não adicionam valor ao negócio e, na maioria das vezes, os processos manuais são automatizados sem nenhuma modificação.

Os requisitos organizacionais não devem ser considerados como uma simples descrição da funcionalidade do sistema, pois tratam do domínio onde o sistema está inserido e das restrições que podem existir no ambiente, no sistema e no desenvolvimento, diminuindo ambigüidades e incertezas. Nesse contexto, de acordo com ALENCAR (1999), a modelagem organizacional facilita a compreensão do ambiente empresarial e é reconhecida como uma atividade valiosa pela engenharia de requisitos. O modelo organizacional é uma representação da estrutura, atividades, processos, informações, recursos, pessoal, comportamento, objetivos e restrições das empresas 
comerciais, governamentais ou de outra natureza, que ajudam a compreender as complexas interações entre as organizações e as pessoas.

As organizações, segundo as técnicas de modelagem organizacional, são representadas a partir da elaboração de modelos que facilitam chegar às especificações de requisitos, funcionais e não funcionais, bem próximas dos requisitos reais da organização. $\mathrm{O}$ processo de modelagem organizacional deve trazer respostas a essas questões: por que, o que, quem, qual, quando, onde e como. Para tanto, existem diversas técnicas de modelagem na literatura com uma significativa variedade de notações.

De acordo com STERGIOU \& JOHNSON (1998), a transformação organizacional tem sido amplamente discutida e praticada. Os autores falam em um "vazio" entre Negócios e Tecnologia da Informação como o grande problema das organizações e sistemas.

Visando diminuir esse "vazio" entre Negócios e Tecnologia da Informação, será tratada, no presente trabalho, a modelagem organizacional como forma de capturar requisitos organizacionais na tentativa de melhorar a compreensão do domínio, interagir com usuários para que eles entendam o que o sistema pode fazer para melhorar o negócio, e adquirir conhecimento da estrutura organizacional e estratégica.

É importante ressaltar que é fundamental para a Engenharia de Requisitos que os modelos sejam compreendidos por todos (desenvolvedores, clientes e usuários), para ser possível validar os requisitos. Para muitos profissionais do negócio, alguns modelos organizacionais da ciência da computação, devido ao alto rigor matemático presente, podem ser de difícil compreensão. Neste sentido, é importante que a técnica de modelagem organizacional seja de fácil entendimento para que as pessoas do negócio participem de todo o processo de modelagem.

O modelo organizacional representa o "mundo" onde as regras do negócio se aplicam. Muitas organizações têm reconhecido que para ser flexível em um ambiente de crescente competitividade, é importante ter um claro entendimento das regras do negócio da organização. Para DALLAVALLE \& CAZARINI (2000), entender as regras do negócio é um fator chave de sucesso para o processo de desenvolvimento de software.

Um bom sistema de informação pode ser uma vantagem competitiva do negócio, mas se o sistema não atende as necessidades do negócio, este pode ter seu desempenho prejudicado. Esse é o motivo do início de uma troca de paradigma da Engenharia de Sistemas orientada a tecnologia para estruturas que focam a modelagem de "regras do negócio" (BUBENKO \& WANGLER, 1993).

Regras do Negócio, segundo ROSCA et al. (1997), são uma nova categoria de requisitos do sistema que representam decisões sobre como executar o negócio, e são caracterizadas pela orientação do negócio e sua tendência às mudanças. Elas se tornam requisitos que governam o 
sistema operacional da organização e determinam como o negócio é executado, podendo ser originadas a partir dos objetivos organizacionais. Segundo GOTTESDIENER (1999), regras do negócio trazem todo o conhecimento escondido em toda estrutura do negócio ou processo, sendo portanto, a essência de requisitos funcionais. Elas representam um importante conceito na fase de definição de requisitos organizacionais, facilitam as modificações no sistema de informação quando as regras mudam e também proporcionam oportunidade para as pessoas do negócio avaliarem a execução de cada processo do negócio. Mesmo sendo recente, regras do negócio são utilizadas por alguns profissionais da tecnologia da informação, porém pouca pesquisa sobre o tema em engenharia de requisitos tem sido realizada.

A natureza e algumas abordagens de regras do negócio serão tratadas no presente trabalho buscando conhecer como elas podem melhorar as especificações de sistema, facilitar as modificações no sistema provocadas pelo ambiente com freqüentes inovações e proporcionar oportunidade para avaliação de cada processo do negócio.

Será realizado também um estudo das diferentes abordagens de Regras do Negócio, que têm como propósito melhorar a qualidade das especificações e atender as reais necessidades do negócio.

\subsection{Objetivo}

Tendo-se levantado a necessidade de se ter a modelagem dos aspectos relativos à organização para que o sistema atenda as suas reais necessidades e seja uma vantagem competitiva do negócio, o presente trabalho tem como objetivo investigar o processo de desenvolvimento de software buscando conhecer técnicas ou métodos que atendam aos requisitos organizacionais, enfatizando o uso de regras do negócio com a finalidade de obter a especificação de requisitos.

A figura 1 ilustra o relacionamento entre os elementos considerados necessários para se atingir esse objetivo. A modelagem organizacional (MO) está relacionada com aspectos estratégicos do desenvolvimento de software. Regras do negócio são uma ponte entre o modelo empresarial e o sistema operacional, e elas estão em um nível tático do desenvolvimento, enquanto as técnicas ou linguagens de modelagem (DFD, UML, entre outras), representam o nível operacional do ciclo de desenvolvimento de software. 


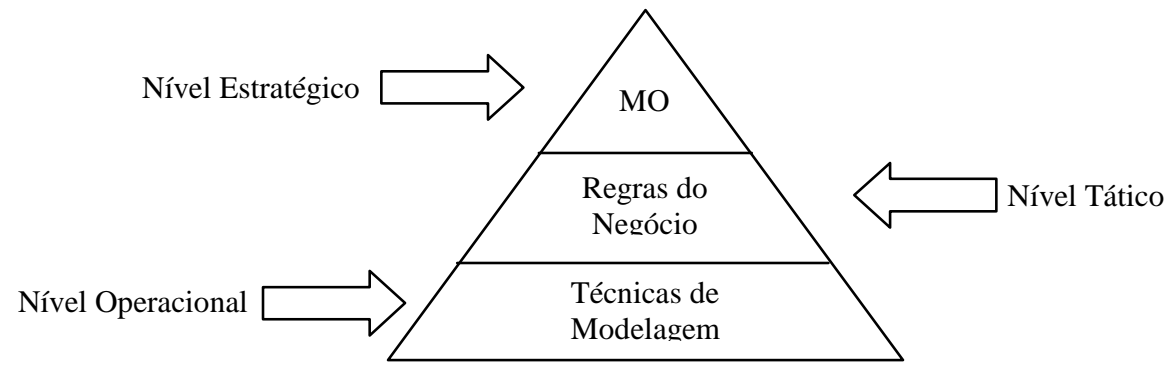

Figura 1 - Desenvolvimento Estratégico de Software.

\subsection{Limitações do Trabalho}

Este trabalho apresenta uma análise de algumas técnicas de modelagem organizacional e algumas abordagens de regras do negócio, não objetivando esgotar o assunto, uma vez que este é recente e existem muitas técnicas novas surgindo.

A escolha pela investigação do processo de desenvolvimento de software utilizando técnicas de modelagem organizacional foi em consequiência da ineficiência dos métodos de análise de sistemas que geralmente modelam as funções que o sistema deve ter, sem adicionar valor ao negócio. No presente trabalho não haverá uma aplicação devido à existência de diferentes abordagens com características e orientações distintas, sendo necessária uma vasta pesquisa exploratória para entender cada abordagem. Realizar mudanças e implantar a Tecnologia da Informação são operações complexas, envolvendo muitos participantes, várias reuniões e passos que devem ser analisados cuidadosamente. Além disso, de acordo com ELEKTRA (2000), um projeto de desenvolvimento de software utilizando técnicas de modelagem organizacional pode ser concluído em um tempo médio de 12 meses. A partir desse prazo é possível a avaliação dos resultados, o que torna inviável no cronograma deste trabalho.

Os aspectos relacionados a ferramentas de suporte ao desenvolvimento de software não são considerados no escopo do trabalho.

\subsection{Método de Pesquisa}

Nesse item serão discutidos os aspectos metodológicos considerados na realização desta pesquisa. A partir do objetivo estabelecido, as perguntas de pesquisa são elaboradas, o método de pesquisa é escolhido e as fases da pesquisa e as etapas do trabalho são definidas. 


\subsubsection{Perguntas de Pesquisa}

A partir do objetivo do trabalho, foram definidas as seguintes perguntas de pesquisa:

$>$ Como desenvolver um sistema que atenda aos objetivos da organização?

$>$ Existem metodologias que se preocupam com os requisitos organizacionais?

$>$ Como o sistema pode ser flexível às mudanças freqüentes do ambiente?

$>$ Qual a importância das regras do negócio na definição dos requisitos organizacionais?

$>$ Quais abordagens tratam regras do negócio?

$>$ As técnicas de Modelagem Organizacional são bem aceitas na literatura?

\subsubsection{Escolha do Método de Pesquisa}

Para atingir o objetivo proposto e responder às perguntas de pesquisa estabelecidas para este trabalho, é empregada uma abordagem de pesquisa descritiva. A pesquisa descritiva, segundo CERVO \& BERVIAN (1983), observa, registra, analisa e correlaciona fatos ou fenômenos sem manipulá-los.

Considera-se a pesquisa descritiva para este trabalho, uma vez que pretende-se investigar métodos que garanta os requisitos organizacionais durante o desenvolvimento de software, sem contudo modificá-los. De acordo com CERVO \& BERVIAN (1983), a pesquisa descritiva pode assumir diversas formas. Neste trabalho emprega-se o estudo exploratório. São realizadas também outras fases complementares: definição do trabalho, pesquisa bibliográfica e a avaliação dos resultados.

Segundo CERVO \& BERVIAN (1983), o estudo exploratório é recomendado quando há pouco conhecimento sobre o tema a ser estudado, sendo realizado para familiarizar-se com o fenômeno ou obter nova percepção do mesmo e descobrir novas idéias. A pesquisa exploratória realiza descrições precisas da situação e quer descobrir as relações existentes entre os elementos componentes da mesma. Esse tipo de pesquisa requer um planejamento flexível para possibilitar a consideração dos mais diversos aspectos de um problema ou de uma situação.

A definição do trabalho compreende o estabelecimento do objetivo a ser cumprido, a determinação das perguntas de pesquisa, a escolha do método de pesquisa e das técnicas de coleta de dados, a definição das fases de pesquisa e das etapas de trabalho e, a escolha das abordagens a serem estudadas. 
Segundo CERVO \& BERVIAN (1983), a pesquisa bibliográfica constitui parte da pesquisa descritiva, enquanto é feita com o intuito de recolher informações e conhecimentos prévios acerca de um problema para o qual se procura resposta ou acerca de uma hipótese que se quer experimentar. A pesquisa bibliográfica procura explicar um problema a partir de referências teóricas publicadas em documentos, buscando-se conhecer e analisar as contribuições culturais ou científicas do passado existentes sobre um determinado assunto, tema ou problema. Os objetivos da pesquisa bibliográfica são: evitar duplicidade de pesquisa; determinar a contribuição da pesquisa para a base de conhecimentos e obter fundamentação teórica para o desenvolvimento do projeto.

$\mathrm{Na}$ avaliação dos resultados serão discutidos os resultados observados em todas as fases anteriores, apresentadas as conclusões obtidas e sugestões para trabalhos futuros nessa área.

\subsection{Organização do Trabalho}

O trabalho está organizado em cinco capítulos, divididos de acordo com os tópicos relacionados ao objetivo do trabalho.

No capítulo 1 é apresentado a definição do trabalho. São discutidos inicialmente o contexto em que o trabalho se insere, o problema de pesquisa, as justificativas que motivam o seu desenvolvimento. São definidos o objetivo, as limitações do trabalho, as perguntas de pesquisa e o método de pesquisa.

No capítulo 2 é mostrado um estudo exploratório de algumas abordagens encontradas na literatura de modelagem organizacional, buscando encontrar as principais características, vantagens e desvantagens.

No capítulo 3 é descrito um estudo exploratório de regras do negócio, algumas abordagens são apresentadas e suas principais características.

No capítulo 4 é apresentado a abordagem EKD que trata a modelagem organizacional e as regras do negócio. Serão apresentados os modelos presentes na metodologia e algumas diretrizes.

No capítulo 5, finalmente, é apresentada uma discussão sobre toda a pesquisa exploratória, são apresentadas as conclusões obtidas e algumas considerações finais e sugestões para trabalhos futuros nesta área de pesquisa. 


\section{Modelagem Organizacional}

\subsection{Considerações iniciais}

Atualmente as empresas precisam de sistemas ágeis a mudanças constantes do ambiente do negócio e para garantir que os sistemas cumpram com sua finalidade, os desenvolvedores devem possuir uma compreensão mais aprofundada sobre a organização, seus objetivos, metas e estratégias de mercado.

O principal problema para o desenvolvimento correto de sistemas de software tem sido a dificuldade em se obter informações sobre o domínio da aplicação. Essa dificuldade levou ao surgimento de técnicas de modelagem organizacional, sendo uma atividade valiosa para a compreensão do ambiente empresarial. Esse capítulo tem como objetivo apresentar a modelagem organizacional como uma técnica que facilita a compreensão do ambiente empresarial, tornando-se uma atividade fundamental para a Engenharia de Requisitos.

\subsection{Modelo Organizacional}

Segundo ALENCAR (1999), sob o ponto de vista da Ciência da Administração, não basta apenas encher as empresas com equipamentos ou sistema de informação de última geração, sem que haja preocupação de atualização dos próprios processos do negócio. É preciso uma reavaliação dos processos de negócio. Neste sentido é que a Modelagem Organizacional permite não só melhor entender requisitos organizacionais que interferirão nos sistemas, mas também identificar alternativas para os vários processos da organização, facilitando os esforços durante o desenvolvimento do sistema de informação e permitindo que a análise organizacional seja melhor integrada aos processos de desenvolvimento do sistema. De acordo com BUBENKO \& WANGLER(1993), um bom sistema de informação deve atender às necessidades do negócio, caso contrário, o sistema estará impedindo o desenvolvimento do negócio. Este é o motivo do início de um novo paradigma, que muda da engenharia da informação orientada à tecnologia e abordagens orientadas a objeto, para estruturas que focam em modelagem de Regras do Negócio.

A tecnologia da informação não deve apenas ser utilizada para a automação dos processos de negócio existentes, mas também servir de base para a reformulação desses processos, a fim de encontrar objetivos de negócio mais amplos como concorrência, competitividade e estratégias. O modelo organizacional é uma representação da estrutura, atividades, processos, informações, 
recursos, pessoal, comportamento, objetivos e restrições das empresas comerciais, governamentais ou de outra natureza, a fim de ajudar a compreender as complexas interações entre organizações e pessoas (ALENCAR, 1999). Cada organização tem sua missão, seus objetivos e seus processos próprios e é importante dar atenção à modelagem desses processos. ALENCAR (1999) destaca os seguintes objetivos da modelagem organizacional:

1. Fornecer um objeto que seja uma representação compartilhável e reusável da cadeia de fornecimento de informação e conhecimento;

2. Suportar tarefas da cadeia de fornecimento, pela habilitação de respostas a questionamentos que não estão explicitamente representados no modelo;

3. Definir os objetos de maneira precisa, de forma que sejam consistentemente aplicados, através dos domínios e interpretados pelos usuários;

4. Suportar visualização do modelo, de forma intuitiva, simples e consistente.

Muitas técnicas de Modelagem de Negócio são propostas, algumas com o foco principal nos aspectos sociais como DOBSON (1994) que descreve os objetivos, política e estrutura da organização. Na linha de BUBENKO (1994) e YU (1993), é realizada a modelagem com múltiplas visões, com análise de metas e objetivos para a modelagem da organização. A organização, segundo esses autores, é representada através de modelos que facilitam a realização de especificações de requisitos mais próximas à realidade da organização.

Os modelos de requisitos existentes descrevem um ambiente organizacional em termos de entidades e atividades, sem se importarem com situações em que os usuários poderão tomar diferentes decisões. Esses modelos têm como objetivo considerar a descrição de sistemas técnicos e não para fornecer descrições mais ricas sobre as organizações sócio-humanas.

As informações capturadas nos modelos existentes, como Diagrama de Fluxo de Dados (DFD) e Diagrama Entidade e Relacionamento (DER), não são suficientes, uma vez que esses modelos descrevem apenas entidades, funções, fluxo de dados e estados do sistema, não expressando as razões envolvidas no processo, ou seja, o porquê fazer uma determinada ação ou tomar uma decisão (alternativas para o "como fazer"). Assim, faz-se necessário uma ontologia mais rica que facilite os esforços da Engenharia de Requisitos para obter uma melhor compreensão sobre os relacionamentos da organização entre os vários atores do sistema e entender as razões envolvidas nos processos de decisões. Algumas técnicas de modelagem organizacional: 
1. A técnica ORDIT (Organizational Requirements Definition of Information Technology Systems), de acordo com DOBSON (1994) apud ALENCAR (1999), serve para ajudar os participantes das organizações a definirem alternativas técnicas e o futuro organizacional, e, consequentemente, o papel da tecnologia da informação, fornecendo um processo sistemático e aproveitável, que seja capaz de suportar gerações de requisitos organizacionais e fornecer métodos e ferramentas associadas que suportem o processo;

2. A técnica de BUBENKO (1993) destaca áreas de conhecimento da organização. É constituída por cinco modelos elaborados a partir de objetivos (Modelo de Objetivos - MO), atores (Modelo de Atores - MA), atividades e uso (Modelo de Atividades e Uso -MAU), conceitos (Modelo de Conceitos - MC) e requisitos (Modelo de Requisitos do Sistema de Informação -MRSI);

3. A técnica i* de YU (1993) ${ }^{2}$ apud ALENCAR (1999), é composta por dois modelos: o Modelo de Dependências Estratégicas (SD) e o Modelo de Razões Estratégicas (SR). O Modelo de Dependências Estratégicas (SD) descreve as relações de dependências externas entre os atores da organização, enquanto o Modelo de Razões Estratégicas (SR) descreve interesses e conceitos dos participantes e as direções que podem seguir. As semânticas dos relacionamentos, no Modelo de Dependências Estratégicas (SD), são caracterizadas em termos de algumas supostas características internas intencionais do agente. Algumas das quais são explicitamente modeladas no segundo tipo de modelo previsto na técnica $i^{*}$, Modelo de Razões Estratégicas (SR). Na estrutura interna intencional de um agente, onde todas as variáveis livres nas fórmulas são entendidas como universalmente quantificadas, inclui-se, pelo menos, os três componentes seguintes: (a) Ux - um conjunto de rotinas; (b) $\mathrm{Hx}$ - um conjunto de regras meiofim; e (c) Ex - um conjunto de elementos primitivamente manipuláveis;

4. O princípio da modelagem de FURLAN (1997) é conhecer a missão da organização. A missão é o motivo pelo qual a empresa foi criada, ou seja, a identidade da organização, sendo um texto curto e objetivo. O próximo passo é definir os objetivos executivos ou objetivos da organização que são os alicerces

\footnotetext{
${ }^{1}$ DOBSON, J. E.; STREMS, R. (1994). Organizational requirements definition for information technology. In: IEEE INTERNATIONAL CONFERENCE ON REQUERIMENTS ENGINEERING, Los Alamitos, IEEE Computer Society. p. 158 -165.

2 YU, E. (1993). Modelling organizations for informations systems requirements engineering. In: IEEE INTERNATIONAL SYMPOSIUM ON REQUERIMENTS ENGINEERING, San Diego, 1993. Proceedings. Los Alamitos, IEEE Computer Society. p.34-41.
} 
para a missão, devem portanto, ser totalmente compatíveis com o que estabelece a missão. Os objetivos estarão melhor definidos conforme o desenvolvimento da empresa. Depois, serão definidos os objetivos estratégicos, que estão relacionados com as áreas funcionais com a finalidade de alcançar os objetivos executivos e os fatores chaves de sucesso. Para alcançar os fatores chaves de sucesso são desenvolvidas estratégias, que são o diferencial da empresa no mercado. Os planos de ação representam a concretização das estratégias.

5. Segundo ROLLAND (2000) e NURCAN (1999), o EKD (Enterprise Knowledge Development) é uma metodologia que fornece uma forma sistemática e controlada de analisar, entender, desenvolver e documentar uma organização e seus componentes, usando a Modelagem Organizacional. De acordo com KIRIKOVA (2000), a família de modelo do EKD é destinada para responder as questões: O que, Como, Onde, Quem, Quando e Por que. Essa estrutura serve como um esquema de classificação conveniente ou "tabela periódica" para entidades de informação. Como elementos químicos, essas entidades podem ser combinadas de infinitas formas para produzir o sistema de informação de interesse da organização. Por outro ponto de vista, é possível ver essa estrutura como uma família de muitos modelos inter-relacionados, onde relacionamentos entre elementos arbitrários pertencentes a submodelos são permitidos. Essa é a teoria mais rica em uso. A proposta de usar o EKD é prover uma descrição clara e nãoambígua de:

$>$ Como a organização funciona atualmente;

$>$ Quais são os requisitos e as razões para a mudança;

$>$ Quais alternativas deveriam ser criadas para encontrar esses requisitos e

Quais são os critérios e argumentos para avaliação dessas alternativas

$\mathrm{O}$ EKD fornece uma base para $\mathrm{o}$ entendimento $\mathrm{e}$ apoio às mudanças organizacionais e ajuda o desenvolvimento de sistemas de informação que apoiará à organização.

De acordo com o trabalho de ALENCAR et al. (1999), o principal conceito da técnica i* são atores, concentrando-se na análise das implicações sob o ponto de vista dos relacionamentos de dependências entre os atores de uma organização. No caso da técnica de BUBENKO (1993), os objetivos são o conceito principal, dos quais derivam-se as atividades e os atores. Dessa forma, pode-se dizer que a técnica i* é orientada a atores e a técnica de BUBENKO (1993) orientada a 
objetivos. A noção de objetivos na técnica i* está vinculada a uma dependência entre dois atores, ou seja, o que um espera obter do outro. Já em BUBENKO (1993), essa noção está vinculada à organização e não a um ator em específico ou a um relacionamento entre dois atores. Em i*, através dos atores decide-se os domínios dos objetivos; em BUBENKO (1993), partindo-se dos objetivos surgem os domínios.

Um fator muito importante para a Engenharia de Requisitos é a compreensão por todos (desenvolvedores, clientes e usuários), uma vez que o problema está claro é possível validar requisitos. ALENCAR et al. (1999) explicam que o entendimento dos modelos recai na questão de pontos de vista. Por parte dos profissionais técnicos, aptos a lidarem com modelos gráficos do tipo DFD, ou DER, o entendimento dos modelos propostos pelas duas técnicas não se diferenciariam quanto à dificuldade ou facilidade de compreensão. A técnica $i^{*}$ trabalha com um pouco de rigor matemático, o que não é muito atraente a alguns desenvolvedores de software. Com pouco esforço esses profissionais compreenderiam o significado dos modelos em ambas as técnicas. Contudo, por parte de outros profissionais não especificamente ligados a área de desenvolvimento de software, os modelos da técnica i* seriam de difícil compreensão, enquanto que os de BUBENKO (1993), seriam mais fáceis de serem entendidos e analisados. De acordo com BUBENKO \& WANGLER (1993), para uma pessoa do negócio ser capaz de ler e validar os modelos, é necessário que a linguagem seja fácil de entender.

Um outro ponto observado por ALENCAR et al. (1999) é que o desenvolvimento segundo i* requer de imediato a noção de estabelecimento dos atores e seus relacionamentos, partindo do modelo de Relacionamentos Estratégicos (SD) e derivando o modelo de razões estratégicas (SR). Enquanto que segundo BUBENKO (1993), o ponto principal está no conhecimento ou identificação dos objetivos da organização, retratados em seu modelo de Objetivos (MO), do qual resultam os modelos de Atividades e Uso (MAU) e o de Atores (MA). As Regras do Negócio propostas em BUBENKO (1993) no Modelo de Objetivos (MO), em princípio não são tratadas especificamente em i* em nível de modelo organizacional.

De acordo com a análise de ALENCAR et al. (1999), a Engenharia de Requisitos força os clientes a considerarem os seus requisitos cuidadosamente e revisá-los no contexto do problema, tendo como objetivo alcançar uma especificação completa do sistema a ser desenvolvido. Procurase identificar da melhor forma possível, com uma maior transparência, as reais ou principais necessidades do cliente. Um projeto só será bem sucedido se houver um consenso entre as partes envolvidas (cliente e desenvolvedores) e entre a própria equipe de desenvolvimento. O processo de desenvolvimento pode ser escalonado entre vários grupos de desenvolvedores, que fisicamente 
podem estar em lugares remotos e distintos, e as informações apanhadas por um ou outro grupo devem ser naturais ou transparentes a todos.

De acordo com BERZTISS \& BUBENKO (1995), a experiência tem mostrado que o uso de uma abordagem dirigida a modelo de objetivos proporciona um melhor entendimento do domínio para os tomadores de decisões, definidores de requisitos, desenvolvedores de software e usuários finais, além do valor econômico de melhorar a comunicação e entendimento, minimizando retrabalho nos estágios finais do processo de desenvolvimento do sistema de informação. Um bom sistema de informação pode ser uma vantagem competitiva do negócio, mas se o sistema não atende as necessidades do negócio, este pode ter seu desempenho prejudicado. Esse é o motivo do início de uma troca de paradigma da Engenharia de Sistemas orientada à tecnologia para estruturas que focam a modelagem de "regras do negócio" (BUBENKO \& WANGLER, 1993). A importância de regras de negócio na modelagem organizacional e especificação de requisitos tem sido discutida por diversos autores (BUBENKO (1993) BUBENKO \& WANGLER (1993), STERGIOU \& JOHNSON (1998), ROSCA et al. (1997), GOTTESDIENER (1999), HERBST (1996) e KILOV \& SIMMONDS (1997)).

A técnica de FURLAN (1997) e a ORDIT não serão tratadas no presente trabalho por não desenvolver modelos com múltiplas visões e não considerar as regras do negócio. Além disso, essas técnicas são pouco referenciadas na literatura. O método EKD será detalhado no capítulo 4.

A técnica de BUBENKO (1993) será tratada no próximo item, por ser orientada a objetivo e ter uma linguagem simples o que facilita a integração das pessoas da organização com os profissionais da informática. Essa integração é um fator muito importante para o sucesso da fase de engenharia de requisitos.

\subsection{Modelagem Organizacional de Bubenko (1993)}

A preocupação inicial de BUBENKO (1993) era considerar como os usuários e clientes de sistema olhavam para o sistema e como suas necessidades e conhecimento eram coletados e registrados na especificação de requisitos. Em SISU - Swedish Institute for Systems Development (Instituto Suíço de Desenvolvimento de Software)- foi desenvolvido um número de modelos especiais para discutir e representar a parte do "POR QUE" dos requisitos do sistema de informação. Essa parte é chamada pelo autor de Modelagem do Negócio. Um grande número de efeitos positivos tem sido registrado, tais como: melhora do entendimento do domínio da aplicação, aumento da comunicação entre projetista e usuários, e melhora na base para projetar sistemas de informação. Uma observação interessante do autor é que Modelagem de Negócio é definitivamente 
apreciada por pessoas que não são ligadas à computação, sendo mais difícil "vender" a idéia para especialistas em computadores e softwares.

A experiência do SISU em modelagem de negócio, segundo BUBENKO (1993), era um componente essencial da formulação da proposta para o projeto $\mathrm{F}^{3}$ (From Fuzzy to Formal), que tem como objetivo o processo de mover os objetivos confusos e desordenados para requisitos funcionais e formais, em termos de um modelo conceitual, e um conjunto de requisitos não funcionais de um sistema de informação. Uma extensão da abordagem Modelagem de Negócio forma a base para documentar a parte "POR QUE" e "O QUE" da especificação de requisitos e ligar com a parte "COMO" da especificação. A parte "POR QUE" e "O QUE", chamada Modelo Organizacional, descreve os objetivos e as oportunidades da organização, que formam a base para o desenvolvimento de um novo sistema de informação. Nessa descrição inclui conceitos básicos processos e atores da organização, e requisitos gerais do sistema de informação.

O sistema não pode ser construído de forma isolada, ele deve corresponder às necessidades de requisitos do usuário. Desenvolver requisitos do negócio para sistema de informação é uma tarefa de aquisição e gerenciamento de conhecimento, envolve projetar processos do negócio, componentes organizacionais e atores, implicando em comunicação complexa e validação de resultados, seleção de fontes de conhecimento corretas, métodos, ferramentas e técnicas (BUBENKO, 1993).

BUBENKO (1993) explica que apesar de na prática ser freqüentemente utilizado, o termo "captura de requisitos" é errôneo porque indica que os requisitos "já estão lá" e que tudo que é necessário são dispositivos para extrair os requisitos dos usuários. Na prática, segundo o autor, essa não é a realidade, são necessários conceitos, métodos e ferramentas que podem ajudar a analisar a situação, para projetar (ou reprojetar) processos de negócio, e para desenvolver e definir os requisitos do sistema de informação passo a passo junto com usuários, sem perder detalhes e a visão do todo. No presente trabalho o termo "captura de requisitos" está ligado a esta visão mais ampla.

A abordagem da modelagem organizacional da linha de BUBENKO (1993) iniciou nos anos 80 pelo projeto Plandata e refinado pelo SISU (Swedish Institute for Systems Development Instituto Sueco de Desenvolvimento de Software) no final dos anos 80. A grande contribuição foi a noção de considerar componentes organizacionais de uma especificação, por exemplo, os objetivos (intenções) de um negócio, além dos tipos de componentes do modelo tradicional, como entidade, relacionamentos e processos. O uso dessa abordagem em muitas aplicações diferentes durante os últimos dez anos mostrou que a razão do sucesso não era apenas o Modelo Organizacional, mas também o gerenciamento apropriado do processo do negócio e engenharia de 
requisitos. A idéia do Modelo do Negócio do SISU era no final estendida para o Modelo Organizacional e mais tarde desenvolvida no projeto ESPRIT F3 (From Fuzzy to Formal).

O problema da comunicação entre desenvolvedores de sistemas e usuários, e a falta de conhecimento do domínio são as causas da má definição de requisitos e consequentemente softwares inadequados. De acordo com BUBENKO (1993), $\mathrm{F}^{3}$ é um método para desenvolvimento, aquisição e comunicação inicial, conhecimento da organização e requisitos do usuário por uma modelagem estruturada, interativa e funcional. Essa abordagem é guiada por modelos conceituais, cada um focando um aspecto particular da aplicação. Essa parte de reunião de requisitos é chamada "Modelagem Organizacional".

BUBENKO (1993) faz uma observação importante com relação ao grande número de ferramentas de métodos CASE. Para o autor esses produtos são direcionados para metade ou final do processo de desenvolvimento de software. Praticamente nenhum deles direciona de forma estruturada: o início do processo, os objetivos do negócio, os estágios de geração de requisitos, e o problema de mover do informal para o domínio formal. Os métodos existentes não são designados para captura explícita e representação de forma estruturada o "conhecimento organizacional e do negócio" para ser subseqüentemente usado na fase de projeto do sistema de informação. Não são mantidas ligações entre modelo organizacional e especificação do sistema. Assim, não pode ser explicitamente feito o gerenciamento de mudança e evolução da organização, e o mapeamento ${ }^{1}$ de mudanças nos requisitos e componentes do sistema de informação.

É de fundamental importância ter uma conexão entre o desenvolvimento de objetivos e estratégias do negócio e o desenvolvimento de sistemas de informação. $\mathrm{O}$ alto custo de manutenção é um fator importante para incentivar o entendimento do negócio e derivar os requisitos desse entendimento. BUBENKO (1993) esclarece que a metodologia $\mathrm{F}^{3}$ não é utilizada apenas para capturar requisitos, mas um método para estabelecimento de uma base mais sólida e completa para projeto e implementação de sistemas em termos de completitude e facilidade de mudança e de gerenciamento. De acordo com a abordagem $\mathrm{F}^{3}$, um Modelo Organizacional é uma descrição parcial de suposições básicas, requisitos e conhecimento do problema do domínio necessários para projetar e implementar um sistema de informação. O autor cita os seguintes itens que devem estar em uma especificação de requisitos:

1. Por que o sistema é necessário? Quais são as metas do ambiente da aplicação? Quais são as prioridades das metas? Como as metas relacionam-se?

\footnotetext{
${ }^{1}$ A experiência de SISU em Modelagem Negócio foi um componente essencial de formulação de propostas para o projeto ESPRIT F3 que visa formalizar aspectos confusos da organização.
} 
2. Quais conceitos ou temas da organização, incluindo seus relacionamentos com objetivos, atividades, processos e atores. Como são definidos? Quais regras do negócio e restrições monitoram esses objetivos?

3. Quais atividades de negócio e processos existem ou deveriam existir, para gerenciar a organização de acordo com os objetivos? Como são realizados os processos de negócio? Quais informações são necessárias?

4. Quem está realizando quais tarefas e processos?

5. Que requisitos são gerados por esses processos?

O Modelo Organizacional deve responder as seguintes questões:

1. Por que o sistema é construído, qual a sua justificativa?

2. Quais são os processos de negócio e quais são apoiados pelo sistema?

3. Quais são os atores da organização que realizam esse processo?

4. Quais conceitos eles estão processando ou falando sobre? Quais são as informações necessárias?

5. Quais objetivos iniciais e quais requisitos podem ser declarados considerando o sistema de informação para ser desenvolvido?

BUBENKO (1993) explica que a modelagem organizacional e a especificação de requisitos são baseadas na idéia de que um processo de especificação de requisitos, de um ponto de vista de documentação, implica na instanciação de um número de modelos inter-relacionados (figura 2). O Modelo Organizacional inclui os seguintes modelos, já mencionados anteriormente, que correspondem às questões citadas acima: Modelo de Objetivo (MO), Modelo de Atividade e Uso (MAU), Modelo de Ator (MA), Modelo Conceitual (MC), e Modelo de Requisitos do Sistema de Informação (MRSI).

Nota-se que o Modelo de Objetivos motiva ou dirige o desenvolvimento de outros modelos. Nesse momento alguns requisitos do sistema podem ser facilmente declarados, nem sempre de forma correta. Por isso, é necessária a elaboração de cada requisito, buscando entender a razão da sua existência, as atividades e os conceitos relacionados. Entendendo a organização, seus objetivos e problemas, tem-se uma visão mais clara do que é realmente necessário.

O Modelo Organizacional é ligado por relacionamentos "implementado-por" para os componentes do modelo do sistema de informação (MSI) e pelo relacionamento "refinado-por" para componentes do modelo definido por requisitos não-funcionais (NRNF). BUBENKO (1993) explica que o conceito de "organização" deve ser interpretado de forma abrangente, podendo significar uma organização inteira ou parte dela. Nos modelos existem componentes, como objetos 
e relacionamentos típicos para cada modelo. Os relacionamentos podem ser internos ao modelo (relacionamento intra) ou externos, onde relatam componentes de dois ou mais modelos (relacionamento inter). Objetos e relacionamento podem ser atributos. Os modelos e seus relacionamentos são controlados por regras estáticas e dinâmicas.

O Modelo de Objetivos (MO) é destinado para descrever e discutir a razão e a motivação dos componentes de um documento de requisitos. Trata-se de um gráfico com os seguintes componentes (tabela 1): objetivos, regras, problemas, causas, oportunidades e ações realizadas, conectados por relações do tipo "motiva" ou "influencia". Objetivos são usados para expressar intenções. Problemas expressam que a organização está, ou pode ficar em um estado não desejado. Oportunidades expressam possíveis situações que não são consideradas objetivos, mas que podem ser vantajosas. Causas expressam razões de problemas. Regras são restrições em componentes e ligações existentes na organização. Ações realizadas expressam ações ou atividades realizadas na organização. A relação "motiva" é um refinamento, transformando os componentes em subcomponentes. A relação "influencia" indica influência positiva ou negativa entre os componentes. Este modelo deve ser desenvolvido em várias sessões, onde cada participante pode ter diferentes objetivos, problemas e oportunidades e ações realizadas (BUBENKO, 1993).

Tabela 1 -Principais características dos componentes do modelo de objetivos.

\begin{tabular}{|l|l|}
\hline \multicolumn{1}{|c|}{ Componentes } & \multicolumn{1}{c|}{ Definição } \\
\hline Objetivos & Expressam intenções \\
\hline Regras & São restrições em componentes e ligações existentes na organização \\
\hline Problemas & Expressam que a organização está ou pode ficar em um estado não desejado. \\
\hline Causas & Expressam razões de problemas. \\
\hline Oportunidades & $\begin{array}{l}\text { Expressam possíveis situações que não são consideradas objetivos mas podem ser } \\
\text { vantajosas. }\end{array}$ \\
\hline Ações Realizadas & Expressam ações ou atividades realizadas na organização. \\
\hline
\end{tabular}




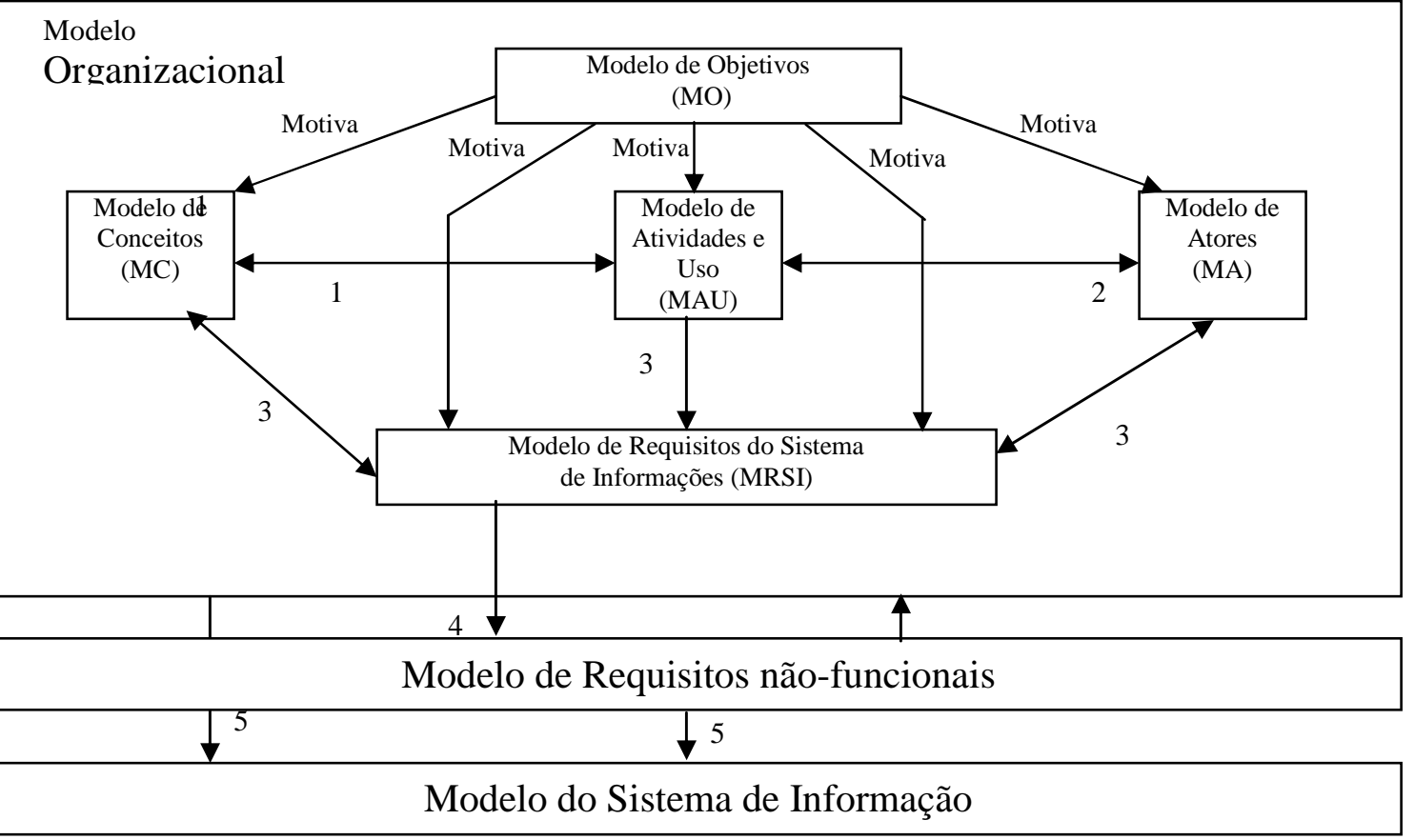

Modelo de configuração

1. "de acordo com" tipo de relacionamento

2. "realizado por" tipo de relacionamento

3. "diz respeito a" tipo de relacionamento

4. "refinado por" tipo de relacionamento

5. "implementado por" e "suportado por" tipo de

Figura 2- Modelo Organizacional e seus modelos relacionados.

Fonte: BUBENKO, (1993), p. 80.

O Modelo de Atividades e Uso (MAU), descreve as atividades existentes a serem modificadas ou a serem projetadas em uma organização. As atividades são definidas a partir de seus processos e do fluxo de material e informações entre eles. O modelo é um gráfico MAU(X,Q) com $X=\{$ Processo, Informação, Material, Processo Externo) e $Q=\{$ Entrada, Saída $\}$. A estrutura desse modelo é similar à do modelo DFD por conter informações e materiais que entram e saem das atividades (BUBENKO, 1993).

O Modelo de Atores (MA), é usado para avaliar e definir os executores (atores) das atividades da organização permitindo um melhor entendimento das possibilidades de comunicação. Os atores podem ser indivíduos, grupos, unidades organizacionais, máquinas, entre outros. O 
modelo é representado por um gráfico $\mathrm{MA}(\mathrm{X}, \mathrm{Q})$ com $\mathrm{X}=\{$ Indivíduos, Recursos não humanos, Unidades Organizacionais, Papel $\}$ e $Q=$ \{Relação Binária, Relação ISA, Relação Parte-de $\}$. Recursos não humanos são máquinas ou equipamentos. Unidades organizacionais representam divisões da organização, tais como: departamentos, projetos e grupos de trabalho. Indivíduos, Unidades organizacionais e Recursos não humanos se submetem a regras do negócio. Atividades ou processos são realizados por atores executando o negócio. A relação binária expressa relação entre dois atores. A relação ISA expressa generalização entre regras ou entre recursos não humanos. A relação Parte-de expressa relação de agregação. Esse modelo está ligado aos outros modelos de diversas formas, como por exemplo: Quem é o usuário de um determinado objetivo? Quem é responsável por gerenciar uma atividade de acordo com um objetivo? Quem é o ator de um requisito não funcional? (ALENCAR et al., 1999).

O Modelo de Conceitos (MC), é usado para definir os conceitos de objetivos, relações e propriedades, evitando discordância de termos no universo da organização. Esse modelo serve como um dicionário de conceitos para usuários, clientes e engenheiros, sendo representado pelo gráfico $\mathrm{MC}(\mathrm{X}, \mathrm{Q})$ com $\mathrm{X}=\{$ Conceito, Atributo, Conceito Grupo $\}$ e $\mathrm{Q}=\{$ Relação binária, Relação ISA, Relação Parte-de\}. Conceito é algo no domínio de interesse que se deseja caracterizar. Atributo é o termo usado para os itens que caracterizam um conceito. Grupo de conceito é um conjunto de conceitos, relações e atributos. Uma relação binária é uma relação entre dois conceitos. Relação ISA expressa generalização enquanto a relação Parte-de é uma relação especial onde os conceitos são vistos a partir do nível mais alto. As regras estáticas e dinâmicas que governam as mudanças da organização são declaradas nesse modelo. Normalmente, regras do negócio no Modelo de Conceitos são vistas como refinamentos operacionais motivados pelas metas e objetivos do negócio, menos precisamente definidos no Modelo de Objetivos (BUBENKO \& WANGLER, 1993).

O Modelo de Requisitos do Sistema de Informações (MRSI), descreve requisitos funcionais e não funcionais. Constitui-se em um meio de declarar e analisar os objetivos, problemas e requisitos do sistema de informação que estão sendo trabalhados. Inicialmente os objetivos precisam ser descritos informalmente, e irá parecer com os tipos de objetos do Modelo de Objetivos. Em um nível mais refinado, o MRSI é descrito em dois modelos: de requisitos funcionais e de requisitos não funcionais. Requisitos funcionais está relacionado com a funcionalidade alvo do sistema de informação tais como operações para criação, modificação e exclusão de relacionamentos, para exibir, consultar e verificar objetos e relacionamentos. Requisitos não funcionais podem ser categorizados em muitas formas de restrições: de operações, políticas, econômicas, da precisão da informação e aspectos de segurança. O Modelo MRSI é representado pelo gráfico MRSI $(X, Q) \operatorname{com} X=\{$ É objetivo, É problema, É limitação, É requisito, 
É característica valiosa $\}$ e $\mathrm{Q}=\{$ Motiva, Influencia $\}$. É objetivo é usado para expressar intenções do sistema de informações. É problema expressa estados ou fatos não desejados. É limitação determina restrições. $E$ requisito identifica requisitos, podendo ser funcionais ou não funcionais. $E$ Característica valiosa expressa uma característica que não é um requisito definitivo, mas uma propriedade desejável que pode ser dispensada ou relaxada dependendo da disponibilidade de tempo e de outros recursos (ALENCAR et al, 1999).

Essa abordagem representa passos importantes em direção a um novo paradigma de desenvolvimento de software, que nos primeiros estágios de desenvolvimento foca na organização e em questões do negócio em vez de em mecanismos de implementação de sistemas de informação.

\subsection{Considerações finais}

Existe um relacionamento natural e lógico entre o negócio e os requisitos do sistema, sendo assim, o modelo organizacional é parte importante do desenvolvimento de software para captura e especificação dos requisitos, nos quais a determinação explícita dos objetivos, problemas, conceitos, atividades, processos e atores direciona para um sistema que atende às reais necessidades do cliente, além de diminuir custos de manutenção.

A modelagem organizacional permite melhorar a comunicação entre usuários, desenvolvedores e analistas de sistemas para desenvolver uma descrição estruturada do negócio. Essa descrição permite a validação e verificação de requisitos pelas pessoas do negócio. A modelagem é um passo importante para chegar a uma base de conhecimento, que é usada para melhorar o negócio, discutir sobre mudanças e a evolução, e estruturar as regras do negócio. Regras do negócio serão tratadas com mais detalhes no próximo capítulo.

A modelagem organizacional pode ser aplicada para diferentes propósitos, e ser realizada por diferentes grupos. Em algumas situações, segundo BUBENKO \& KIRIKOVA (1994), o modelo organizacional pode ser utilizado como uma técnica para analisar a situação corrente de uma organização, ou parte dela, e traçar novos objetivos para o futuro. Em outras situações, pode ser usado para desenvolvimento de novos produtos ou para reprojetar atividades do negócio.

A natureza e algumas abordagens de regras do negócio serão tratadas no próximo capítulo, mostrando que é importante ter um entendimento claro delas para o sucesso do desenvolvimento de software.. As regras do negócio representam uma interface entre os objetivos organizacionais e o sistema operacional que garante que os objetivos sejam alcançados. 


\section{Regras do Negócio}

\subsection{Considerações iniciais}

As organizações estão percebendo a importância de sistemas computacionais flexíveis para acompanhar o mercado cada vez mais competitivo e em constantes mudanças. Nesse contexto, uma importante questão refere-se aos requisitos capturados na análise do ambiente no processo de engenharia de software. Em geral, a captura e entendimento dos requisitos não são tarefas simples, por se tratar muitas vezes de problemas ainda abstratos para o cliente. Este capítulo tem como objetivo apresentar Regras do Negócio como uma forma de ajudar a resolver o problema da má definição de requisitos, mostrando que elas representam um importante conceito na fase de definição de requisitos organizacionais, facilitando modificações no sistema de informação quando essas regras mudam, e proporcionam oportunidade para as pessoas do negócio avaliarem a execução de cada processo.

\subsection{O que são Regras do Negócio?}

Regras do Negócio são componentes de um sistema de informação organizacional, cuja importância tem sido reconhecida nos últimos anos. De acordo com LEITE \& LEONARDI (1998), regras do negócio representam um importante conceito dentro do processo de definição de requisitos para sistemas de informação. Para os autores, regras do negócio devem ser vistas como uma declaração genérica sobre a organização.

Regras do negócio, segundo ROSCA et al. (1997), são uma nova categoria de requisitos do sistema que representam decisões sobre como executar o negócio, e são caracterizadas pela orientação do negócio e sua tendência às mudanças. LEITE \& LEONARDI (1998, p. 69) entendem regras do negócio diferente de requisitos: "Regras do Negócio são declarações sobre a forma da empresa fazer negócio. Elas refletem políticas do negócio. Organizações têm políticas para satisfazer os objetivos do negócio, satisfazer clientes, fazer bom uso dos recursos, e obedecer às leis ou convenções gerais do negócio. Regras do Negócio tornam-se requisitos, ou seja, podem ser implementados em um sistema de software como uma forma de requisitos de software desse sistema”. O principal argumento de LEITE \& LEONARDI (1998) é que regras do negócio são 
declarações resumo, as quais podem ser implementadas em diferentes formas por diferentes procedimentos.

Segundo KILOV \& SIMMONDS (1997), uma regra de negócio é definida em termos de notação (matemática) de proposições mostrando que precisão é essencial quando formula-se regras do negócio. Uma notação imprecisa de "regras do negócio" é inútil porque pode ser aplicado a quase tudo (por exemplo, regras do negócio são coisas suportadas pelo mecanismo ZYX, o qual é um mecanismo de regra do negócio). Quando for utilizado dessa forma, o termo "regras do negócio" é meramente um barulho, cujo valor é determinado pela moda corrente.

Regras do negócio descrevem a comunidade de coisas do negócio. Uma regra do negócio é uma proposição sobre coisas do negócio, relacionamentos entre regras e operações aplicadas nas regras, do ponto de vista do negócio (Business Rules for the Enterprise Viewpoint ${ }^{1}$ apud KILOV \& SIMMONDS, 1997). Uma proposição é um fato ou estado observável de negócio envolvendo uma ou mais entidades pelo qual é possível afirmar ou negar que isso sustenta essas entidades (Open Distributed Processing ${ }^{2}$ apud KILOV \& SIMMONDS, 1997).

Na visão de OULD (1995)³ apud STERGIOU \& JOHNSON (1998), regras do negócio podem ser apresentadas na forma de políticas, procedimentos, padrões, níveis de responsabilidade, mecanismos de autorização e delegação.

Para ROSCA \& WILD (1996), regras do negócio são declarações sobre o negócio e entidades do negócio, expressando objetivos, políticas, restrições e baseline sobre como o negócio deveria ser feito.

O termo "baseline", não tem uma tradução definitiva. Utiliza-se muitas vezes a palavra "base" ou "referência". Na verdade o sentido é uma combinação desses dois termos. A baseline é uma referência permanente e que serve de âncora para que possa sempre direcionar onde está no desenvolvimento de software. Baseline de requisitos é um conjunto de representações que evoluem no tempo, mas que são sempre o referencial do software em questão.

Regras do negócio são mais do que declarações sobre campos de dados ou implementação do sistema, elas definem tarefas dos atores da organização, os serviços que a organização dispõem e os recursos necessários para apoiar os processos do negócio. Regras do negócio cobrem um grande espectro de categorias e para ilustrar, ROSCA \& WILD (1996) citam alguns exemplos:

\footnotetext{
${ }^{1}$ Business Rules for the Enterprise Viewpoint of RM-ODP. Ansi X3H7-96-07R2, Dec., 1996

${ }^{2}$ ISSO/IEC JTC1/ SC21 / WG7 - Open Distributed Processing - Reference Model: Part 2: Foundations (IS 10746-2/ITU3 Recommendation X. 902, Feb, 1995)

${ }^{3}$ OULD, M. Business Process: Modelling and Analysis for Reengineering and Improvement, Chichester. John Wiley \& Sons, 1995
} 
1) Um estímulo-resposta que permite a descrição de condições necessárias para realizar uma atividade: "Criar uma atividade de registro de reclamação do cliente".

2) Uma regra especificando uma pré-condição de uma atividade: "Identificação da Informação é requerida quando um cliente pede informações de sua conta".

3) Uma regra especificando restrição de estrutura de dados: "Salvar endereço da conta deve coincidir com o endereço da verificação da conta"

Segundo CERI \& FRATEMALE (1997) ${ }^{1}$ apud LEITE \& LEONARDI (1998), regras do negócio respondem às necessidades da aplicação, modelam a reação dos eventos que ocorrem no mundo real, com efeitos tangíveis no conteúdo da base de dados, assim como encapsulam o comportamento reativo da aplicação para tais eventos. Regras do negócio para ROSCA et al. (1997), tornam-se requisitos que governam o sistema operacional da organização e determinam como o negócio é executado atualmente. Podem ser originadas dos objetivos organizacionais e em geral são declarações sobre a forma da organização realizar o negócio, refletindo políticas, procedimentos e restrições, fazendo bom uso dos recursos, de acordo com as leis e convenções do negócio.

GOTTESDIENER (1997) afirma que regras do negócio podem oferecer muitos benefícios: rapidez no desenvolvimento de software, melhor qualidade dos requisitos; facilidade de mudança e balanceamento entre flexibilidade e controle centralizado. A pesquisa sobre regras do negócio direciona para a verdadeira integração entre pessoas do negócio e tecnologia. Ao permitir que regras do negócio sejam definidas e gerenciadas separadamente, fazendo uma ligação com a Engenharia de Software, gerando e mantendo aplicações das regras do negócio, tem-se um excelente potencial para evoluir o estado da arte de Sistemas de Informação.

HERBST (1996) explica que com os progressos ocorridos no nível de implementação, tem sido enfatizado o tratamento das regras do negócio. Regras do negócio cobrem à integridade dos dados, as restrições da dinâmica organizacional e a uma declaração de como o negócio é feito. Regras do negócio são elementos importantes de muitas pesquisas de teoria organizacional, como Administração Cientifica de Taylor e no Modelo da Burocracia de Weber. Para LEITE \& LEONARDI (1998), regras do negócio são uma ponte entre o modelo empresarial e o sistema operacional e são derivadas do modelo de apoio à decisão.

A definição de regras do negócio não menciona computadores, software, linguagens de programação, base de dados ou alguma outra tecnologia. Uma regra de negócio deve ser feita

\footnotetext{
${ }^{1}$ CERI, S., FRATEMALE, P. (1997). Designing Database Applications with Objects and Rules: The IDEA Methodology,
} Addison-Wesley. 
explicitamente e ser aprovada por uma pessoa competente do negócio. A ênfase no entendimento, especificação, reutilização de regras do negócio está em sua semântica em lugar de em muitas diferentes formas de expressar sua sintaxe. Similarmente, o entendimento de um programa (e reutilização de construções da programação) é possível apenas se baseado em semântica em lugar da sintaxe usada para expressar essa semântica (KILOV \& SIMMONDS, 1997).

HOYDALSVIK \& SINDRE (1993) ${ }^{1}$ apud LEITE \& LEONARDI (1998) afirmam que uma das principais motivações para buscar regras do negócio diretamente na fase de análise, é o fato de tornar mais fácil manter um sistema computacional, uma vez que facilitará fazer mudanças necessárias no sistema quando as regras do negócio modificarem.

A propriedade essencial de regras do negócio é que elas são expressas em termos de um modelo organizacional em vez de em termos de modelos de dados. Isso é devido ao fato que essas regras devem ser capturadas por pessoas orientadas ao negócio, não sendo necessariamente desenvolvedores de software. Outra importante propriedade de regras do negócio é que estas mudam freqüentemente devido à natureza dos fatores que as influenciam: regulamentos governamentais, forças do mercado, tomada de decisão. Mudanças nas regras do negócio necessitam ser apoiadas dentro dos processos do negócio para a organização reagir a essas influências (ROSCA \& WILD, 1996).

HERBST et al. (1994) fazem uma comparação entre métodos orientados a função, a dados e a objetos e revelam que nenhum método simples permite uma especificação gráfica conveniente para especificação de diferentes aspectos de regras do negócio no nível conceitual. Entretanto os autores consideram que a combinação de muitos métodos pode ser aplicada, uma vez que cada método representa uma específica visão nas regras do negócio.

GOTTESDIENER (1997), afirma que o entendimento de regras do negócio está se propagando, no entanto é ainda uma nova área de pesquisa. Regras do negócio estão começando a ser reconhecidas como um conceito distinto, uma prática, uma metodologia e/ou uma técnica de requisitos. Regras do negócio são uma declaração que define ou restringe algum aspecto do negócio, pretendendo-se afirmar a estrutura do negócio ou controlar ou influenciar o comportamento do negócio. ROSCA et al. (1997) afirmam que muitos requisitos caem na categoria conhecida como regras do negócio, os quais expressam requisitos computacionais que determinam ou afetam em como o negócio é realizado. Regras do negócio enfocam como clientes são tratados, como recursos são gerenciados, ou como situações especiais são tratadas cumprindo processos do negócio. Elas representam decisões do negócio para cumprir esse trabalho com fins de prover o

\footnotetext{
${ }^{1}$ HOYDALSVIK G.; SINDRE G. On the purpose of Object-Oriented Analysis. In Proceedings of OOPSLA'93, Conference on Object-oriented Programing Systems, Languages and Application. ACM Press, USA, 1993.
} 
serviço ao cliente. Assim, regras do negócio compreendem um conjunto importante de requisitos de um sistema sendo desenvolvido ou obtido pela organização.

\subsection{Representação de Regras do Negócio}

Diferente de GOTTESDIENER, (1997), que afirma que regras do negócio devem ser escrita de forma declarativa, usando gramática padrão, HERBST (1996) explica que regras do negócio podem ser representadas de acordo com as regras das bases de dados ativas, usando três componentes básicos: Eventos, Condição e Ação (ECA). Muitos estudos de caso para extrair regras do negócio foram aplicados em sistemas de informação e revelam a necessidade da extensão dessa estrutura para ECAA (Evento, Condição, Então-Ação, Se não-Ação). Para o evento deve ser conhecida quando a regra do negócio tem que ser processada. Para a condição é importante saber o que deve ser verificado, o que tem que ser feito se caso a condição for verdadeira ou se for falsa.

HERBST (1996) explica que a estrutura ECAA permite especificar regras do negócio individuais e a definição de processos completos. A linha que divide a integridade e o processo é confusa, algumas pesquisas tentam separar esses dois aspectos, mas essa separação é muito artificial e pode deixar vazios no processo de especificação, porque a avaliação da integridade da semântica pode ser parte do processo e isso poderia resultar em chamadas a outros processos. Na pesquisa do autor, a condição da integridade corresponde a uma parte da condição da regra do negócio, que por sua vez abrange o evento que pode disparar a avaliação da propriedade e a ação que depende do resultado. Para a especificação do processo é necessário ligar o componente da ação da regra do negócio aos eventos, os quais podem disparar outras regras do negócio.

A ontologia do modelo empresarial, quando examinada em nível mais detalhado, se mostra na forma de eventos, restrições, condições e ações. Para ROSCA et al (1997), ECA tem uma melhor definição de semântica operacional.

Se no momento em que o evento ocorre, a condição é encontrada, então a ação é iniciada. Os eventos, condições e ações são formulados como expressões no objeto do Modelo Organizacional. Regras ECA são mais geralmente aplicadas do que parece. BUBENKO \& WANGLER (1993) discutem o uso de regras similares, a interpretação prudente de casos especiais (tais como negligenciar significados por omitir um dos componentes da regra), e permitir que regras ECA expressem muitos tipos de regras do negócio na taxinomia. Adicionalmente, uma regra ECA pode ser usada para expressar semânticas não operacionais, tais como os objetivos da organização. 


\subsubsection{A estrutura ECAA}

Na pesquisa de HERBST (1996) é demostrado um estudo de caso de uma seguradora. Esse sistema cobre seguro de responsabilidade pessoal, contra terceiros e contra roubo entre outras propriedades asseguradas. $\mathrm{O}$ processo realizado manualmente foi analisado através de entrevistas com pessoas do departamento e constatou-se 131 regras ECAA em diferentes níveis de abstração. Os dados e procedimentos da parte automatizada do processamento de indenizações, implementada em Cobol, foram analisados manualmente em walkthrough ${ }^{1}$ estruturado. A análise do código resultou em 627 regras ECAA adicionais. Isso demonstra a dificuldade de separar restrições de integridade e níveis de processo.

Segundo HERBST (1996), para analisar o conteúdo de regras do negócio, é necessário uma sintaxe especifica para a especificação dos seguintes três tipos de regras: regras automatizadas, regras de integridade estática e regras de integridade dinâmica (transacional). Entretanto, na pesquisa de HERBST (1996) a sintaxe de regras do negócio tem sido omitida, uma vez que é dada uma ênfase especial nos problemas administrativos como resultado do grande número de regras do negócio relevantes no real sistema de informação.

Para ilustrar o escopo e potencial uso de regras do negócio será mostrado o registro de sinistros em nível geral. Esse processo é iniciado com uma pessoa fazendo contato com a companhia de seguros, a primeira regra de negócio executa uma verificação, se a pessoa é um assegurado e se o assegurado quer informar um SINISTRO.

Regra do Negócio 1: 'PESSOA-CONTATA-NOS':

ON (chamada telefônica) ou (carta da pessoa)

IF (pessoa é um assegurado) E ( assegurado relata um sinistro)

THEN inicia registro do sinistro

Chama evento 'SINISTRO DECLARADO'

O processamento da próxima regra leva para registro provisório de sinistro se o assegurado já forneceu todas as informações sobre o sinistro, se não ele recebe um formulário para completar.

Regra do Negócio 2: 'REGISTRO-PROV-SINISTRO'

ON $\quad$ sinistro declarado

\footnotetext{
${ }^{1}$ Walkthrough é uma técnica de revisão formal de projetos, onde o projeto é avaliado com o objetivo de encontrar defeitos.
} 
IF

(informação sobre o sinistro foi avaliada)

THEN

registra sinistro provisoriamente

data-registro:= hoje ()

chama o evento 'SINISTRO-REGISTRADO'

ELSE

manda formulário para o assegurado

Chama o evento 'FORMULARIO DE SINISTRO ENVIADO'

O registro de informação incompleta sobre o sinistro é seguido pela checagem preliminar no caso do sinistro ser coberto pela apólice do assegurado. Dependendo do resultado, o pedido do assegurado pode ser rejeitado e um formulário é enviado ao assegurado para completar as informações.

Regras do Negócio 3: 'ACEITA-PROV-SINISTRO'

ON $\quad$ sinistro provisório registrado

IF (sinistro é assegurado pela apólice)

THEN aceito sinistro provisoriamente

envia formulário para o assegurado

chama evento 'FORM-SINISTRO-ENVIADO'

chama evento 'SINISTRO-PROV-ACEITO'

ELSE rejeita sinistro

chama evento 'SINISTRO-REJEITADO'

O assegurado é lembrado se ele não retornar o formulário em 60 dias:

Regra do Negócio 4: 'LEMBRAR-SOBRE-FORM-SINISTRO'

ON 60 dias depois do evento 'FORM-SINISTRO-ENVIADO'

IF (formulário do sinistro não retornar)

THEN lembrar o assegurado

Outros 30 dias depois, o registro provisório do sinistro é apagado se o formulário não tiver retornado:

Regra do Negócio 5: PRAZO-FINAL-FORM-SINISTRO'

$\mathrm{ON}$

90 dias depois do evento ('FORM-SINISTRO-ENVIADO') 
IF

(formulário do sinistro não retornou)

THEN

apague provisoriamente sinistro aceito

HERBST (1996) explica que essa última regra no exemplo é disparada pelo evento 'formsinistro-enviado' e 'form-sinistro-recebido' em 90 dias. Cada formulário recebido é verificado e se um formulário não está corretamente preenchido, retornará ao assegurado. Caso contrário, um registro definitivo de sinistro inicia.

Regra do Negócio 6: REGISTRO-DEF-SINISTRO'

$\mathrm{ON}$ FORM-SINISTRO-RECEBIDO DENTRO (90 dias depois (FORM-SINISTRO-ENVIADO))

IF

(informação está completa)

THEN chama o evento 'INICIA-DEF-REGISTRO-SINISTRO'

ELSE retorna formulário para assegurado

Chama evento 'FORM-SINISTRO-ENVIADO'

Subseqüentemente a execução dessas regras do negócio, o processo de tratamento definitivo de pedidos do assegurado pode iniciar. HERBST (1996) enfatiza que esses exemplos mostram o uso potencial de regras do negócio para especificar dinâmicas relevantes nos conceitos de gerenciamento de workflow e reengenharia de processos de negócio ${ }^{1}$. Por esta razão, depois de ter avaliado a viabilidade da pesquisa de regras do negócio, é provável a intensificação da especificação de workflow.

\subsubsection{Abstrações e Refinamento de Regras do Negócio}

HERBST (1996) através desse estudo de caso constatou que o alto número de regras do negócio torna o trabalho muito complexo. Para reduzir essa complexidade, HERBST adapta o princípio de diagrama de fluxo de dados (DFD) nivelado (como utilizado na análise estruturada), no qual o diagrama pai e o filho devem ser comparados e equilibrados. Nesse conceito, diferentes níveis de especificação de regras do negócio são alocadas para subprocessos fechando um conjunto finito de regras do negócio.

\footnotetext{
${ }^{1} \mathrm{O}$ termo do inglês: Business Process Engineering (BPR).
} 
HERBST (1996) explica que a figura 3 descreve uma simples rede de regras do negócio, na qual, o círculo representa um evento e paralelogramos são componentes de condição e ação. O diagrama de nível 1, processo 1 consiste de [BR-1], [BR-2] e [BR-3]; entretanto [BR-1] e [BR-2] são refinadas pelos processos 2 e 3 nos níveis abaixo. Esse nivelamento permite uma especificação modular do processo e uma reutilização das regras do negócio. Regras do negócio reutilizadas são sempre disparadas pelo mesmo evento e sempre chamam os eventos idênticos. Entretanto, dependendo do subconjunto de regras do negócio, que define um processo específico, no qual diferentes regras podem reagir em diferentes eventos. [BR-4] como um elemento do processo 2 e 3 conduz ao evento [E-6] que dispara [BR-5] e [BR-6] no processo 2 e [BR-8] no processo 3. Se uma regra do negócio reutilizada é refinada novamente, o resultado do processo de baixo nível é automaticamente um subprocesso de todos os processos que tem as regras do negócio reutilizadas. Como exemplo [BR-4] é adicionalmente refinada no processo 4 é subprocesso do processo 2 e 3 . O modelo pode ser considerado dinâmico devido ao conceito de regras do negócio do autor incorporar diferentes níveis de abstração e além disso permitir a descrição de atividades concorrentes e incorporar explicitamente a dimensão tempo.

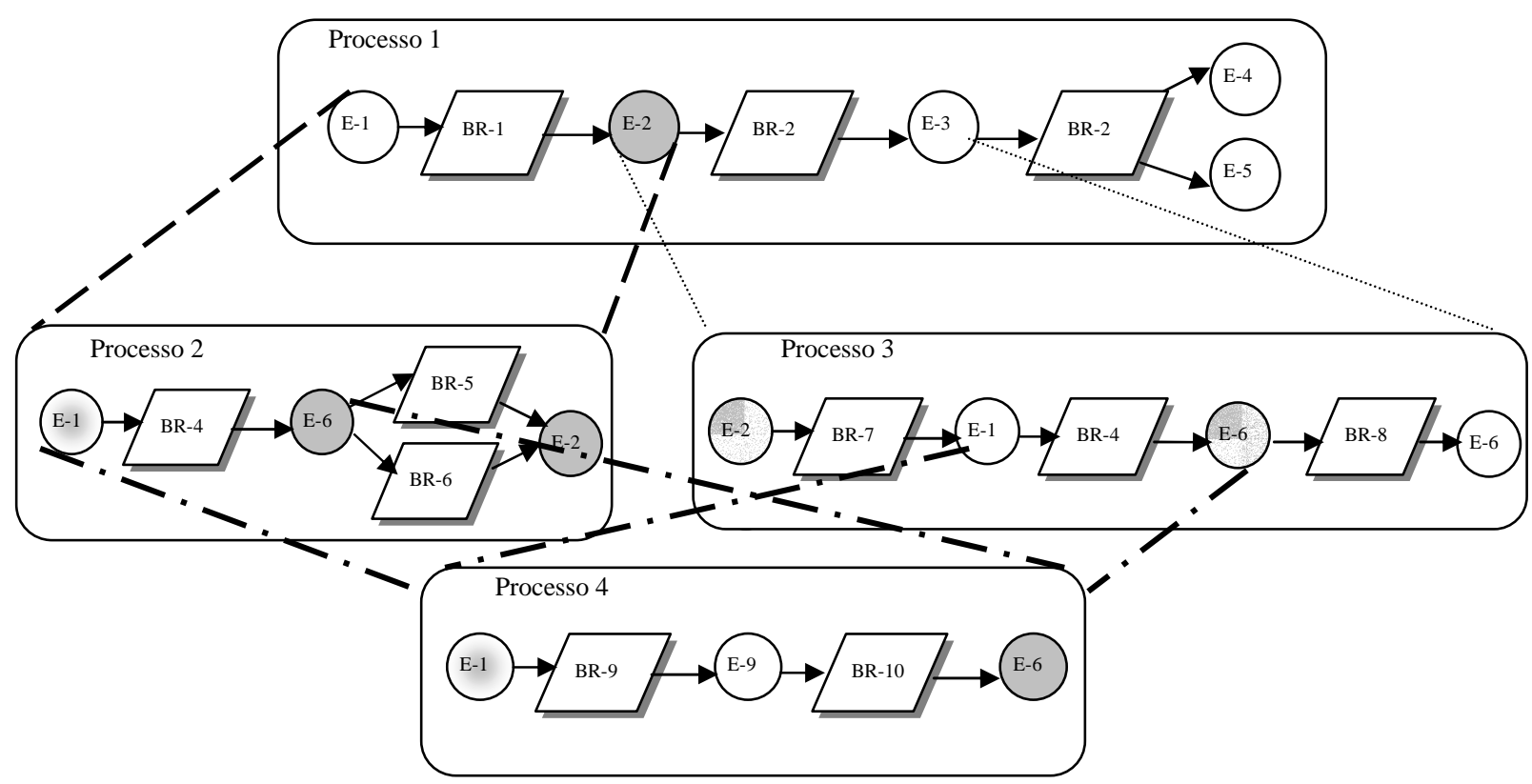

Figura 3- Especialização de Regras do Negócio.

Legenda:

E-n: Evento $n$

BR-n: Regra do Negócio

Fonte: HERBST (1996), p. 152. 


\subsubsection{Um Modelo para Regras do Negócio}

O modelo introduzido por HERBST (1996) é apresentado em duas partes: a primeira é sobre o núcleo do meta modelo incluindo os submodelos de Regras do Negócio, Processo e Modelo de Componentes de Dados e o segundo está de acordo com fixação de regras do negócio dentro dos submodelos.

O submodelo de regras do negócio consiste de quatro meta-tipo entidade: Regra do Negócio, Evento, Condição e Ação. A parte do relacionamento entre regras do negócio e esses componentes é usada em lugar do relacionamento padrão, porque uma específica regra do negócio apenas existe pela agregação desses componentes. Cada regra do negócio tem exatamente um evento, quando muito, uma condição e uma ou duas ações (then/else). Eventos e condições podem ser complexos e podem ter relacionamentos recursivos m:n.

No submodelo de processos, HERBST (1996) esclarece que as ações de regras do negócio podem ser relatadas para eventos resultados da cadeia ECA descrevendo a dinâmica do processo como o exemplo descrito na figura 4. Cada processo é definido por um conjunto finito de regras do negócio. Fatos adicionais considerados são nome do processo, proprietário do processo, metas do processo, unidades organizacionais envolvidas (ou funcionários), restrições temporais e relacionamentos com outros processos. Entre processo e regras do negócio existem dois tipos diferentes de relacionamentos: um processo é especificado pelas regras do negócio e um processo pode refinar uma regra do negócio, que é um elemento de processo de alto nível. Na figura 4, o subprocesso do lado esquerdo é especificado pelas regras do negócio [BR-4], [BR-5] e [BR-6]; além disso, esse subprocesso refina [BR-1] que tem seu próprio lugar no processo 1 . O foco na dinâmica do processo, como exemplo a visão funcional, pode ser analisado de dois diferentes pontos de vistas:

1. Processo $\Rightarrow$ regra do negócio: Quais regras do negócio definem um processo específico?

Exemplo: O nível 1 (topo) do processo de 'PROCESSO-SINISTRO' é especificado pelas regras introduzidas no exemplo anterior.

2. Regra do negócio $\Rightarrow$ processo: Quais processos são referenciados pelos componentes das regras do negócio?

Exemplo: Dentro do processamento de sinistro de uma companhia de seguro, existem regras do negócio, das quais podem disparar outros processos na organização, como modificar os termos da política dos seguros. 
HERBST (1996) explica que o submodelo modelo de componente de dados inclui metatipos de entidades para a especificação do modelo conceitual de dados. O mais popular modelo de dados para modelagem conceitual é Modelo Entidade Relacionamento (MER) que incorpora conceitos tais como: tipo de entidade, tipo de atributo e tipo de relacionamento. A semântica do relacionamento entre componentes de regras do negócio e modelo de dados é a conversão, modificação, derivação ou exclusão dos dados. O relacionamento entre os submodelos Regras do Negócio e Componentes de Modelos de Dados podem ser analisados de dois diferentes pontos de vista:

1. Regras do Negócio $\Rightarrow$ componente do modelo de dados: Quais impactos tem uma específica regra do negócio nos componentes do modelo de dados?

Exemplo: A regra do negócio 1: 'PESSOA-CONTATA-NOS' faz referencia para a:

Tipo de entidade 'Assegurado' (condição)

$\begin{array}{ll}\text { Tipo de entidade 'Pessoa' } & \text { (condição) } \\ \text { Tipo de entidade 'Sinistro' } & \text { (condição e ação) }\end{array}$

2. Componente do Modelo de Dados $\Rightarrow$ regras do negócio: Quais regras do negócio usam a específica construção?

Exemplo: O tipo de entidade 'Assegurado' é referenciado pelas regras do negócio:
1: 'Pessoa contata-nos'
(condição)
2: 'Registro-Prov-Sinistro'
(ação)
4: 'Lembrar-pelo-form-sinistro'
(ação)
6: 'Registro-def-sinistro'
(ação)

\subsubsection{Regras do negócio no ambiente}

Regras do negócio definidas e exemplificadas por HERBST (1996), descrevem como o negócio é feito; entretanto, para obter uma visão integrada do universo do discurso, as regras devem estar embutidas no seu ambiente. Por esta razão, o meta modelo consiste de muitos submodelos, os quais estão intimamente ligados para o submodelo central de Regra do Negócio. A figura 4 mostra o relacionamento entre o submodelo Regra do Negócio e o outros submodelos:

1. Origem: cada regra do negócio tem apenas uma origem. Regras do negócio podem ser originadas dentro ou fora da organização. Regras de origem externa podem ser ainda 
divididas em fatos naturais que são infinitos e normas especificadas pela sociedade que podem mudar a qualquer tempo. Regras de origem interna podem ser primárias ou secundárias: uma origem é primária se o conteúdo é originalmente descrito em um documento fonte; uma origem é secundária se foi derivada de outra fonte. $\mathrm{O}$ conhecimento sobre a origem de regras do negócio permite entre outras coisas uma análise de dois pontos de vista:

$>$ Origem $\Rightarrow$ regra do negócio: quais regras do negócio têm sido recuperadas de uma específica origem (em caso de modificações em regras no mundo real de uma específica origem)?

Exemplo: No contrato da apólice para seguros contra terceiros dá origem a um certo conjunto de regras do negócio.

$>$ Regra do negócio $\Rightarrow$ origem: onde uma regra específica do negócio tem origem (para verificar a consistência entre a implementação no mundo real)?

Exemplo: A regra do negócio 4: 'LEMBRAR-SOBRE-FORM-SINISTRO' tem origem nas linhas guias da organização que definem o processo de sinistro.

2. Processo: regras do negócio podem ser elementos de processos, nos quais consistem ao menos uma regra do negócio. Os processos são ligados com as unidades organizacionais.

3. Componente de modelo de dados: regras do negócio podem referir a componentes do modelo de dados.

4. Unidade organizacional: por cada componente de regras do negócio, uma unidade organizacional e o responsável pela regra têm que ser identificados. A tarefa do componente da regra do negócio para a unidade organizacional responsável pelo conteúdo conduz em regras dentro e entre unidades. Essa classificação pode ajudar no apoio da administração de regras do negócio. A análise do relacionamento entre regras do negócio e unidade organizacional pode ser feita por dois diferentes pontos de vista:

$>$ Unidade Organizacional $\Rightarrow$ regras do negócio: Por quais eventos, condições ou ações uma específica unidade organizacional é responsável?

$>$ Regra do negócio $\Rightarrow$ unidade organizacional: Quais unidades organizacionais são responsáveis por regras específicas do negócio?

5. Componente do SI: cada componente de uma regra do negócio é atribuído para um componente do Sistema de Informação (SI). O processo descrito na rede de regras e 
eventos na figura 4 não provê nenhuma informação sobre distribuição manual e componentes automatizados de um Sistema de Informação. Para obter essa informação, componentes das regras do negócio têm que ser nomeados atores (subsistema manual) ou componente de software (subsistema automatizado), como exemplo: funções e disparadores de base de dados. É adequado para questionar as formas correntes de processar e otimizar essa distribuição manual e automatizada de componentes do SI durante o desenvolvimento de um SI . Existem três pontos de vista:

$>$ Descrição de sistema atual;

$>$ Descrição de possíveis tarefas (análise das alternativas);

$>$ Descrição de tarefas planejadas (análise dos objetivos do sistema).

Segundo POO (1992) ${ }^{1}$ apud HERBST (1996), as políticas de alto nível do negócio são normalmente transformadas em representações computacionais de baixo nível e "enterradas profundamente no código do programa", isto é, ficam perdidas no código do programa. Para apoiar a manutenção do sistema de Informação, a análise das tarefas correntes ajuda encontrar a implementação de específicas regras. Segundo HERBST (1996), a análise de alternativas é apenas necessária para definir uma tarefa planejada, se o sistema atual não está satisfazendo. As possíveis tarefas dependem especialmente da questão, se isso é possível para implementar um componente da regra dentro do SI. Para determinação da tarefa planejada dos componentes, muitos aspectos devem ser considerados:

$>$ Desejabilidade: deve determinar se o controle do processamento do componente da regra deve ser deixado para o sistema computacional (com respeito as razões éticas).

$>$ Flexibilidade: componentes da regra implementados em um sistema computacional são processados muito estritamente; isso pode prevenir ações adequadas em situações excepcionais.

$>$ Consistência de regras forçadas: a falta de flexibilidade pode também ser considerada como uma vantagem, porque esses componentes implementados em um sistema computacional são sempre processados na mesma forma consistente.

\footnotetext{
${ }^{1}$ POO, C.C.D (1992). A framework for software maintenance. Proceeedings of the fifth International Conference on advanced Information Systems Engineering. Springer, Berlin, p. 88-104.
} 
$>$ Dados: quanta dificuldade existe para armazenar todos os dados necessários por um processamento automático de um componente de regra?

$>$ Complexidade: é possível implementar a lógica do componente com custos aceitáveis?

$>$ Custos: diferentes alocações de componente de regras resultam em diferentes custos para seu processamento. Isso poderia especialmente ser relevante para reengenharia de processos para reduzir custos.

$>$ Número de interações: muitas interfaces necessárias para o processamento do negócio deveriam ser minimizadas. Deveriam se esforçar para processamento de regras homogêneas e nomear a regra do negócio para o SI ou para o ambiente onde o sistema está inserido.

6. Ator: unidades organizacionais podem consistir de pessoas (atores) que são responsáveis pela execução manual de componentes de regras do negócio. O tipo de entidade Ator é um subtipo de um componente do SI. Na ordem para definir quem processa um componente da regra, eles são designados para atores específicos que registram eventos, avaliam condições e realizam ações. O relacionamento pode ser analisado de dois pontos de vista:

Ator $\Rightarrow$ regra do negócio: para cada evento, condição ou ação, um específico ator é responsável? Exemplo: Um atendente que processa sinistro é responsável por executar uma regra do negócio.

Regra do negócio $\Rightarrow$ ator: qual ator é responsável pela correta execução de uma especifico componente de uma regra do negócio?

7. Componente do Software: componente de regras do negócio pode ser implementado no software e executado automaticamente. O tipo de entidade Componente de Software é o segundo subtipo de um componente de SI. Componentes como por exemplo, módulos de biblioteca centralizada, armazenamento de procedimento, disparador de base de dados ou declarações podem ser usados para implementar e automatizar componentes específicos de regras do negócio. O relacionamento pode ser analisado de dois pontos de vista:

Componente de software $\Rightarrow$ regras do negócio: Quais eventos, condições ou ações são implementadas em um específico componente 
de software? Exemplo: $\mathrm{O}$ atendente que processa sinistro é responsável por executar regras do negócio 2: 'REGISTRO-PROV-SINISTRO' e 3: 'ACEITA-PROV-SINISTRO'.

Regra do negócio $\Rightarrow$ componente de software: Quais componentes de software inclui a semântica de componente específico da regra do negócio? Exemplo: Regra do negócio 2: 'REGISTROPROV-SINISTRO' é executada pelo atendente que processa os sinistros.

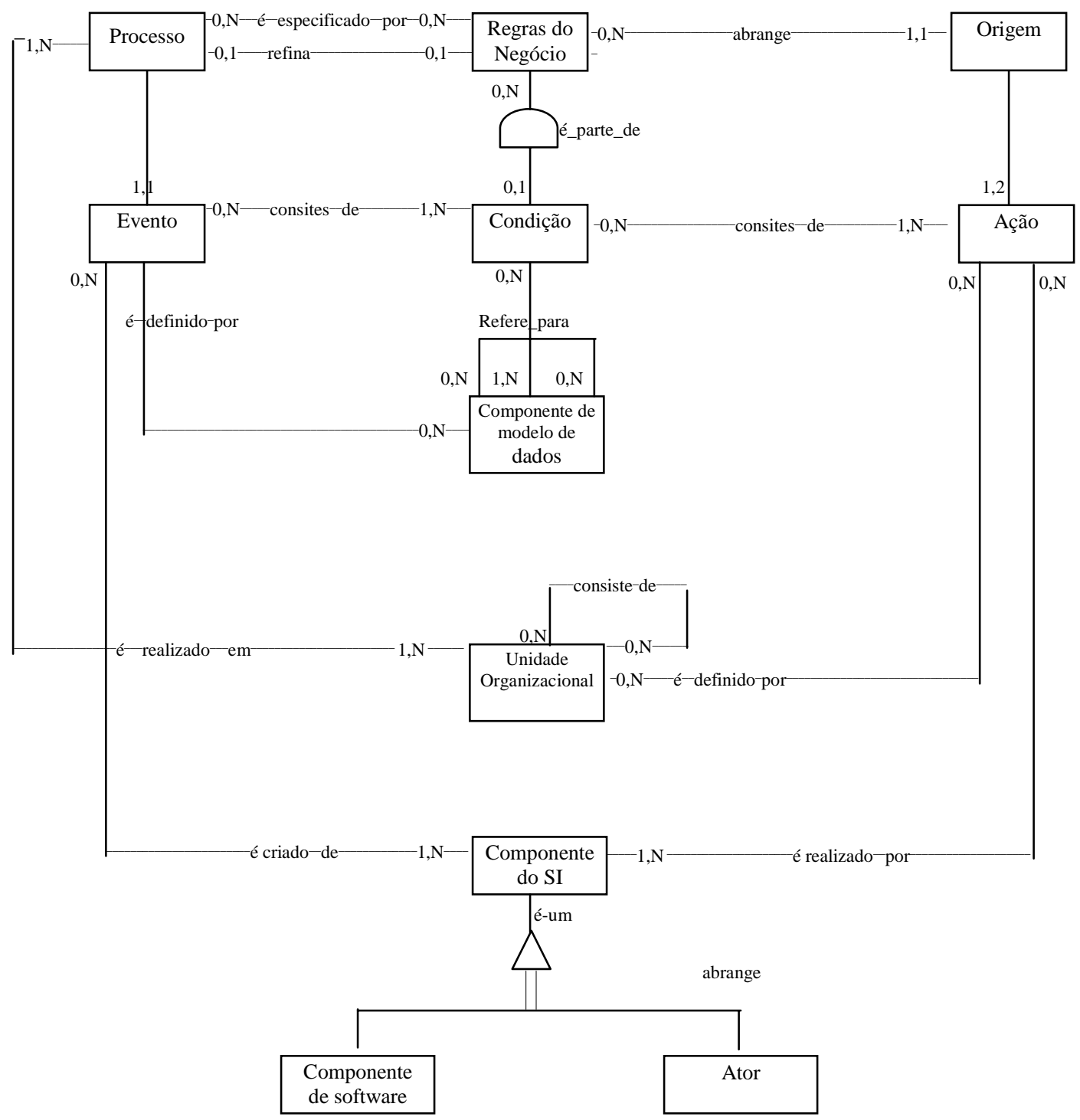

Figura 4- Encaixando Regras do Negócio no ambiente.

Fonte: HERBST (1996), p. 156. 


\subsubsection{Um sistema repositório para regras do negócio}

Um repositório completamente desenvolvido tem o mesmo princípio de um Sistema Gerenciador de Base de Dados com alguma funcionalidade especial para administrar meta-dados. Isso inclui a capacidade de especificar meta modelos, customizar a interface do usuário e implementar mecanismo de verificação e geradores apropriados. Para enfrentar um grande número de meta-dados, um sistema repositório tem que prover de sofisticadas possibilidades de consultas; essas deveriam suportar resultados em representações gráficas. Em lugar de construir um sistema repositório do nada, ele é baseado em uma solução avaliável que pode ser adaptada para o específico propósito. Aplicado para a administração de regras do negócio, o sistema repositório empregado deve suportar um esquema dicionário que é equivalente ao meta modelo introduzido anteriormente. Esse modelo é particular da pesquisa de HERBST (1996), na qual considera-se que o sistema deve ser adaptado para suportar as seguintes tarefas: registro e verificação de regras do negócio, derivação dos componentes dos modelos de dados e especificação da estrutura dos dados. É necessária uma interface flexível para o usuário e uma linguagem de programação poderosa, além disso, um componente gráfico para apoiar diferentes notações de representações de regras do negócio.

\subsection{Regras do Negócio na Organização}

GOTTESDIENER (1997) afirma que cada regra do negócio deve ser decomposta em outras discretas regras do negócio. $\mathrm{O}$ autor cita o seguinte exemplo: uma pessoa do negócio pode afirmar: "o número total de produtos regularizados vendidos no país não deve exceder o limiar definido pelos limites reguladores do país de origem”. Essa declaração contém muitas regras discretas do negócio e termos para pessoas já familiarizadas com o negócio. A declaração traz implicitamente definições ('produtos regularizados' e 'país'), derivações ('número total de', 'limiar'), fatos ('produtos vendidos no país', 'limites definidos pelo país de origem') e restrições ('total' e 'não exceder limites').

Uma regra do negócio pode ser decomposta até uma forma elementar como um átomo (indivisível), até ser suficiente para se referir a um único conceito. A regra do negócio não contém declarações de controle de fluxo, tipicamente encontrada em lógica de programação e deve ser escrita de forma declarativa (não procedural), usando gramática padrão, linguagem natural que as pessoas do negócio possam ler e entender de forma não ambígua (GOTTESDIENER, 1997). 
Segundo HERBST (1996), o principal objetivo da análise de sistemas é colecionar todas as informações relevantes do universo do discurso. Universo do discurso é todo o contexto no qual o software será desenvolvido, operado e mantido. Isso inclui todas as fontes de informação e todas as pessoas (atores) relacionadas com a aplicação. O Universo do Discurso é na realidade composto pelos objetivos estabelecidos pelo cliente (LEITE \& LEONARDI, 1998).

Presume-se que regras do negócio são de importância estratégica e tática para o sucesso do negócio. Isso significa que, entre outras coisas, as regras são formuladas e analisadas pelas pessoas orientadas ao negócio, não por profissionais técnicos ou engenheiro de software. Decisões sobre custo, qualidade e responsabilidade e bons serviços não são propostos ou delegados por projetistas de sistemas ou programadores. Na realidade, é freqüente o caso em que a única forma para determinar regras do negócio de uma organização é olhar para o sistema operacional: Como o Serviço de Clientes marca uma visita? Como o software calcula o reembolso do seguro? Isso tem motivado a discussão de "mineração (mining)" de regras do negócio através de um tipo de atividade de engenharia reversa de software. Entretanto isso pode ser difícil ou até impossível, uma vez que manifestações de regras do negócio podem estar por todo o código (HERBST, 1996).

Como mostrado na figura 5, regras do negócio estão posicionadas entre objetivos organizacionais e o sistema operacional da organização. O sistema operacional é a combinação de software, hardware e pessoas que executam o trabalho dentro da organização. Objetivos da organização são em geral aspirações: "fazer mais dinheiro", "fazer clientes satisfeitos", "manter os acionistas satisfeitos com seu investimento", entre outros. Os objetivos são a fonte definitiva de todos os requisitos no sistema operacional. Por causa das ambigüidades e conflitos inerentes nos objetivos organizacionais, regras do negócio não são simplesmente refinamento dos objetivos; mais do que isso, elas representam decisões sobre o que é feito para alcançar os objetivos da organização. Regras do negócio tornaram-se requisitos que governam o sistema operacional da organização e determina como é atualmente executado (ROSCA et al., 1997).

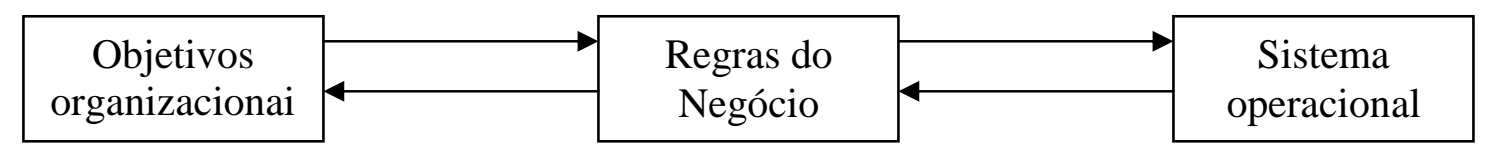

Figura 5- Colocação do contexto de Regras do Negócio.

Fonte: ROSCA et al. (1997), p. 237. 
ROSCA \& WILD (1996) vêem regras do negócio como a camada média de um sandwich de três camadas composto de: Modelos de Objetivos e Políticas, Regras do Negócio e Modelo de Dados e Processos (figura 6). A camada inferior é representada por Modelos de Processos e Dados da organização, e possui restrições (regras do negócio). A camada topo é representada por objetivos, políticas e restrições da organização. Esses são freqüentemente expressos em termos gerais e vagos que podem ser traduzidos em regras que devem alcançar as metas; essas regras são definidas regras do negócio. Nesse contexto, regras do negócio estão freqüentemente tratando situações caracterizadas por inconsistências, incompletude e incerteza. Mas o problema não é só a importância de alcançar consistência e completitude e eliminar a ambigüidade, há também o problema de chegar a um conjunto de possíveis e conflitantes objetivos e entendimento das consequiências de um conjunto de ações sobre os objetivos do negócio. O conjunto de regras sobre uma organização quase certamente terminará em inconsistências não resolvidas e não tratará todos os casos de interesse. Além disso, muitos especialistas no domínio usarão projeções e suposições em seus julgamentos, os quais são algumas vezes fonte de ambigüidade Portanto, é necessário capturar as metas que as regras estão direcionadas para alcançar e as conseqüências de quebrar as regras.

\begin{tabular}{|c|}
\hline Metas e Objetivos \\
\hline Regras do Negócio \\
\hline Modelo de Dados e Processos \\
\hline
\end{tabular}

Figura 6-Contexto de Regras do Negócio.

Fonte: ROSCA \& WILD (1996).

Os trabalhos típicos dessa área têm como foco a detecção de inconsistências e incompletitude das especificações de software. ROSCA \& WILD (1996) pesquisam em direção a uma abordagem para trabalhar com a presença desses problemas.

ROSCA et al. (1997) afirmam que as pesquisas sobre organização têm em comum que certas partes da organização podem e deveriam ser descritas por regras formalizadas e que existem regras que não deveriam ser formalizadas. O desenvolvimento de sistemas de informação leva a descrições detalhadas e formalizadas de todos os fatos, o quais são implementados e executados 
automaticamente. Entretanto, segundo HERBST (1996), existem muitas exceções as regras, que em processos informatizados, muitas vezes, não podem ser processadas corretamente sem intervenção manual. Os seguintes passos deve ser seguidos na análise de sistemas enfocando regras do negócio:

Definir hierarquicamente o processo do Universo do Discurso.

Coletar todos os fatos relevantes para os processos e especificá-los como regras de negócio. Por razões de administração, classifica-se todas as regras do negócio de acordo com muitos critérios discutidos em HERBST (1995).

$>$ Derivar todos os modelos em regras do negócio (como tipos de entidades, tipos de relacionamentos e atributos) e estruturá-los em um modelo conceitual de dados.

Análise do modelo de dados com respeito às restrições de integridade e especificá-las como regras do negócio.

As especificações podem ser usadas no projeto e implementação do sistema, depois de verificadas e validadas, de acordo com a figura 7 .

Segundo ROSCA et al. (1997), as regras do negócio devem ser expressas em um modelo em nível empresarial, não em termos de base de dados ou programas, uma vez que as regras são descritas e gerenciadas por pessoas do negócio. A implementação das regras do negócio não é muito simples, certamente não é só o significado habitual da reunião das especificações do sistema.

Uma característica importante das regras do negócio é que elas estão constantemente se modificando. Regras do negócio são formuladas com a finalidade de contribuir para o sucesso do negócio, e portanto se espera que as regras sejam constantemente avaliadas e modificadas para melhorar o negócio. Regras do negócio podem ser geradas por fontes externas ou em resposta a essas, tais como corpos regulamentares, leis, forças do mercado ou realidade física. Se o negócio não tem controle sobre essas forças externas, a organização deve ser preparada para mudar a regra do negócio que governa essa operação.

Quando as regras do negócio mudam, o sistema operacional precisa mudar, requerendo assim, maior investimento em manutenção e evolução. Essa é a fonte do problema que apresenta altos riscos, não apenas devido a custos, mas dificuldades de seguir um cronograma. Naturalmente, esse problema de adaptação dos sistemas para mudar requisitos é um clássico e universal. 


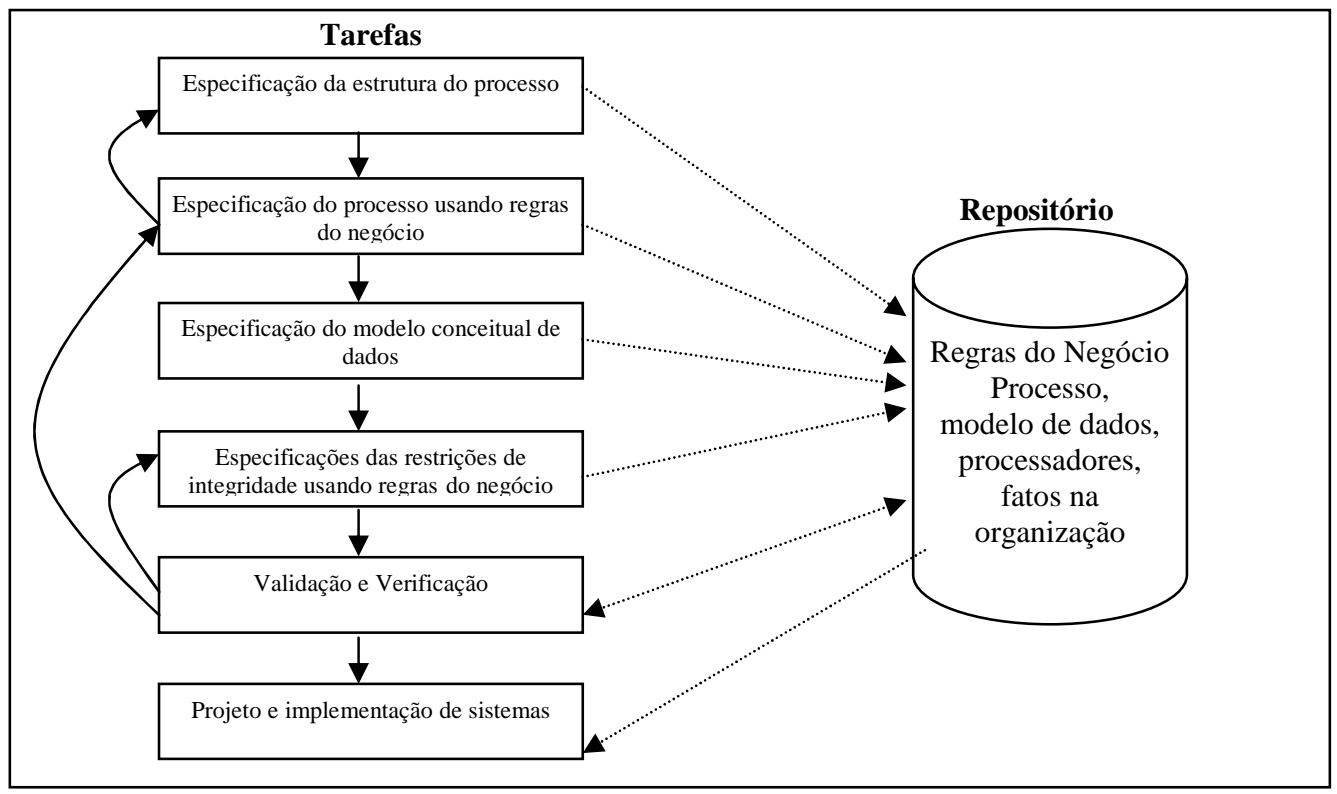

Figura 7- Análise de Sistemas focando em regras do negócio.

Fonte: HERBST (1996), p. 148.

\subsection{Regras do Negócio: Abordagem de Apoio à decisão}

ROSCA et al. (1997) propõem uma metodologia que se estende por todas as fases do ciclo de vida das regras do negócio: aquisição, desenvolvimento, mudança em resposta a mudanças na influência externa ou interna e mudanças baseadas na evolução do nível de satisfação de requisitos.

A propriedade essencial de regras do negócio é expressa em termos relacionados à organização em vez de termos do sistema que implementará as regras. As regras do negócio são adquiridas e analisadas por pessoas do negócio, uma vez que o tipo de raciocínio necessário deve corresponder aos objetivos do negócio, bem diferente do que é proposto pela maioria das linguagens de especificação de software (ROSCA et al., 1995).

Uma visão comum a respeito de regras do negócio é que um conjunto de regras deveria ser mapeado automaticamente para código, permitindo mudanças nas regras para serem respondidas rapidamente com mudanças no código correspondente. A pesquisa de ROSCA et al. (1995) se preocupa com a pouca atenção que tem sido dada para a atividade pré-requisito de como desenvolver e envolver um conjunto satisfatório de regras do negócio. 
Um modelo conceitual orientado ao negócio deve expressar todas as regras do negócio, por exemplo, uma organização pode ser vista consistindo de múltiplos agentes executando tarefas para realizar múltiplos processos do negócio, cuja proposta é prover serviços para outras organizações (GREENSPAN \& FEBLOWITZ ${ }^{1}, 1993$ apud ROSCA et al., 1995).

Na abordagem de ROSCA et al (1997), o ponto interessante de regras do negócio não é se elas estarão em conflito, mas saber o que fazer quando existir conflito ou o que fazer quando as regras que não estão em conflito são violadas em tempo de execução. É importante capturar as influências de uma regra sobre a outra em apoio do raciocínio sobre propostas para o conjunto de regras do negócio. O raciocínio baseado no mecanismo de apoio à decisão é um tipo apropriado de estrutura para a captura de regras do negócio.

No trabalho de ROSCA et al. (1995), no Desenvolvimento de Software Baseado em Decisão (Decision Based Software Development - DBSD), existe o Espaço em Questão (Issue Space) que captura deliberações sobre artefatos no domínio do discurso, o qual constitui o Espaço do Objeto (Object Space). Regras do negócio são expressas em termos da ontologia do Espaço dos Objetos.

Um bom fundamentado conjunto de regras do negócio desenvolvido por pessoas que conhecem o assunto em questão será baseado em projeções e suposições. A evolução desse conjunto de regras corresponde a habilidade para revisar as estruturas de decisão e propagar resultados através dessas estruturas. O ponto mais importante é que existe uma representação explícita das regras e sua razão não é avaliada apenas pelos analistas mas também por desenvolvedores por todo o ciclo de vida. Essa estrutura, segundo ROSCA et al. (1995), promete ser mais geral e apropriada para a tarefa do que o senso mais limitado de regras do negócio da literatura. Na próxima sessão será apresentada uma arquitetura proposta por ROSCA et al (1995), que oferece apoio à decisão para Regras do Negócio.

\subsubsection{Arquitetura: Apoio à decisão x Ciclo de vida de Regras do Negócio}

Na abordagem de ROSCA et al. (1995), é proposta uma arquitetura para apoiar o processo de Regras do Negócio durante seu desenvolvimento, operação e evolução (figura 8). Na fase de desenvolvimento, as questões do processo do negócio são discutidas, as decisões fundamentais são registradas e materializadas em um conjunto de regras do negócio. Essas regras são ligações fundamentais da decisão, essa informação tem grande valor durante as fases do ciclo

\footnotetext{
${ }^{1}$ GREENPAN, S. FEBLOWITZ M. (1993). Requirements engineering using the SOS paradigm. In Proceeding of IEEE International Symposium on Requirements Engineering, San Diego.
} 
da regra do negócio. As regras são chamadas de ligações fundamentais porque oferecem respostas baseadas na melhor informação disponível antes do uso operacional das regras do negócio para as seguintes questões: Quais alternativas têm sido escolhidas para resolver uma questão? Por quê?

Durante a fase operacional, ROSCA et al. (1995) distinguem entre Regras do Negócio Determinísticas e Não-Determinísticas. Regras determinísticas caracterizam unicamente as situações onde podem ser aplicadas, portanto, se elas estão codificadas no software do sistema, elas são automaticamente aplicadas pelo sistema, sem interação humana; ou elas são rigorosamente aplicadas por pessoas orientadas ao negócio. As regras não-determinísticas não permitem ao sistema tomar decisões automaticamente, requerendo interação humana porque muitas regras do negócio poderiam ser aplicáveis à situação. Essas decisões são chamadas de decisões operacionais, que também podem ser caracterizadas por elementos de decisão cujos valores são instanciados apenas durante a fase operacional. Além disso, instanciar estruturas de decisão com valores operacionais, pode consultar a decisão fundamental das regras do negócio relatadas (criadas na fase de desenvolvimento) para fazer uma decisão informada. Também, uma fundamentação analógica pode ser aplicada para procurar decisões em situações similares. Nesse caso novas questões são criadas para esses casos de decisão e sua fundamentação.

As justificativas iniciais são freqüentemente inapropriadas devido à necessidade de experiência com as regras do negócio da organização. Decisões condicionais são decisões baseadas em justificativas incertas, nas quais os desenvolvedores têm escolhido monitorar durante o uso operacional. Em caso de decisões condicionais, onde existe uma decisão sobre a adequação da suposição da decisão, propõem-se monitorar as consequiências da decisão durante a operação. Essa informação medirá os efeitos de aplicar as regras do negócio e depois indo através do processo de analisar as medidas adquiridas, será validada ou negada a decisão de escolha de uma particular regra do negócio. Esse processo também validará ou negará as suposições da decisão que também afetarão as decisões relatadas. A informação resultante da análise das métricas dos dados é chamada de justificativas posteriores, porque são baseadas em informações obtidas depois do desenvolvimento de regras do negócio. Essas justificativas são usadas para prover resposta para a questão: A regra escolhida tem alcançado as metas propostas? E em qual nível?

ROSCA \& WILD (1996), sugerem as seguintes dimensões de análise para tratar as regras do negócio disponíveis:

O nível de incerteza dos dados referidos para as regras do negócio. Alguns fatos podem ser conhecidos com razoável certeza (idade, endereço), enquanto outros requerem julgamento porque são assuntos relacionados à satisfação (baixo risco, fidelidade do cliente). Nesse último caso, instanciação de variáveis dentro da regra do negócio (regra 
básica) não pode ser feita automaticamente pelo sistema, ela requer assistência humana.

O número de regras aplicáveis para uma situação. Aqui são distinguidos três casos:

1) situações incompletas, nas quais nenhuma regra tem sido especificada;

2) situações determinísticas, nas quais existe uma regra especificada;

3) situações inconsistentes e não-determinísticas, caracterizadas por múltiplas regras do negócio.

A aceitabilidade do resultado de uma regra do negócio. Conforme essa dimensão, tenta-se determinar se a execução de uma regra alcançou uma meta desejada. Podem existir casos em que um pouco de preocupação sobre a aceitabilidade é aumentada durante a elicitação de uma regra do negócio, devido ao fato das pessoas basearem suas decisões em suposições. Nesses casos, a métrica de aceitabilidade é definida e usada para calcular os resultados da aplicação dessa regra.

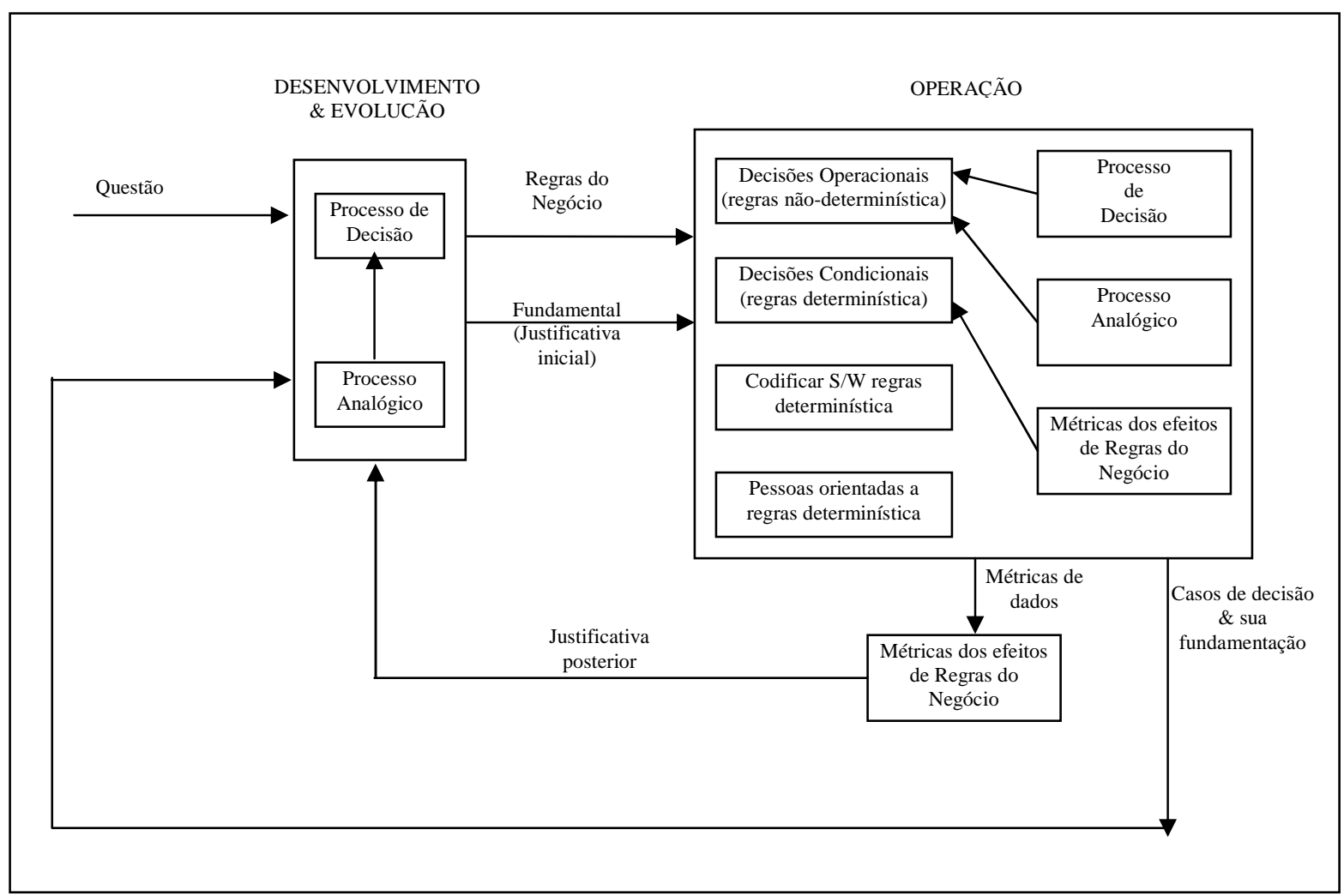

Figura 8- Arquitetura para ciclo de vida de regras do negócio no SAD.

Fonte: ROSCA et al. (1995), p. 115. 
Na fase de evolução, a informação obtida da fase de operação é usada para refinar regras do negócio existentes e gerar novas. ROSCA et al. (1995) explicam que, se a informação monitorada associada com a decisão condicional invalida a decisão e sua fundamentação, outra regra do negócio alternativa tem que ser escolhida baseada em outra suposição ou uma nova regra do negócio tem que ser criada. Se novas questões são criadas como resultado de uma decisão operacional, elas serão analisadas como um novo conjunto de regras do negócio junto com sua fundamentação que será gerada. Além disso, todo o tempo é possível refinar certas regras nãodeterminísticas substituindo por regras determinística ou melhor restringindo regras não determinísticas.

Essa arquitetura, de acordo com ROSCA et al. (1995), apóia a codificação de regras do negócio dentro do sistema operacional permitindo consideração à estabilidade e determinismo de regras do negócio, à confiança colocada na análise das regras do negócio e à necessidade de acomodar rapidamente mudanças nessas regras do negócio.

Uma solução de um sistema determinístico é sugerida no caso em que regras do negócio são bem entendidas, a confiança na análise é muito alta e a necessidade de acomodar mudanças das regras rapidamente não é vista como crítica. Nesse caso, a arquitetura fornece para o desenvolvimento de um sistema tradicional regras codificadas no software ou facilmente executadas pelas pessoas.

Uma solução de um sistema determinístico é ainda sugerida no caso em que as regras são razoavelmente entendidas, mas a confiança nas suposições da análise é baixa. Nesse caso, a arquitetura fornece aumento dos requisitos adicionais para monitorar as suposições da análise na execução do sistema, para que haja o desenvolvimento tradicional de sistema e codificação das regras. Esse monitoramento pode ser usado para confirmar e negar a análise das regras do negócio, entretanto, o método de realizar mudanças é feito tradicionalmente, no qual o sistema muda para acomodar os requisitos modificados. Essa opção não acomoda a necessidade de modificações rápidas.

As regras não-determinísticas representam a solução para as situações onde as regras do negócios não são bem entendidas devido à falta de fundamentação nos termos do ambiente do sistema, ou regras do negócio inconsistentes, nas quais por definição, a análise para resolver as regras do negócio não pode ser feita com confiança, e a necessidade de acomodar rapidamente as mudanças é crucial. Nesse tipo de caso, o final da análise das regras do negócio é transferida do tempo de análise para o tempo de execução. As regras do negócio aplicáveis e as estruturas de apoio à decisão são fornecidas para os usuários do sistema em tempo de execução para ajudá-los a tomar decisão de quais regras aplicar, no caso de regras inconsistentes e como interpretá-las no 
caso de regras sem fundamentação. As mesmas ferramentas usadas por um analista durante a análise dos requisitos são usadas para guiar o comportamento do sistema. Essa arquitetura apóia o desenvolvimento de sistemas em caso de inconsistência e requisitos ambíguos. Isso permite avançar o desenvolvimento mesmo quando os requisitos não são completamente entendidos.

A operacionalização de regras do negócio requer uma estratégia (construída dentro da infra-estrutura da organização) e táticas (métodos tais como transformação) para desenvolver regras do negócio no sistema operacional. Para cada tipo de regra do negócio na taxinomia ${ }^{1}$, é necessário uma pesquisa para o desenvolvimento, preferivelmente com o mínimo tempo e dinheiro. Algumas classes de regras do negócio são diretamente capazes de desenvolver, enquanto outras requerem variação de níveis de transformação e implementação; há ainda as que não têm nenhum caminho direto dentro da operação, e devem ser aproximadas de outras formas.

Se a análise é correta ou seja, se as decisões das regras do negócio e operacionalizações são ambas realizadas sem erros e com total perspicácia, então o sistema operacional deveria satisfazer os objetivos da organização. Isso parece ser uma suposição usualmente feita na engenharia de requisitos (RE): os requisitos são válidos, e sendo válidos e a implementação for correta, então os objetivos globais foram encontrados. Porém, essa idéia é muito simplista para a realidade, e é necessário caminhar fora dessa idéia para ver o que mais é necessário. Não é viável assumir que os objetivos da organização são destituídos de conflitos. Um conjunto de regras que suportam objetivos conflitantes não podem ser implementado sem problemas. A implementação terá que balancear os conflitos. A usual engenharia de requisitos presume que todas as metas conflitantes tem que ser trabalhadas fora dos requisitos do projeto do sistema. Segundo ROSCA et al. (1997), isso nunca será o caso, pelo menos nas organizações provedoras de serviços conhecidas pelos autores.

Além disso, de acordo com ROSCA et al. (1997), o raciocínio seguido nas regras do negócio é sempre baseado em suposições sobre o que influenciará e quais são as conseqüências. Essas suposições poderiam estar erradas. No entanto, se todas as suposições estiverem corretas e todas as regras do negócio relevantes forem seguidas, poderá haver mais razões por que o sistema operacional não encontra alguns objetivos do negócio; poderia estar faltando regras do negócio ou alguma coisa do raciocínio do processo. E todo esse raciocínio e a tomada de decisão raramente ocorrem no contexto de ambiente completamente estável; objetivos mudam, assim como condições do negócio, estratégias e decisões táticas.

Deveria ser reconhecido que, da mesma maneira que o sistema pode nunca encontrar completamente esses requisitos, o estado do raciocínio sobre o sistema também nunca será 
completado, totalmente correto ou consistente. Deveria haver uma constante tentativa para revisar regras do negócio e suas operações, baseada em observações do sistema operacional e a realização dos objetivos. Para esse fim, a metodologia prescreve instrumentação do sistema com monitoramento para checar a realização dos objetivos do negócio, avaliando a validade das suposições escondidas nas regras do negócio. O ditado "Regras são feitas para serem quebradas" aplica-se aqui. Regras realmente serão quebradas, porque as regras estão em conflito com outras regras, ou a implementação não é completa, ou os dados necessários não são disponíveis na mesma situação (ROSCA et al., 1997).

\subsubsection{Estrutura para representar o conhecimento do domínio}

O conhecimento do domínio na abordagem de ROSCA et al. (1997), como citado anteriormente, é dividido em dois espaços: Espaço do Objeto (Object Space) e Espaço em Questão (Issue Space). O Espaço do Objeto (EO) contém a ontologia do domínio dos tipos de objetos e regras do negócio associadas. Regras do negócio podem ser anexadas para objetos do domínio do discurso ou para alguns dos seus atributos. A representação da ontologia é inspirada pela linguagem RML de GREENSPAN \& FEBLOWITZ (1993). O Espaço em Questão (EQ) captura as deliberações feitas durante o processo de tomada de decisão, também armazena as informações sobre alternativas, critérios, interações e consequiências que exibem um específico domínio da fonte do conhecimento para ajudar no desenvolvimento de novas regras do negócio. O completo conjunto de primitivas da estrutura de apoio à decisão é mostrado na figura 9. Existe uma comunicação bem próxima entre os dois espaços de conhecimento base. As questões de EQ são anexadas a objetos ou atributos de objetos no EO.

De acordo com ROSCA et al. (1995) e ROSCA \& WILD (1996), no modelo de apoio à decisão, requisitos funcionais e não-funcionais geram questões que precisam ser resolvidas. Essas questões são refinadas durante o processo de deliberação. Para resolver uma questão são consideradas diferentes soluções alternativas. As alternativas são avaliadas contra um conjunto de critérios para decidir qual oferece a melhor solução. A decisão envolve avaliação do nível em que cada alternativa encontra um conjunto completo de critérios e escolhas que satisfazem esse conjunto. Argumentos e contra-argumentos são registrados para documentar a avaliação das alternativas ou a criação de novas questões que podem surgir depois da tomada de decisão. As suposições dos argumentos são explicitamente representados para ajudar selecionar a informação que é necessária para ser monitorada durante a fase operacional para validar algumas decisões. A melhor solução alternativa é reflexo das regras do negócio.

\footnotetext{
${ }^{1}$ Sistema especializado em nomear e organizar coisas em grupos com características similares.
} 




Figura 9- Estrutura de Apoio à decisão Baseado-Questão.

Fonte: ROSCA \& WILD (1996), p. 118.

No processo de avaliação das soluções alternativas de uma questão, relacionamentos de conflito e /ou sinergia entre alternativas de uma questão, alternativas de outras questões no Espaço em Questão devem ser as primeiras considerações. Esses tipos de relacionamentos são expressos em nossa estrutura por ligações invalida/valida entre alternativas de questões diferentes. Depois que um conjunto de alternativas viáveis (que não são invalidadas por decisões retiradas de outras questões) para a questão corrente for selecionado, as alternativas serão avaliadas contra um conjunto de critérios para decidir quais oferecem a melhor decisão, ou melhor encontra o critério. A importância de cada critério ligado à corrente questão pode também ser afetado pelas decisões retiradas de outras questões. Esse tipo de relacionamento é expresso pelas ligações de influencia entre a solução alternativa de uma questão e um critério ligado a outra questão (ROSCA \& WILD, 1996).

As suposições representam uma importante tarefa na identificação de um conjunto de métricas operacionais que serão usadas em tempo de execução para avaliar se a decisão é válida. As métricas operacionais são monitoradas na execução do sistema e quando violações são encontradas, os tomadores de decisão são informados. Essa informação pode levar a mudanças entre o apoio à decisão e o sistema operacional.

Dada uma questão que precisa ser debatida, o início da estrutura é instanciada com elementos do processo de deliberação durante a fase de desenvolvimento. Além disso, as regras do 
negócio são geradas como artefatos do processo de decisão, duas outras estruturas são criadas: o contexto da decisão e a matriz de decisão. O contexto conterá todas as questões relevantes relatadas na questão corrente por ligações valida/invalida e influencia. A matriz de decisão irá sintetizar o critério de tomada de decisão, as alternativas consideradas juntas com sua base de argumento e suposições. Se a decisão produzida na fase de desenvolvimento contém condições, cujos valores podem ser avaliados apenas em tempo de execução, a conclusão do processo de decisão ocorrerá na fase operacional. Nessa fase o usuário pode consultar a matriz de decisão e o contexto criado na hora do desenvolvimento e tomar uma decisão informada. Essa fase produz a especificação de requisitos do espaço de decisão. Essa informação pode ser usada pelos projetistas de software que produzirão o projeto do sistema e o projeto do espaço de decisão. Esse espaço de decisão pode ser usado pelos programadores do sistema e implementadores do espaço de decisão. Tendo acesso as regras do negócio fundamentais e apoiando os requisitos do software, os engenheiros de software podem tomar decisões que são importantes para a natureza do negócio que resultaria em simples soluções de software. Durante a execução do sistema, os requisitos podem ser revisados. Nesse caso, o sistema de apoio à decisão fornecerá uma estrutura para a tomada de decisão, sendo possível realizar comparações e descobrir decisões análogas. Isso pode levar a modificação de três espaços de decisões mencionados acima juntos com o correspondente projeto e implementação (ROSCA et al., 1995).

\subsubsection{Taxinomia de Regras do Negócio}

A motivação do trabalho de ROSCA et al. (1997) sobre regras do negócio surgiu após três anos de esforços em requisitos associados com projetos de reengenharia de processos de negócio. Em um desses projetos, a informação chamada regras do negócio foi considerada importante para juntar e documentar, mas não existia nenhum método particular. Existiam métodos de modelagem de requisitos e ferramentas, mas regras do negócio não faziam parte e tinham que ser adicionadas como anotações para modelos de processo de negócio, ou apenas capturadas separadamente em anotações.

ROSCA et al. (1997) estudaram uma amostra de um projeto com 250 declarações chamadas regras do negócio para tentar entender melhor que tipo de informações estavam sendo capturadas. Uma tentativa de classificá-las produziu a taxinomia mostrada na figura 10. Essa 
taxinomia não é reivindicada para ter uma validação científica, mas apenas indica que tipo de regras do negócio está presente nessa aplicação particular.

A taxinomia é dividida dentro de regras para processos e regras para dados. A classificação é bem próxima da classificação feita por MARTIN \& ODELL (1995). Embora, uma alta porcentagem de regras era extremamente simples (restrição de valores de atributo e restrição de cardinalidade), elas pareciam ser de tão baixo nível para ter um impacto importante no negócio. ROSCA et al. (1997) acreditam que esses tipos de regras dominaram por causa da confiança no estilo de pensar em Entidade-Relacionamento. Regras orientadas a processo são menos populares, mas entre elas o estímulo e respostas são bem numerosos. Existem muitas regras simples, com uma semântica operacional clara. Outros tipos de regras, da mesma importância, são mais difíceis de serem entendidos pelas pessoas orientadas ao negócio. Existem ainda, outros tipos de regras não apresentados nessa taxinomia.

ROSCA et al. (1997) afirmam que foram encontradas na literatura descrições de regras do negócio similarmente estreitas, ligadas pelo o que se pode alcançar com a construção de um modelo específico ou mecanismo de implementação. No estudo dos autores, restrições de cardinalidade em Modelo de Entidade-Relacionamento são geralmente chamadas de regras do negócio, apesar de sua expressividade extremamente limitada. Outras discussões de regras do negócio falam sobre restrições de integridade e regras disparadoras, as quais são expressíveis e capazes de fazer cumprir com o sistema corrente de base de dados. Regras do negócio têm recebido muita atenção em publicações e outras literaturas como resposta a questões para muitos problemas de tecnologia da informação. Algumas pesquisas simplesmente defendem a idéia de que é importante gastar o esforço para dar consciente consideração para regras do negócio. Até mesmo juntar uma lista de declarações em linguagem natural é considerado um primeiro passo. Outras propostas são mais estruturadas, confiando na sintaxe de diagramas de Entidade e Relacionamento. Há ainda muitas propostas de pesquisa de modelo conceitual para descrever uma organização, com a notação de regras específicas que mais adiante especificam os requisitos da organização. 


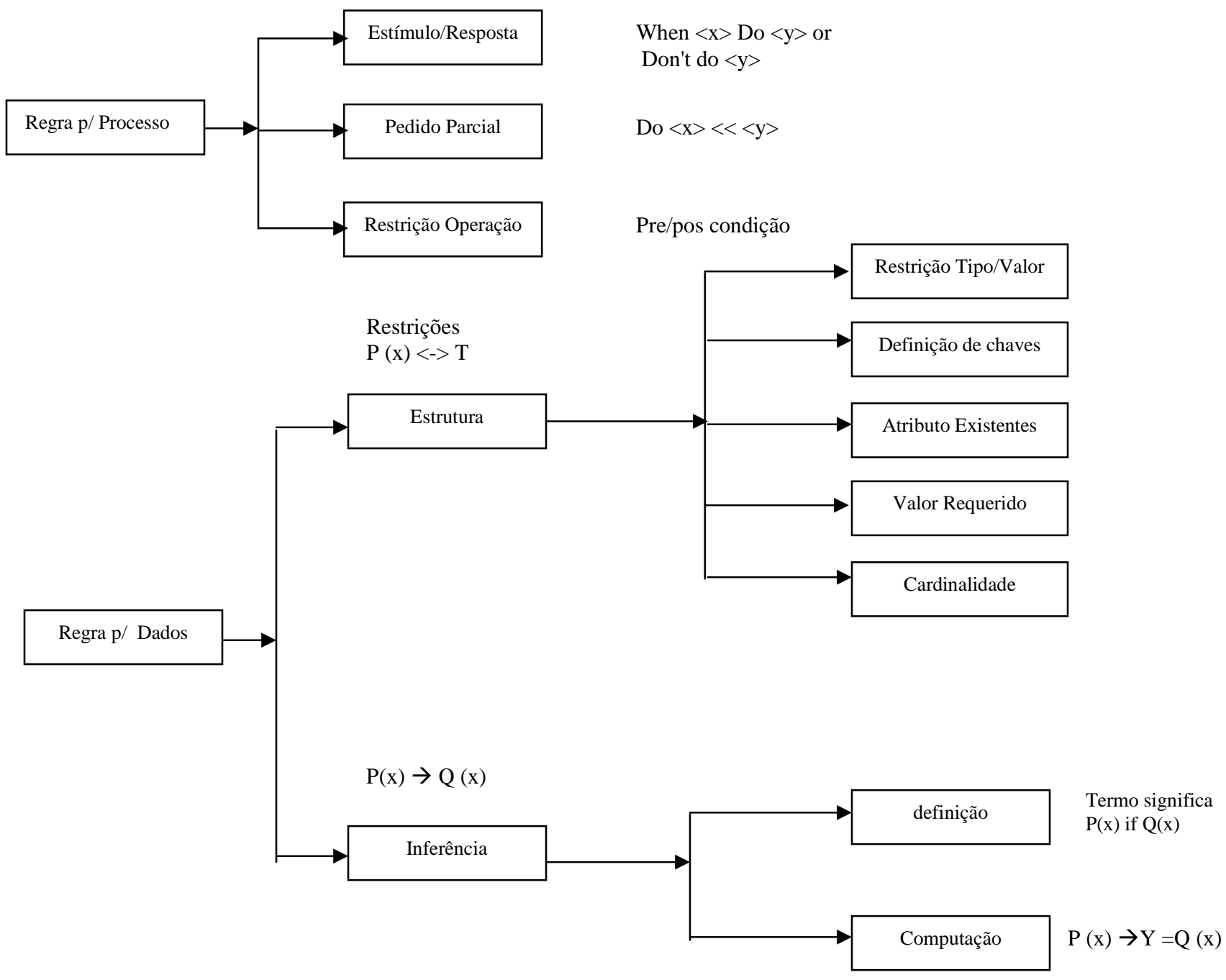

Figura 10- Taxinomia de Regras do Negócio.

Fonte: ROSCA et al. (1997), p. 238.

Alguns elementos da metodologia de ROSCA et al. (1997) têm sido discutidos na literatura da engenharia de requisitos. Por exemplo, em $\mathrm{CHUNG}^{1}$ et al. (1995) apud ROSCA et al. (1997), requisitos não-funcionais são tratados como metas que têm que ser encontradas através de um processo de tomada de decisão, no qual mudanças são esperadas. Em LAMSVEERD ${ }^{2}$ et al. (1995) apud ROSCA et al. (1997), a metodologia de elaboração de requisitos direcionada a metas tenta competir com " não-idealização de metas inalcançáveis " e também modelos ligados a metas.

\footnotetext{
${ }^{1}$ CHUNG, L. NIXON, B. YU, E. (1995). Using non-functional requirements to systematically support change. In Second IEEE International Symposium on Requeriments Engineering.

2 LAMSVEERDE, A. DARIMONT, R. MASSONET, P. (1995). Goal-directed elaboration of requirements for a meeting sheduler: problems and lessons learnet. In Proceedings of RE'95. IEEE Computer Society Press.
} 
Em FICKAS \& FEATHER ${ }^{1}$ (1995) apud ROSCA et al. (1997), têm uma discussão de monitoramento de requisitos para contribuir na execução do sistema para determinar e conhecer em qual nível os requisitos estão sendo encontrados pelo sistema.

\subsubsection{Um metamodelo para o ambiente de regras do negócio}

A metodologia para apoiar o ciclo de vida de regras do negócio consiste de:

$>$ Uma estrutura de modelo (metamodelo);

Uma prescrição de atividades para povoar modelos;

Técnicas para usar a informação da análise de requisitos, incluindo apoio contínuo em todo ciclo de vida.

Essa seção descreve um metamodelo, em preparação para descrever atividades da metodologia. O metamodelo descrito aqui tem sido implementado na experimental modelagem de requisitos e análise para suportar a metodologia. O ambiente consiste de três submodelos: Modelo Organizacional, de Regras do Negócio e o de Espaço de Decisão (figura 11).

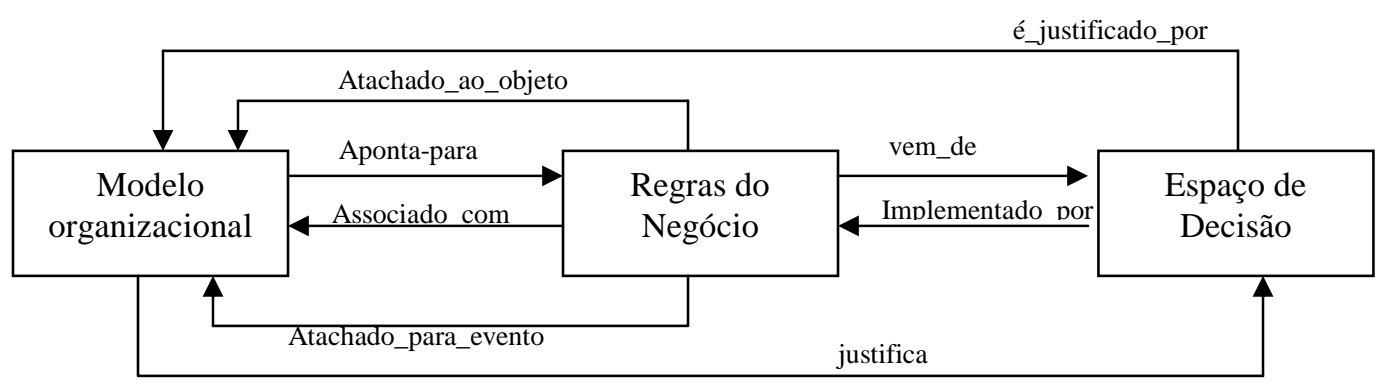

Figura 11 - O ambiente de regras do negócio.

Fonte: ROSCA et al. (1997), p. 239.

O modelo organizacional representa o "mundo" onde as regras do negócio se aplicam. Isso define os conceitos de domínio sobre quais regras são expressadas. O submodelo de Regras do Negócio representa as próprias regras do negócio. O submodelo Espaço de Decisão oferece informações sobre os objetivos organizacionais que compreende a origem de regras do negócio e captura o raciocínio principal da seleção e última geração de regras do negócio.

\footnotetext{
${ }^{1}$ FICKAS, S., FEATHER, M. (1995) Requirements monitoring in dynamic enviroments. In Proceedings of IEEE International Symposium on Requirements Engineering.
} 


\subsubsection{Método de extração de Regras do Negócio baseado SAD ${ }^{1}$}

Para a representação do modelo empresarial ROSCA et al. (1997) escolheram o Modelo de Vida de INTELLICORP (1995) ${ }^{2}$. Nesse modelo, uma organização é representada em termos de "objetos" e "processos". Objetos são representados pelo conjunto de Diagrama de Objetos que essencialmente são Diagramas de Entidade e Relacionamento (DER). Os processos do negócio são representados pelo conjunto de Diagramas de Eventos que definem a sequiência de operações para a execução do processo. Esses diagramas de eventos modelam uma hierarquia de processos de negócio, decompondo cada operação em diagrama, se necessário detalha-se em mais um diagrama. Os diagramas de eventos são especificações executáveis do processo assim que: 1) variáveis de entradas e saídas para operações são especificadas; 2) regras disparadoras são criadas para definir ramificações e controle de condições; 3) procedimentos para definir operações são escritos. O Modelo de Vida permite anexar regras para diagramas de eventos, com uma particular semântica operacional baseada nesses diagramas de Objetos e Processos.

\subsubsection{Submodelo de Espaço de Decisão}

O submodelo de Espaço de Decisão foi mostrado na figura 9, e representa a questão primitiva do modelo de apoio à decisão. A melhor alternativa de solução é reflexo no artefato resultante, o qual nesse caso é representado pelas Regras do Negócio dos Sistemas de Apoio à Decisão, um conjunto de regras em formato de sistema de apoio à decisão. Todo o conteúdo das informações sobre primitivas pode ser recuperado da matriz associada com uma questão específica. ROSCA et al. (1997) apresentam um modelo maior em relação ROSCA et al. (1995), com ligações com outros modelos do ambiente de regras do negócio: Modelo Organizacional e Regras do Negócio.



Adicionalmente, uma regra ECA pode ser usada para expressar semânticas nãooperacional, tais como os objetivos da organização expressos no nível critério. ROSCA et al. (1997) explicam que a análise de requisitos pode ser feita para analisar inter-relacionamentos entre

\footnotetext{
${ }^{1}$ SAD- Sistemas de Apoio à Decisão

2 Intellicorp. Livemodel User's Guide, Betaversion, 1995.

${ }^{3}$ ECA: é composta de três componentes básicos: Evento, Condição e Ação.
} 
os submodelos. Baseado nos links entre esses submodelos o seguinte tipo de análise pode ser realizado:

\section{Regras do Negócio $\Rightarrow$ Modelo Organizacional}

Quais componentes dos processos governam uma definição ou restrição de regras do negócio? Quais operações (eventos ou ações) executam uma regra do negócio? Quais tipos de objetos são chamados pelas regras do negócio? Essa informação pode ser usada para uma análise de impacto e sensibilidade quando a regra muda.

\section{Modelo Organizacional $\Rightarrow$ Regras do Negócio}

Em quais regras do negócio um tipo específico de objeto participa? Essa informação pode ser usada para analisar o impacto e sensibilidade quando o estado de um objeto muda.

Quais regras do negócio definem, restringem e governam um processo específico de componente? Essa informação pode ser usada para o aperfeiçoamento do processo do negócio.

\section{Regras do Negócio $\Rightarrow$ Espaço de Decisão}

De onde a regra vem? Isso liga uma regra do negócio para questão que a gerou. Assim, pode-se ter uma compreensiva idéia da razão da existência da regra do negócio olhando as alternativas, os critérios, as suposições e os argumentos que foram declarados durante a deliberação de regras do negócio.

\section{Espaço de Decisão $\Rightarrow$ Regras do Negócio}

Quais regras do negócio enfocam questões específicas? Essa informação permite uma análise de impacto e sensibilidade quando fatores como regulamentos do Governo, companhia de polícia, entre outros mudam. Essa é também uma importante fonte de informação para reutilizar processos.

\section{Espaço de Decisão $\Rightarrow$ Modelo Organizacional}

Quais tipos de objetos e atributos são focados pela decisão ou questão? Isso pode ser útil para análise de impacto e sensibilidade quando a decisão é modificada.

\section{Modelo Organizacional $\Rightarrow$ Espaço de Decisão}

Quais decisões e questões envolvem esse objeto ou atributos? Quais decisões são afetadas quando um objeto muda? 


\subsubsection{Metodologia}

A metodologia proposta por ROSCA et al. (1997) estende-se por todas as fases do ciclo de vida das regras do negócio: aquisição, desenvolvimento, mudança em resposta a mudanças na influência externa ou interna e mudanças baseadas na evolução do nível de satisfação de requisitos.

Os três maiores passos de aquisição de regras do negócio são: análise inicial, a análise e geração de regras do negócio em diferentes áreas de habilidades e análise final (figura 12). Durante a análise final e inicial, sessões de brainstorming são realizadas para entender melhor quais são as metas, políticas e restrições do negócio que precisam ser modeladas. Como resultado, a versão inicial do modelo organizacional e o espaço de decisão são esboçados; e também é definido o primeiro conjunto de regras do negócio que específica como o negócio deveria ser executado. Por isso eles definem as metas da organização, que são regras estratégicas do negócio que expressam um nível muito alto de decisões. Essas regras precisam ser refinadas na ordem que se tornam operacionais.

Baseado nas entidades e processos declarados no modelo empresarial, nas estruturas de decisão capturadas no espaço de decisão e nos dados estatísticos originários da forma da organização fazer negócio, regras do negócio podem ser automaticamente extraídas do algoritmo descrito na figura 13. Essas regras são mais concretas do que regras estratégicas. Elas escondem a estrutura das regras operacionais no formato ECA que são expressas em uma regra de linguagem formal, como uma usada no Modelo de Vida de Intellicop (1995). No final desse passo, uma regra de negócio formal será definida por cada solução alternativa no espaço de decisão e será avaliada para o seu desenvolvimento. Por simulação do processo, essas regras podem ser anexadas a disparadores operacionais nos diagramas de processo, como definido no modelo. Podem ocorrer múltiplas iterações e cada operação desse nível deve ser realizada até chegar a um conjunto estável de regras do negócio.

Durante a análise final de aquisição de regras do negócio todos os conjuntos existentes de regras do negócio, Espaço de Decisão e parte do Modelo Organizacional são colocados juntos, conduzindo à detecção de redundâncias e conflitos. A detecção é facilitada pelos tipos de análises discutidas anteriormente. Essas redundâncias e conflitos são eliminados, ou se não for possível, devem ser deixados explicitamente aos projetistas, desenvolvedores e usuários do sistema de informação. 


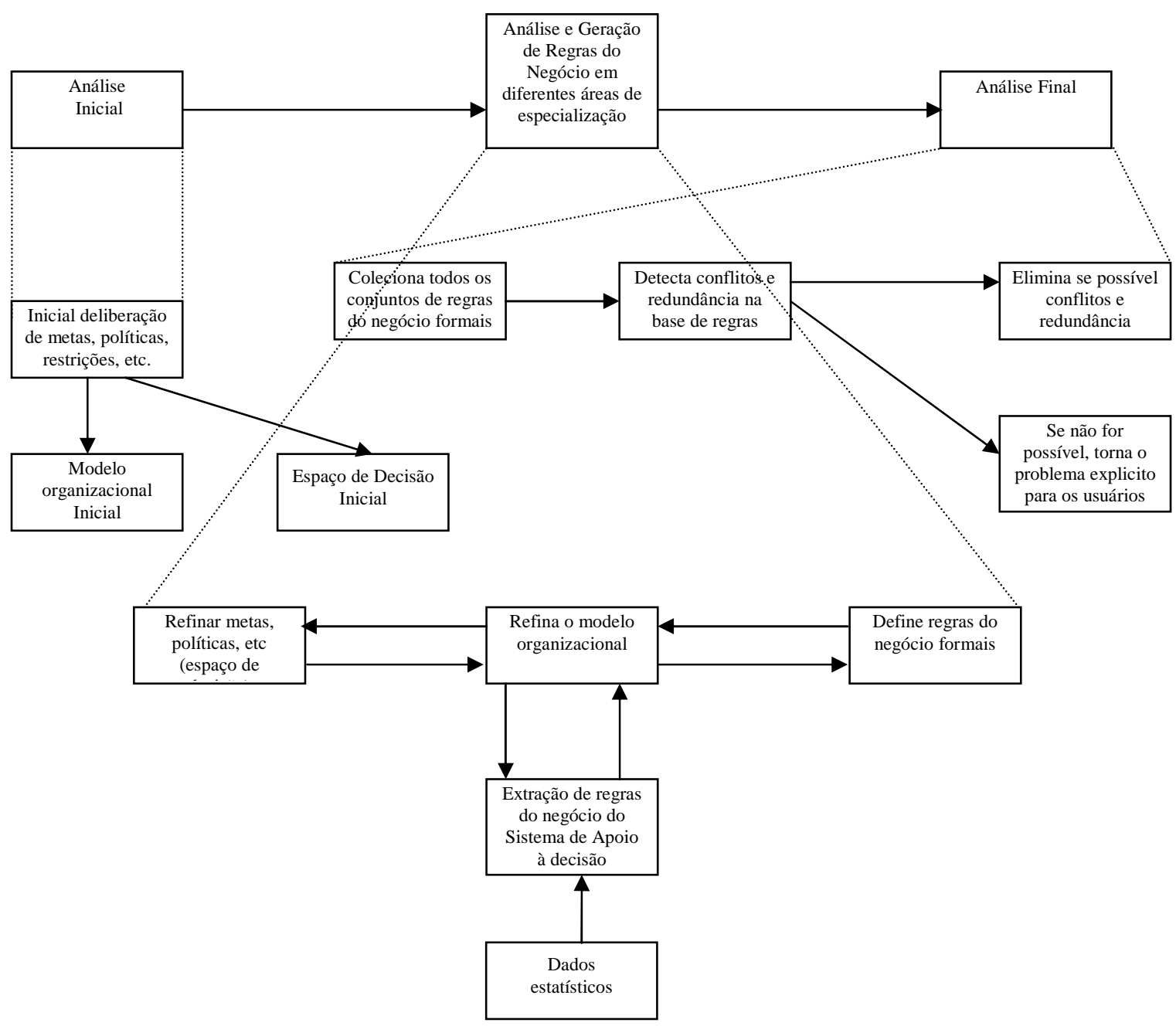

Figura 12- Aquisição de Regras do Negócio.

Fonte: ROSCA et al. (1997), p. 241.

DURING LASEventDiag

WHEN Assess Resource Needs with

PIncident and Ppacient is finished yielding ?Resources needed

SO THAT (( Patient has a Breathing less than 18 and Patient has a pulse equal to high) or Incident has a

distance less than 22)

THEN DO Send Ambulance

Figura 13- Exemplo de Estímulo/Resposta (disparador).

Fonte: ROSCA et al. (1997), p. 242. 


\subsubsection{Desenvolvimento de Regras do Negócio}

Depois que as regras do negócio são definidas e integradas dentro do processo de modelagem organizacional, elas tornam-se operacionais. Conseqüentemente, sempre que um novo caso é executado por meio de um modelo de processo dentro da organização, existem duas situações que podem ser alcançadas com a aplicação de regras do negócio (figura 14):

1) A situação é determinística, caracterizada pela regra do negócio simples e os dados referenciados pela regra são conhecidos com certeza. Assim, a regra pode ser automaticamente aplicada pela base do sistema de informação, pelas pessoas ou por máquina.

2) A situação é caracterizada por múltiplas conflitantes regras do negócio. Nesse caso pode ser mostrada uma matriz de decisão associada com essas regras e deixar o usuário entender, analisar a informação contida nas estruturas de decisões e avaliar o método de cada alternativa associada a cada regra. O usuário pode escolher uma das regras propostas ou aplicar seu próprio julgamento e selecionar outra regra.

3) Se a regra aplicada é ambígua, por exemplo, contém termos sem fundamentações, ou as fundamentações não podem ser feitas com certeza no tempo de análise, ROSCA et al. (1995) mostram a interpretação desses termos usando ligações entre regras do negócio, Espaço de Decisão e Modelo Organizacional. Essa forma de definição de regras do negócio anexada a vários atributos de entidades no negócio pode ser disponível para consulta. O usuário pode escolher um dos valores legais de um termo sem fundamentação baseado na definição de regras do negócio ou pode discordar com essas regras e escolher um valor de acordo com seu próprio julgamento. Essa pesquisa permite que o desenvolvimento siga adiante igualmente quando requisitos não são entendidos.

4) Para avaliação de como os objetivos da organização estão sendo alcançados, ROSCA et al. (1997) propõem um instrumento que monitora se a suposição da regra do negócio é válida. Essa informação é retornada para o sistema para atualização de regras do negócio, do modelo organizacional e espaço de decisão. 


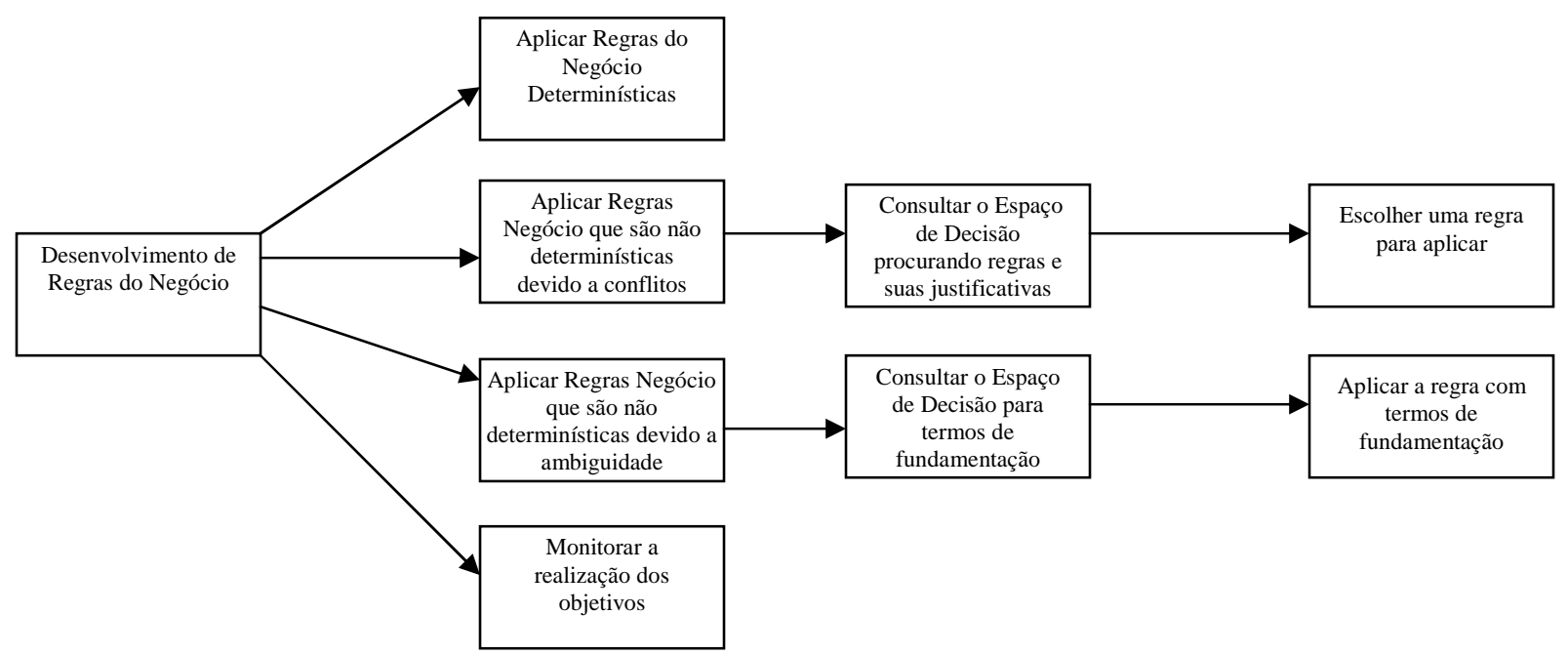

Figura 14- Desenvolvimento de Regras do Negócio.

Fonte: ROSCA et al. (1997), p. 242.

\subsubsection{Evolução de Regras do Negócio}

Existem muitas possibilidades de melhorar regras do negócio baseadas na informação capturada na estrutura da metodologia (figura 15). Dados obtidos através de monitoramento do sistema operacional podem ser usados para estudar e validar as suposições registradas no espaço de decisão, conduzidas para regras mudadas. Podem surgir novas fontes de informação internas e externas. Novas soluções podem ser escolhidas pelos usuários para resolver situações conflitantes e ambíguas. Por exemplo, estudando o Espaço de Decisão, é possível detectar alguns critérios, alternativas ou argumentos que poderiam ser adicionados ou eliminados. Ou ainda, localizando as regras aplicadas, pode-se detectar que alguns atributos estão faltando ou deveriam ser adicionados para mais precisas regras do negócio (ROSCA \& WILD, 1996). Conseqüentemente, o modelo organizacional e o espaço de decisão é continuamente atualizado para manter o ritmo com constantes mudanças que ocorrem ambas dentro e fora da organização. Dependendo da natureza da mudança observada, regras do negócio são modificadas por qualquer um, escolhendo ou modificando regras existentes, ou criando novas regras se nenhuma das existentes encontra-se no novo contexto das coordenadas (ROSCA et al., 1997). 


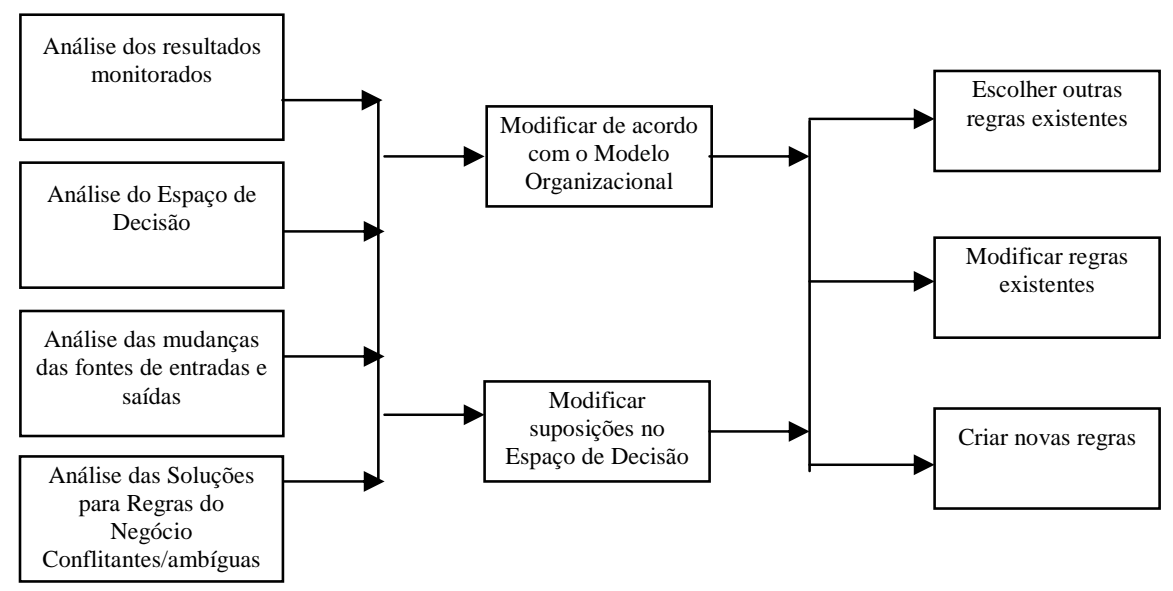

Figura 15- Evolução de Regras do Negócio.

Fonte: ROSCA et al. (1997), p. 243.

\subsection{Regras do Negócio como baseline de Requisitos}

LEITE \& LEONARDI (1998) estudaram a inclusão de regras do negócio como um elemento de baseline, sendo baseado em descrições em linguagem natural. A identificação e a inclusão das regras do negócio na baseline dos requisitos ajudarão na identificação dos requisitos do software.

De acordo com LEITE \& PÁDUA (1995), a baseline é a estrutura que incorpora sentenças em linguagem natural sobre o sistema desejado, sendo criada durante o processo de engenharia de requisitos, mantendo-se envolvido no processo de construção do software. Baseline é estruturada como:

1. visão do modelo léxico: é implementado pela LEL (Language Extended Lexicon), que é centrada na idéia de descrições circulares de termos da linguagem que melhora a compreensão do ambiente.

2. visão do modelo básico: é uma sentença de estrutura centrada no conceito básico das identificações de ações dos clientes, como uma forma indireta de procurar as informações necessárias para apoiar as decisões do negócio.

3. visão do modelo de cenário: representa cenários e descrições dos comportamentos. Cada cenário é descrito pelo título, objetivo, um contexto, atores, pesquisa e uma série de episódios. Um episódio também pode ser um cenário. 
4. visão de hipertexto: suporta a evolução e apresentação de outras visões e permite a navegação pelas baselines de requisitos como um hipertexto regular.

5. visão configuração: tem um mecanismo para controlar configurações e versões das visões dos modelos léxicos, básico e de cenário.

A proposta de LEITE \& LEONARDI (1998), é integrar regras do negócio com a visão de baseline de requisitos (figura 16). Regras Funcionais do Negócio são relativas às ações da organização e seguem o seguinte padrão: Frase Não Verbal + Verbo + [Frase Não Verbal], como o exemplo: A reunião pode ser replanejada ou cancelada. As Regras Não Funcionais descrevem políticas ou padrões que a organização deve seguir. Podem ser classificadas em regras do macrosistema e de qualidade. As regras do macrosistema descrevem as políticas que são relatadas para características específicas do Universo do Discurso e têm o seguinte padrão: [Propriedade] + Frase Não verbal + Relação + [Propriedade] + Frase Não Verbal, uma vez que:

$>$ Propriedade é a frase que tem a característica de uma Frase Não Verbal;

$>$ Frase Não Verbal é a frase que deveria ser uma entrada na LEL;

Relação é um Frase Verbal;

Propriedade e relação podem ser uma entrada na LEL.

Como exemplo:

O salário do empregado sênior deve ser maior do que o salário do empregado júnior.

\begin{tabular}{|c|c|c|c|c|}
\hline Propriedade & $\begin{array}{l}\text { Frase Não } \\
\text { verbal }\end{array}$ & Relação & dade & $\begin{array}{l}\text { Frase não } \\
\text { verbal }\end{array}$ \\
\hline
\end{tabular}

Regras de qualidade são demandas da organização das características dos processos ou produtos que geralmente refletem políticas para padrões de qualidade ou expectativas da organização. Têm o seguinte padrão:

Frase Não Verbal +[Deveria|Não Deveria|Ser Preciso|Não Ser Preciso] + Frase Verbal + Propriedade + [Por Que + Causa $]$

Exemplo:

A informação sobre a data da reunião tem que ser avaliada tão logo for possível por que os participantes têm que modificar.

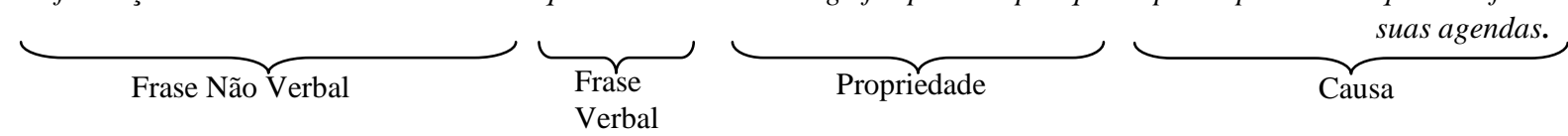




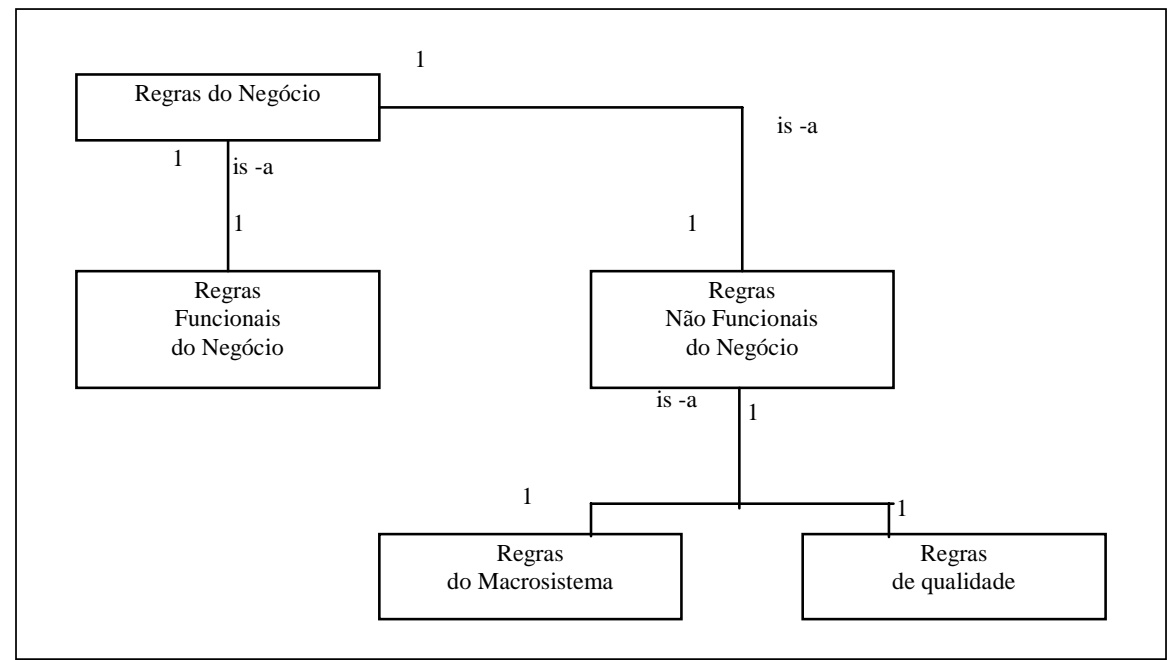

Figura 16-Taxinomia para Regras do Negócio.

Fonte: LEITE \& LEONARDI (1998), p. 70.

Em LEITE \& LEONARDI (1998) é descrito o processo de extrair regras do negócio. O primeiro passo é conhecer as regras do ambiente no qual o sistema será inserido. Após definido o contexto, é necessário definir quais fontes de informação estão sendo usadas. A fonte pode ser documentos da organização, principalmente quando já existem políticas definidas. Caso a organização não tenha esses documentos, é necessário utilizar outras formas para adquirir essas informações: observação, brainstorming, entrevista, reuniões e/ou outras formas. Depois que as fontes de informação estão definidas e avaliadas, deve-se categorizar sentenças de acordo com seu propósito na organização. As sentenças são observadas de acordo com limites, responsabilidades e direitos das entidades da organização. Essa heurística ajuda na identificação de políticas regentes em torno da tomada de decisões.

Segundo LEITE \& LEONARDI (1998), essa fase deve ser realizada junto à média e à alta gerência, caso contrário, uma validação desse ciclo deve ocorrer, ou seja, a média e alta gerência devem ler e aprovar as regras. Essa identificação deve ser feita, independente da LEL e da construção de cenários. Depois que as regras forem validadas pelos clientes (média e alta gerência), elas são escritas de acordo com o padrão descrito no item anterior. Seguindo essa proposta é possível ligar as frases das regras de negócio para a entrada do léxico e se for escrita corretamente, os termos usados na descrição das regras do negócio estarão em LEL, desde que as políticas tenham sido escritas na linguagem do Universo do Discurso. Esse é um estudo inicial de LEITE \& LEONARDE (1998) e tem como objetivo integrar as políticas da organização dentro do processo de definição de requisitos. 


\subsection{Considerações finais}

Diversas definições, opiniões e conceitos de regras do negócio foram apresentados no presente capítulo, apesar de algumas diferenças, todas mostram a preocupação com a natureza do negócio. A grande motivação para esse estudo foi devido ao fato de existir preocupação apenas com aspectos técnico-funcional, não considerando aspectos relacionados à organização na fase de análise de desenvolvimento de sistemas de informação.

Regras do negócio na organização são decompostas em outras regras do negócio discretas. Os passos de HERBST (1996) para análise de sistemas focando em regras do negócio representam uma abordagem importante para o desenvolvimento de software. A representação das regras do negócio foi apresentada usando a estrutura ECAA, que permite especificar regras individuais e a definição de processos completos. Uma outra forma de apresentação de regras do negócio é como baseline de requisitos, estudos de LEITE \& PÁDUA (1995) e LEITE \& LEONARDI (1998), que usam expressões em linguagem natural acessível aos usuários. Esse é um processo social, no qual diferentes atores devem cooperar para que toda a informação seja capturada. Essa cooperação depende da tecnologia, na qual a baseline é uma instância, e das políticas e procedimentos usados na organização.

Regras do negócio ajudam a integrar a dinâmica da organização aos sistemas de informação, trazendo grande vantagem competitiva, essa vantagem só será real se o software se adaptar à dinâmica do ambiente. Elas prometem estreitar a distância tradicional entre os aspectos funcionais dos sistemas e os requisitos organizacionais, permitindo assim, complementar as especificações, apontando estratégias, alternativas e objetivos a serem seguidos. Essa forma de compreender o domínio do sistema, faz com que as pessoas do negócio entendam o que o sistema pode fazer para melhorar a qualidade de seus negócios e rever os processos atuais.

O fato de poder tornar mais fácil manter um sistema computacional, realizando as modificações necessárias no sistema, quando as regras do negócio modificarem, é uma das principais motivações para buscar essas regras diretamente na fase de análise. Percebe-se que ao ignorar as regras do negócio, têm-se importantes implicações em termos de custo, qualidade, tempo e satisfação do usuário. Dessa forma, a identificação e a avaliação das regras do negócio são um pré-requisito essencial para o sucesso de um projeto de desenvolvimento de sistemas organizacionais, utilizando para isso a tecnologia da informação, que em conjunto com os requisitos do negócio podem resolver o grande vazio entre Negócios e Tecnologia da Informação. Esse capítulo trouxe uma apresentação geral do estado da arte de regras do negócio, que compõem uma primeira fase de estudo sobre o tema. 
No próximo capítulo será apresentado o EKD (Enterprise Knowledge Development), que é uma metodologia que fornece uma forma sistemática e controlada de analisar, entender, desenvolver e documentar uma organização e seus componentes, usando a Modelagem Organizacional. Dentre os submodelos do Modelo Organizacional dessa abordagem, o Modelo de Regras do Negócio é usado para definir e manter explicitamente regras do negócio formuladas, consistentes com o Modelo de Objetivos. Nessa abordagem as regras do negócio podem ser regras internas do negócio e políticas da organização, elas são definidas por objetivos enquanto também afetam a realização de outros objetivos, além disso, elas disparam processos de negócio e referem conceitos definidos no Modelo de Conceitos. 


\section{Modelagem Organizacional: uma nova abordagem}

\subsection{Considerações iniciais}

Para acompanhar o mercado cada vez mais competitivo e em constantes mudanças, as organizações devem ser flexíveis. Essa flexibilidade depende da habilidade de adaptação ao processo de mudanças. O processo de mudança não é um processo simples, para realizá-lo com sucesso a organização deve ter conhecimento e entendimento da situação atual, da situação futura que se espera alcançar e como será alcançada. A tecnologia da informação deverá acompanhar as mudanças constantes dos requisitos organizacionais. Nesse capítulo será apresentada uma abordagem que proporciona uma forma estruturada de descrever o conhecimento organizacional, tornando a organização e a tecnologia da informação bem integradas, proporcionando um sistema que realmente atende às necessidades do cliente. Essa abordagem é uma evolução da modelagem organizacional de BUBENKO et al. (1993) descrita no capítulo 3.

\subsection{As mudanças na organização}

A necessidade de reengenharia e gerenciamento de mudanças está crescendo rapidamente, tornando o maior fator de sobrevivência e competência das companhias. Nesse caso a organização precisa desenvolver uma disciplina que organiza todo o conhecimento necessário para identificar a necessidade de mudança na organização e cumprir essas mudanças de maneira conveniente e profissional (BERNUS \& NEMES, 1997). Para KIRIKOVA (2000), estruturas e abordagens de modelagem organizacional se diferem, mas estão destinadas a atingir o mesmo objetivo: possibilitar o entendimento apropriado de aplicações. Esse entendimento não significa apenas conhecer de que consistem os elementos da organização e como eles estão relacionados em aspectos diferentes, mas também como esses elementos trabalham juntos na organização como um todo. Entendimento significa também uma consciência sobre a tarefa da organização no ambiente e razões para possíveis mudanças no comportamento do sistema.

Para acompanhar e gerenciar as mudanças é necessário:

$>$ ter uma visão clara de como a organização funciona atualmente;

quais os requisitos que mudarão e a razão da mudança; 
quais alternativas deveriam ser criadas para encontrar esses requisitos e

quais são os critérios e argumentos para avaliar essas alternativas.

Para tanto são necessárias descrições para representar e comunicar percepções e idéias. Essas descrições são apresentadas através do modelo organizacional. O conhecimento da organização é estruturado através desse modelo que, sendo suficientemente detalhado e não ambíguo, torna-se uma poderosa ferramenta para o entendimento ou desenvolvimento da organização, permitindo discussão entre objetos visuais e tangíveis que são o centro da atenção coletiva de um grupo de pessoas (BUBENKO et al., 1998). A tão conhecida frase "conhecimento é poder" tem sido aplicada nas organizações bem sucedidas. Gerenciar conhecimento tornou-se muito importante no atual ambiente, mas não é uma tarefa simples (NISSEN, 1999).

Para BUBENKO et al., 1998, o modelo não mostrará uma exata reflexão do mundo real. Ele é apenas uma coleção de percepções do mundo real, refletindo as estruturas de referências e experiências dos contribuidores. Um modelo de boa qualidade é baseado na discussão explícita dos participantes e relacionamentos entre elementos de diferentes submodelos. Para tanto, as discussões deveriam focar na organização por diferentes pontos de vistas, envolvendo participantes com conhecimentos diferentes. O modelo fornece, de forma natural, uma possibilidade para os participantes entrarem em questões e fenômenos que são relacionados com sua parte do negócio e ver o impacto de suas decisões ou requisitos de todos os processos da organização. Os modelos proporcionam benefícios para a cultura e aprendizado organizacional. Os participantes devem explicitamente contribuir com seus conhecimentos do domínio, suas habilidades e experiências. Eles devem ser abertos, construtivos, ativamente participativos. É muito importante que eles saibam ouvir, respeitar e responder aos outros, e que tente encontrar e clarear relacionamentos e aspectos escondidos. Apenas dessa forma, os efeitos de sinergia do grupo podem ser alcançados. $\mathrm{O}$ desenvolvimento do conhecimento organizacional é extremamente dependente dos participantes e não dos facilitadores ${ }^{1}$.

A modelagem realizada em grupo tem vantagens e desvantagens. As vantagens são as idéias criativas ressaltadas pelo número de pessoas que aumentam o conhecimento e competências do grupo. As soluções são caracterizadas pelo consenso e são mais próximas à realidade quando "pessoas chaves" participam. Existe um bom balanço entre criatividade e crítica. As desvantagens são tensões sociais que impedem a cooperação. As pessoas presentes que têm prestígio político

\footnotetext{
${ }^{1}$ facilitador é a pessoa que lidera e adverte durante as sessões de modelagem e apóia cada um na aquisição de conhecimento e idéias do grupo de aplicação.
} 
dentro da organização podem intimidar ou influenciar a participação de outras pessoas, desencorajando o pensamento inovador. Isso também ocorre se houver diferenças substanciais na posição e temperamento dos membros. O trabalho pode ser descoordenado se finalizado por vários indivíduos ou se algumas pessoas abdicarem de suas tarefas e responsabilidades (BUBENKO et al., 1998; SALTER, 1997).

A modelagem organizacional, discutida no capítulo 2, iniciou-se nos anos 80 pelo projeto Plandata e refinado pelo SISU ${ }^{1}$ (Swedish Institute for Systems Development - Instituto Sueco para o Desenvolvimento de Software) no final dos anos 80. A grande contribuição foi a noção de considerar componentes organizacionais de uma especificação, por exemplo, os objetivos (intenções) de um negócio, além dos tipos de componentes do modelo tradicional, como entidade, relacionamentos e processos. O uso dessa abordagem em muitas aplicações diferentes durante os últimos dez anos mostrou que a razão do sucesso não era apenas o Modelo Organizacional, mas também o gerenciamento apropriado do processo do negócio e engenharia de requisitos. A idéia do Modelo do Negócio do SISU era, no final, estendida para o Modelo Organizacional e mais tarde desenvolvida no projeto ESPRIT $\mathrm{F}^{3}$ (From Fuzzy to Formal). A modelagem organizacional $\mathrm{F}^{3}$ foi então elaborada pelo projeto ESPRIT ELKD e está agora sendo aplicada no projeto ESPRIT ELEKTRA (Electrical Enterprise Knowledge for Transforming Applications). A estrutura de modelagem de ELEKTRA é denotada EKD (Enterprise Knowledge Development) que inclui a Modelagem Organizacional como parte (BUBENKO et al., 1998).

O projeto ELEKTRA visa principalmente a aplicação do método EKD para problemas de gerenciamento de mudanças dentro de organizações da Grécia e Suécia, gerando um conjunto de práticas genéricas de forma a aplicá-las em outras companhias. Segundo ROLLAND et al. (2000), a pesquisa do projeto ELEKTRA visa a criação de uma base de conhecimento para o gerenciamento de mudança. Um dos objetivos do projeto era: capturar as melhoras práticas do negócio para reusá-las em situações similares em outras companhias de eletricidade.

\subsection{Conhecimento Organizacional}

As descrições estruturadas tornam possível ver como diferentes partes de uma organização interagem. Pode-se traçar descrições e verificar quais processos estão relacionados, e como contribuem para um particular objetivo. Inversamente, é possível verificar se existem

\footnotetext{
${ }^{1}$ O Instituto Sueco de Desenvolvimento de Software foi fundado em 1984 e realizou mais de 100 projetos de análise de sistemas e negócio, no quais a metodologia de modelagem organizacional foi usada.
} 
objetivos para os quais nenhum processo está contribuindo. Percebe-se que as descrições estruturadas permitem a realização de diferentes tipos de análises e discussões sobre o que tem sido dito e escrito sobre a organização. Esses modelos podem ser efetivamente usados para representar e discutir como projetar e melhorar processos organizacionais, e como desenvolver estratégias futuras. Entretanto, os modelos são limitados, uma vez que eles apenas apresentam percepções subjetivas de como as coisas são.

Segundo BUBENKO et al. (1998), um grande benefício da modelagem é o efeito nos participantes. Em um projeto bem sucedido, os efeitos podem ser:

$>$ melhora no entendimento das partes essenciais da organização;

$>$ encontro de soluções para problemas práticos ou

$>$ consenso sobre questões que no início eram difíceis de serem definidas.

Esses modelos são importantes para melhorar a comunicação e a aprendizagem organizacional (tabela 2).

Tabela 2 - Benefícios do EKD.

Adaptada do texto de BUBENKO et al. (1998)

\section{Benefícios}

Entender melhor o negócio;

Facilitar a aprendizagem e comunicação organizacional sobre questões essenciais;

Ajudar entender e promover as capacidades e processos da organização;

Melhorar a comunicação entre o sistema de informação stakeholders $^{1}$ e desenvolvedores;

Desenvolver uma descrição estruturada do negócio para analistas da organização discutirem;

Auxiliar os desenvolvedores de sistemas de informação e stakeholders na determinação dos requisitos e objetivos do sistema;

Chegar a uma descrição dos objetivos da organização, entidades, processos, requisitos, que é mais consistente e mais completo do que usando a tradicional abordagem baseada em textos;

\footnotetext{
${ }^{1}$ Stakeholders: esse termo foi introduzido para designar todos os envolvidos no projeto, diretamente ou indiretamente, ou que tenham interesse no resultado do projeto.
} 


\section{Benefícios}

Chegar a um documento, chamado repositório de conhecimento, que pode ser usado para:

- Raciocínio sobre o negócio;

- Discutir mudanças no negócio e componentes do sistema de informação;

- Traçar a cadeia de componentes e decisões que leva a várias interpretações de decisões e componentes do sistema de informação.

Segundo KIRIKOVA (2000), o EKD pode ser usado em situações diferentes e com propósitos diferentes, como nas seguintes situações:

$>$ Na engenharia de requisitos para definição e especificação de requisitos.

$>\mathrm{Na}$ análise do negócio para detecção do problema.

$>$ Na reengenharia de processos do negócio para definição de novos sistemas de negócio.

$>$ No gerenciamento de conhecimento organizacional ou aprendizagem organizacional para formar a base de propagação e ampliação de conhecimento.

\subsection{O que é EKD?}

Segundo ROLLAND (2000), o EKD é uma metodologia que fornece uma forma sistemática e controlada de analisar, entender, desenvolver e documentar uma organização e seus componentes, usando a Modelagem Organizacional. O objetivo ao se usar o EKD é prover uma descrição clara e nãoambígua de:

$>$ Como a organização funciona atualmente;

$>$ Quais são os requisitos e as razões para a mudança;

$>$ Quais alternativas deveriam ser criadas para encontrar esses requisitos;

$>$ Quais são os critérios e argumentos para avaliação dessas alternativas

A família de modelos do EKD destina-se a responder as questões: O que, Como, Onde, Quem, Quando e Por que. Essa estrutura serve como um esquema de classificação conveniente ou "tabela periódica" para entidades de informação. Como elementos químicos, essas entidades podem ser combinadas de infinitas formas para produzir o sistema de informação de interesse da organização. Por outro ponto de vista, é possível ver essa estrutura como uma família de muitos modelos inter- 
relacionados, onde relacionamentos entre elementos arbitrários pertencentes a submodelos são permitidos. Essa talvez seja a teoria mais rica em uso (KIRIKOVA, 2000).

De acordo com BUBENKO et al. (1998), o conteúdo básico da estrutura EKD inclui: um conjunto de técnicas de descrição, a participação de stakeholders e um conjunto de diretrizes para o trabalho (figura 17). O conjunto de técnicas de descrições fornece um conjunto de modelos que é usado para descrever o sistema a ser analisado ou construído, e a organização na qual ele será operado. Esse conjunto de técnicas é usado pelos desenvolvedores do sistema. As técnicas de descrições sozinhas não serão muito valorosas, sem um envolvimento direto dos atuais clientes, usuários finais, gerentes, proprietários, entre outros. Um fator crítico de sucesso de um projeto que inclui a aplicação do EKD na construção de um sistema de informação ou reestruturação da organização é a participação e o envolvimento dos stakeholders.

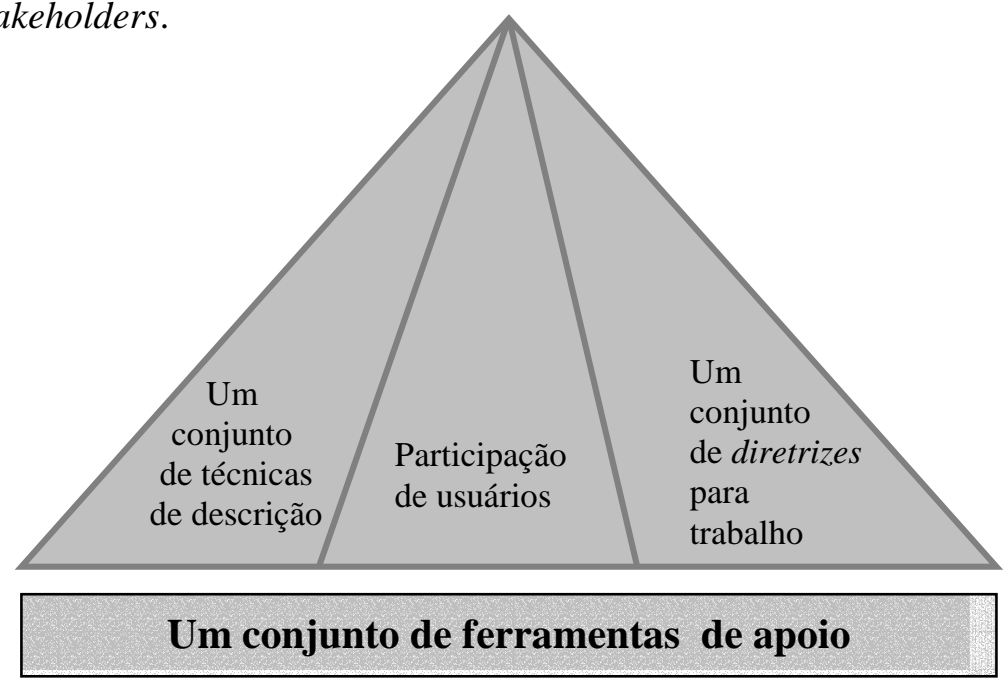

Figura 17- Conteúdo da estrutura do EKD

Fonte: BUBENKO et al. (1998), p. 18.

Para KIRIKOVA (2000), o EKD prescreve o desenvolvimento da especificação de requisitos como um escopo de atividades do grupo de trabalho. O resultado desse trabalho é o Modelo Organizacional que reflete a organização e seus requisitos. Uma característica essencial da metodologia é a possibilidade de ver como cada requisito é relacionado aos objetivos, atividades, pessoas e particularidades da organização. De acordo com ROLLAND et al. (2000), durante o desenvolvimento do conhecimento organizacional, desenvolvedores e stakeholders se deparam com situações que requerem a tomada de decisões para atingir suas intenções. O EKD ajuda o processo de conhecimento organizacional através de seus modelos que proporcionam várias visões da organização. Segundo LOUCOPOULOS et al. (1998), o EKD pode ser visualizado em três "planos" ou "níveis" (figura 18):

1. Objetivos Organizacionais; 


\section{Processos Organizacionais e}

3. Sistemas de informação.

Ao usar EKD é possível iniciar em um nível e mover-se para outros níveis, dependendo da situação. Por exemplo, se a organização não é bem conhecida, ou existe a necessidade de documentação apropriada da empresa, o ponto mais apropriado é o nível de Processos Organizacionais. Realizar a modelagem nesse nível mostrará uma "fotografia" clara dos processos organizacionais em termos de tarefas que os atores executam para completar suas obrigações na organização; como essas tarefas podem interagir cooperativamente para atingir seus objetivos; quais os tipos de atividades que eles precisam empenhar em suas obrigações; quais objetos são necessários para essas atividades (recursos físicos, objetos de informação); e finalmente, quais regras impõem os processos organizacionais. Essa é uma abordagem bottom-up em um nível organizacional.

Uma visão mais estratégica é a top-down que se inicia com os objetivos organizacionais e depois procede com a modelagem de como esses objetivos podem ser atingidos nos processos organizacionais. Essa é uma situação de engenharia tradicional, onde os requisitos e visão deveriam ser definidos no plano dos objetivos do negócio. Antes de desenvolver um sistema de informação, é necessário entender as influências que esses objetivos terão na parte operacional do negócio. Trabalhando no plano dos processos do negócio, define-se as características operacionais que ocasionarão, por sua vez, modelos do plano de sistemas de informação. Outra situação é quando existe a necessidade de entender o sistema de informação já implantado, as tecnologias usadas e como esses sistemas estão relacionados com o processo organizacional. Nesse caso uma abordagem de modelagem reversa será adotada para mapear a construção do sistema de informação nos conceitos dos processos organizacionais (LOUCOPOULOS et al., 1998).

De acordo com LOUCOPOULOS et al. (1998), o termo "processo organizacional" precisa de alguma elaboração nesse estágio. A visão tradicional de processos de negócio é a visão funcional. Uma visão funcional de uma organização considera funções do negócio relacionadas de uma forma hierárquica. Essa mesma hierarquia é construída através de uma decomposição severa de funções de negócio. Tipicamente, a ligação é feita através de sucessivos detalhamentos de funções em sub-funções, sub-sub-funções até um nível de detalhe que esteja de acordo com as idéias e opiniões dos analistas. Funções são ligadas via fluxo de dados. Essa não é a visão no EKD que considera o conceito de "processo organizacional" como composto de quatro componentes organizacionais chaves:

1. As tarefas que são executadas pela organização para encontrar os objetivos dos processos;

2. As atividades envolvidas em cada tarefa; 
3. Os objetos que são envolvidos juntos com sua evolução da criação para extinção (com o contexto de um processo organizacional);

4. As regras que determinam os componentes de processos.

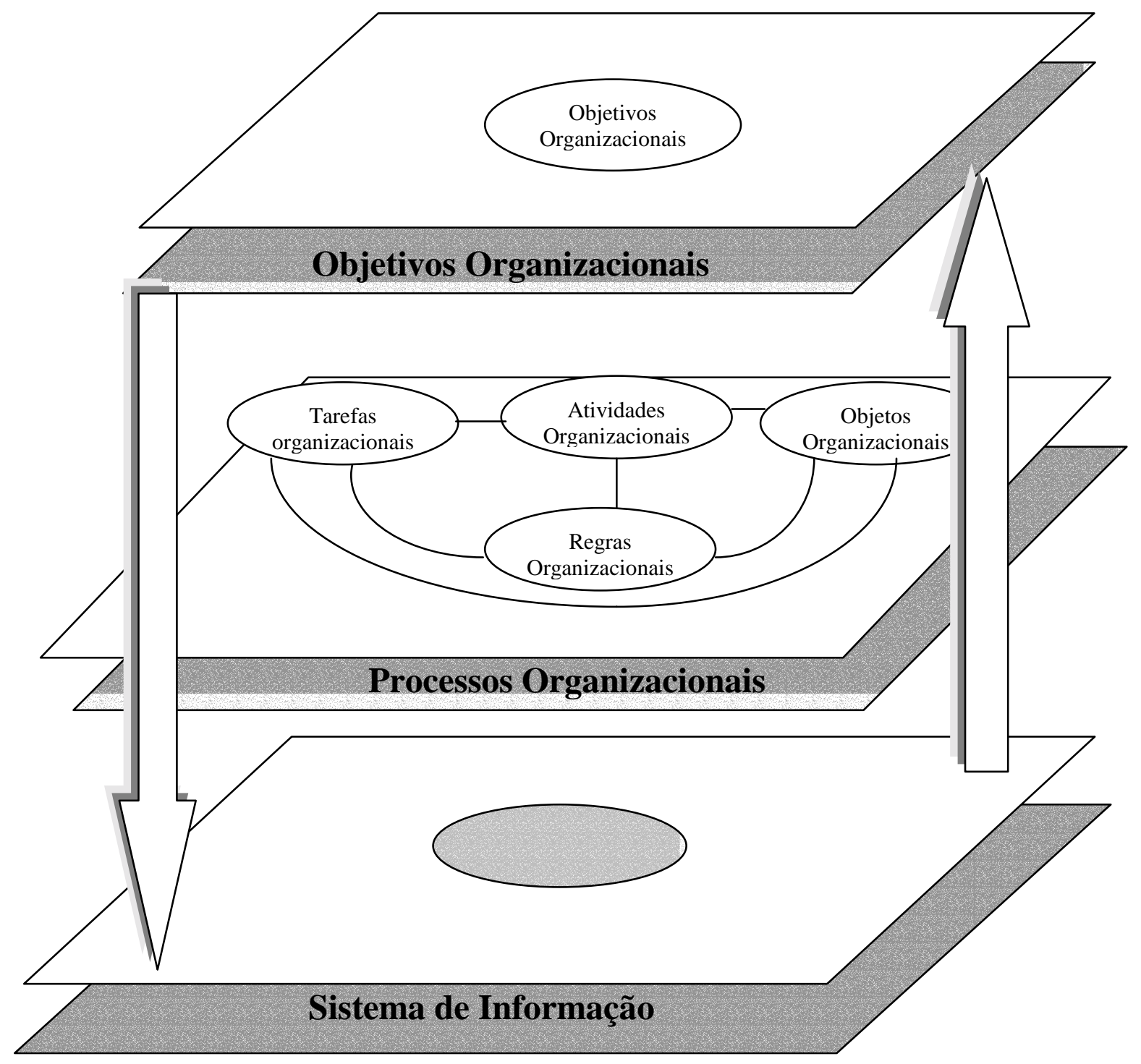

Figura 18- Uma visão da Modelagem EKD.

Fonte: LOUCOPOULOS et al. (1998), p. 3. 
Em outras palavras, segundo LOUCOPOULOS et al. (1998), um processo organizacional pode ultrapassar uma divisão funcional, o que proporciona uma visão verdadeiramente dinâmica da organização. Os modelos usados no método EKD enfocam os seguintes pontos:

1. Modelo de Objetivos das situações AS_IS e TO_BE (como é e como será), porque é importante conhecer o que a organização correntemente trabalha e o que pretende atingir no futuro.

2. Modelo de Atores e suas tarefas, porque na realidade, em um nível operacional, pessoas trabalham juntas para completar os requisitos de um processo do negócio. $\mathrm{O}$ comportamento detalhado da tarefa de um indivíduo e suas interações forneceriam um critério calculável para os processos do negócio.

3. Modelo dos Objetos envolvidos no processo e usado pelos atores para cumprir suas tarefas na organização, porque tal conhecimento levará à definição dos recursos e sistema de informação que são necessários para apoiar a forma que os atores completam suas tarefas.

4. Modelo das Regras do Negócio relacionado aos processos do negócio, porque condições diferentes vão requerer a invocação de processos de negócios diferentes. São as regras do negócio que determinam os estados permissíveis dos objetos do negócio e a interação entre tarefas diferentes.

De forma resumida, os modelos EKD são usados para entender, analisar, melhorar e consertar algum sistema. Os stakeholders nesses sistemas têm objetivos que precisam ser encontrados pelo sistema. Sistemas são compostos de partes de interface e interdependentes, que trabalham juntas para realizar uma função útil. As partes do sistema podem ser uma combinação de coisas, incluindo pessoas, informação, software, equipamentos, produtos ou matéria-prima. Na realidade, modelos operacionais deveriam descrever o que o sistema faz, controla, baseia-se, o que usa para realizar sua função, e o que produz. Os componentes do método EKD são definidos em termos de conceitos que constituem a abordagem e a notação que habilita o uso desses conceitos. O conjunto total de conceitos do EKD é denominado metamodelo EKD que define a forma lógica do conhecimento organizacional. O metamodelo inclui informações sobre a semântica do conhecimento organizacional, identificando as entidades organizacionais e seus atributos e relacionamentos explícitos entre eles. É importante distinguir metamodelos EKD e notações EKD. O metamodelo representa meios para definir a informação que se deseja manter sobre aspectos diferentes complementares do sistema. Para cada aspecto do sistema pode existir apenas um metamodelo EKD. Em contraste, a notação EKD é o meio para apresentar o EKD metamodelo; cada metamodelo pode ser visto em termos de muitas notações diferentes. Por exemplo, no Modelo de Objetivos o conceito de objetivo tem uma definição única. Entretanto, é permitido usar 
muitas notações para descrever incluindo texto, caixas e setas entre outros. É importante escolher notações que (LOUCOPOULOS et al., 1998):

1. Sejam fáceis de usar: o principal objetivo dessas notações é serem compreendidas por todos usuários EKD, sem que se requereira muito treinamento.

2. Clareza: cada metamodelo contém extensa informação sobre as entidades organizacionais. Apresentar toda essa informação em um simples diagrama, seria inviável. O objetivo da notação proposta é prover uma estrutura apropriada para informações EKD. Cada notação concentra em conceitos específicos que formam o esqueleto do metamodelo, dando uma imagem da situação "a primeira vista", enquanto impede detalhes que poderiam confundir o usuário. Naturalmente, é possível melhorar esse esqueleto com o restante da informação ou, idealmente, usar uma ferramenta que ajudará a armazenar e explorar toda a informação disponível.

\subsection{Componentes do EKD}

Os componentes do EKD são modelos conceituais que examinam a organização e seus requisitos de um número de perspectivas inter-relacionadas. Esses modelos são abstrações do mundo físico. Para uma dada organização, esses modelos irão constituir coletivamente o Modelo Organizacional. Alguns desses modelos podem conter informações relevantes que apontam a necessidade de avaliação de alternativas de situações operacionais. Tais informações incluem critério para avaliação, escolhas disponíveis, parâmetro de medidas e argumentos registrados a favor e contra escolhas (ROLLAND et al., 2000).

Durante o estágio de desenvolvimento, o modelo organizacional pode ser um meio de entendimento e comunicação entre os participantes ou entre participantes e outros stakeholders do processo EKD, tornando-se um ponto de referência comum, cruzando muitas áreas diferentes a fim de que sua posse não seja confinada a aplicações específicas ou grupos particulares. Além disso, deve ser independente de qualquer tecnologia, podendo ser implementado por diversas tecnologias. O modelo precisará ser modificado apenas quando a situação e o contexto nos quais a organização existe mudar. $\mathrm{O}$ modelo pode ser usado como um meio de avaliação das opções, no qual os custos de cada opção potencial podem ser avaliados tão bem quanto mais clara estiver a documentação de todos os aspectos intangíveis (LOUCOPOULOS et al., 1998).

De acordo com ROLLAND et al. (2000), o EKD apóia a construção de modelos diferentes, representando o estado inicial da organização e o futuro estado, além da expressão de estratégias 
alternativas para mudanças, a avaliação dessas estratégias, e outras atividades como brainstorming. A "regra de parada" para o desenvolvimento do Modelo Organizacional é um conjunto de modelos descritos em detalhes suficientes a fim de que possa ser usado como uma base para implementar as sugestões nos modelos, ou para resolução de problemas por outros meios.

\subsection{Como usar EKD}

A abordagem EKD envolverá tipicamente estrategistas, gerentes táticos e funcionários do nível operacional, que juntamente com o facilitador e técnicos, familiarizados com EKD, iniciarão o processo de:

1. Diagnóstico: modelar a situação corrente e os requisitos de mudanças;

2. Entendimento: interpretar, entender, raciocinar, deliberar e discutir o estado corrente e futuro da empresa;

3. Projeto: discutir e modelar as situações alternativas futuras e os cenários.

O modelo resultante estará disponível para os tomadores de decisões atuarem sobre as estratégias futuras, táticas e objetivos da empresa (figura 19). O Modelo Organizacional contém um número de submodelos inter-relacionados (figura 20). Cada um representa algum aspecto da organização. De acordo com BUBENKO et al. (1998), os tipos de submodelos e as questões que eles abordam são:

1. Modelo de Objetivos (MO): enfoca na descrição de idéias da organização. Descreve o que a organização e os empregados querem alcançar ou evitar, e quando. Usualmente esclarece questões como:

$>$ para onde deveria ser movida a organização;

$>$ quais os objetivos mais importantes e prioridades desses objetivos;

$>$ como cada objetivo é relacionado aos outros e quais problemas estão escondidos na realização das metas.

2. Modelo de Regras do Negócio: é usado para definir e manter explicitamente regras do negócio formuladas e consistentes com o Modelo de Objetivos. Regras do Negócio podem ser vistas como operacionalização ou limites dos objetivos. O Modelo de Regras do Negócio geralmente esclarece questões como:

$>\quad$ Quais regras afetam os objetivos da organização;

$>\quad$ Quais são as políticas declaradas; 
$>$ Como cada regra do negócio é relacionada com os objetivos e

$>$ Como os objetivos serão apoiados pelas regras.

3. Modelo de Conceitos (MC): é usado estritamente para definir "coisas" e "fenômenos" relacionados a outros modelos. Representa entidades organizacionais, atributos e relacionamentos. Entidades são usadas para definir mais estritamente expressões do Modelo de Objetivos tanto quanto o conteúdo do conjunto de informação do Modelo de Processos do Negócio. O Modelo de Conceitos usualmente esclarece questões como:

$>$ Quais entidades ou conceitos são reconhecidos na organização (incluindo seus relacionamentos com objetivos, atividades e processos, e atores);

$>$ Como as entidades são definidas e

$>$ Quais regras do negócio e restrições monitoram esses objetos e conceitos.

4. Modelo de Processos do Negócio (MPN): é usado para definir processos organizacionais, e a forma pela qual eles interagem e manuseiam a informação e materiais. Um processo de negócio deve consumir as entradas em termos de informação e/ou material e produzir uma saída de informação e/ou material. Em geral o MPN é similar aos tradicionais modelos de diagramas de fluxo de dados (DFD). O Modelo de Processos do Negócio esclarece questões como:

$>$ Quais atividades e processos do negócio são reconhecidos na organização (ou deveriam ser) para gerenciar a organização em concordância com as metas.

$>$ Como os processos de negócio e tarefas deveriam ser realizados (workflows, transição de estado, ou modelo de processos), e quais as informações necessárias.

5. Modelo de Atores e Recursos (MAR): é usado para descrever como diferentes atores e recursos se relacionam, e como eles são relacionados a componentes do Modelo de Objetivos, e a componentes do Modelo do Processo do Negócio. Por exemplo: um ator pode ser responsável por um particular processo no MPN ou o ator pode buscar um particular objetivo no MO. O Modelo de Atores e Recursos normalmente esclarece questões como: quem está ou deveria estar realizando quais processos e tarefas, e como estão a estrutura de informação e responsabilidade entre os atores definidos.

6. Modelo de Requisitos e Componentes Técnicos (MRCT): torna-se relevante quando a proposta do EKD é ajudar a definir os requisitos para o desenvolvimento de um sistema de informação. A atenção é direcionada para o sistema técnico que é necessário para 
apoiar os objetivos, processos e atores da organização. Inicialmente é necessário desenvolver um conjunto de requisitos de alto nível ou objetivos para o sistema de informação como um todo. Baseado nesses requisitos, o sistema de informação é estruturado em um número de subsistemas, ou componentes técnicos. O MCRT é uma tentativa inicial de se definir toda a estrutura e propriedades do sistema de informação para apoiar as atividades do negócio, como definido no MPN. O Modelo de Requisitos Componentes Técnicos usualmente esclarece questões como: quais requisitos são gerados pelos processos do negócio, qual o potencial da tecnologia da informação para melhoria do processo.

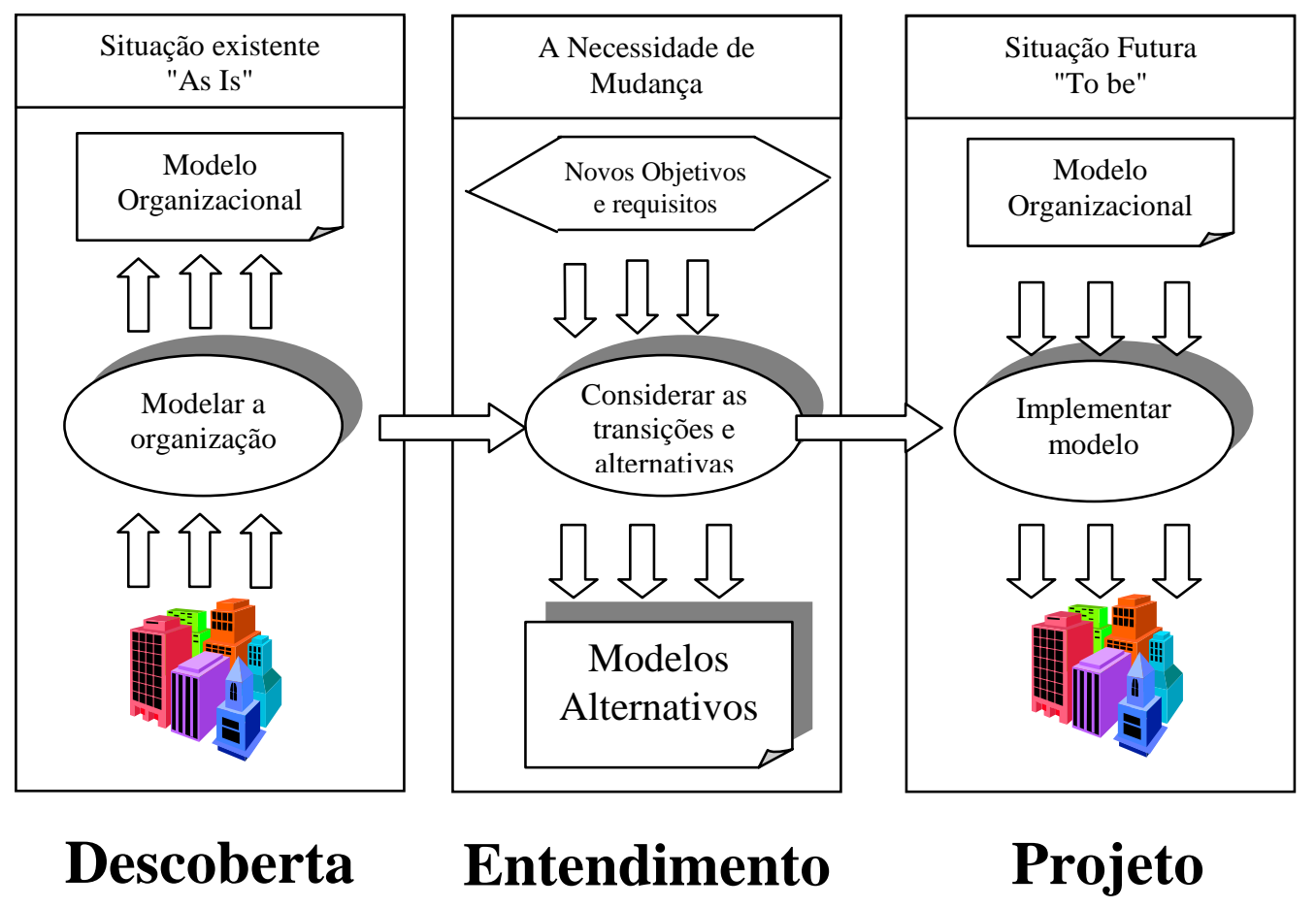

Figura 19 - Tipos de atividades envolvidas no processo EKD.

Fonte: BUBENKO et al. (1998), p. 20.

Cada um desses submodelos inclui um número de componentes que descreve diferentes aspectos da organização. Por exemplo, o Modelo de Objetivos contém objetivos do negócio, problemas do negócio que são divididos em tratamento, fraquezas, causas, oportunidades do negócio e restrições. Os componentes dos submodelos são relacionados entre si (relacionamento intramodelo), tanto quanto com componentes de outros submodelos (relacionamento inter-modelos).

A figura 20 mostra o relacionamento entre modelos. A habilidade de traçar decisões, componentes e outros aspectos em todas as partes da organização é dependente do uso e entendimento 
desses relacionamentos. Quando se desenvolve um modelo organizacional completo, esses relacionamentos entre componentes de diferentes submodelos executam uma tarefa essencial. Por exemplo, declarações do modelo de objetivos permitem que diferentes conceitos sejam definidos no Modelo de Conceitos. Da mesma forma, objetivos do Modelo de Objetivos motivam processos particulares no Modelo de Processos do Negócio. Os processos são necessários para atingir os objetivos declarados. Uma ligação (link) é definida entre um objetivo e um processo. Ligações entre modelos fazem o modelo transparente, mostrando por que certos processos e requisitos do sistema de informação têm sido introduzidos.

De acordo com BUBENKO et al. (1998), existem limitações na forma em que os submodelos e seus relacionamentos podem ser povoados. Esses são controlados por um número de regras de consistência estáticas e dinâmicas, que controlam seus estados de transição permissíveis. Os relacionamentos entre modelos são importantes porque permitem a análise e comparação dos elementos organizacionais.

Os componentes do modelo organizacional têm representações gráficas, como caixas retangulares, elipse, e outras formas. O relacionamento entre esses componentes é representados com ligações (links). Existem dois textos associados a cada componente: short name e long name. O short name é usado para numerar e identificar os componentes do modelo, deve ser único para servir de referência. O long name é usado para expressar e armazenar a descrição do componente. A seguir os modelos serão descritos em mais detalhes. É difícil descrever EKD sem apresentar exemplos, assim será apresentado um caso de uma biblioteca de BUBENKO et al. (1998). A situação da biblioteca é totalmente imaginária. 


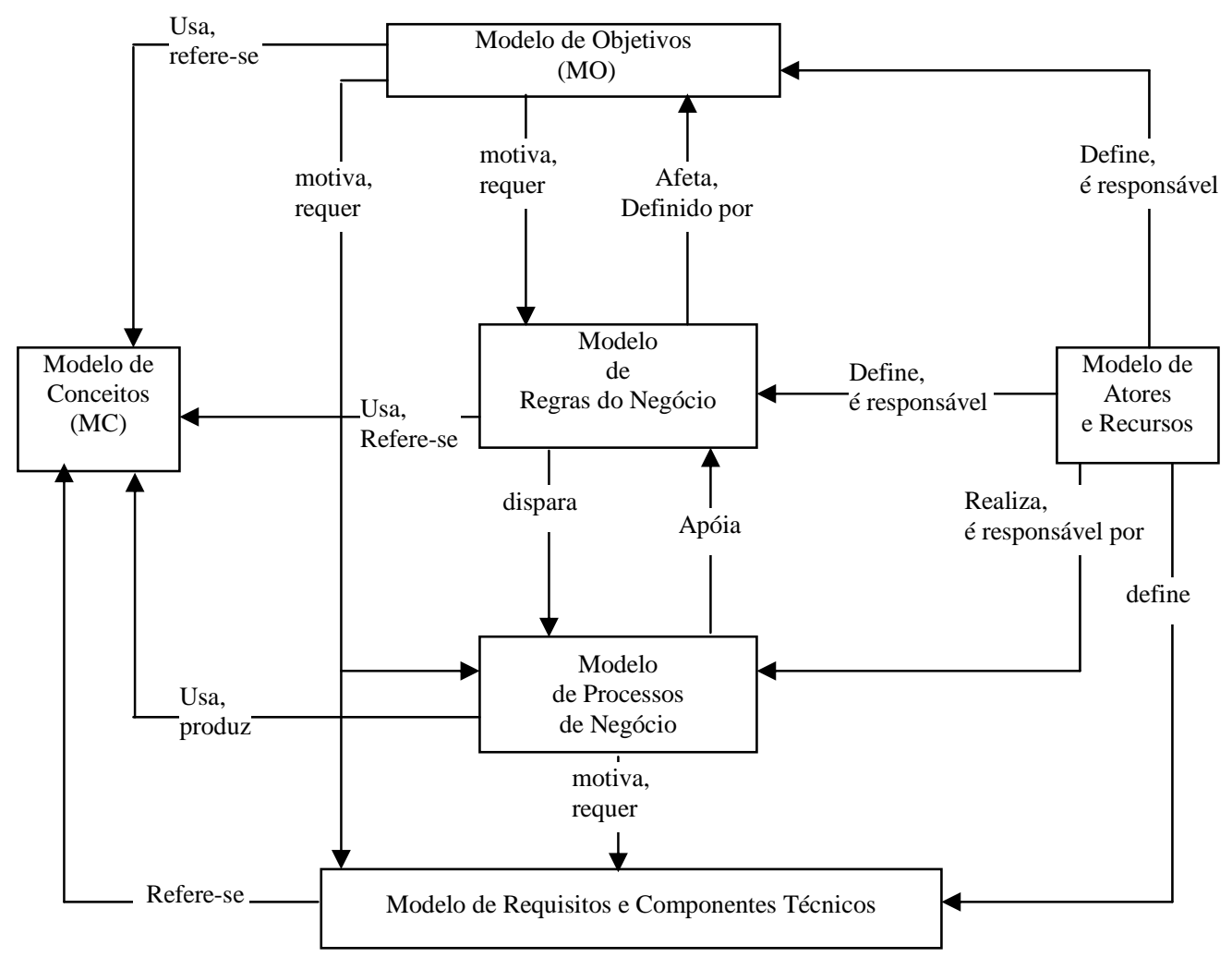

Figura 20 - Submodelos que compõem o Modelo Organizacional.

Fonte: BUBENKO et al. (1998) p. 22

\subsubsection{Modelo de Objetivos}

O Modelo de Objetivos é usado para descrever os objetivos da organização e todas questões associadas para atingi-los. O Modelo de Objetivos descreve essencialmente a razão, ou a motivação para atividades e entidades de outros submodelos. As entidades desse modelo são relacionadas à organização e a sua razão de existir. Os objetivos e requisitos do sistema de informação não devem ser declarados nesse modelo. O Modelo de Objetivos forma a estrutura com a qual a relevância dos processos e requisitos técnicos do sistema são medidos e na qual eles estão ligados. Através de ligações com outros modelos, o MO explica porque processos e requisitos existem ou não existem. Os componentes do MO são relacionados através de ligações semânticas monodirecionais, cujos os principais tipos são apoio, impedimento e conflitos (LOUCOPOULOS et al. 1998).

A presença do modelo de objetivos fornece uma possibilidade de declarar explicitamente os objetivos da organização, que por sua vez concede aos funcionários a oportunidade de harmonizar seus objetivos com os da organização (KIRIKOVA, 2000). 
Os componentes do modelo de objetivos são: objetivo, problema, causa, restrição e oportunidade. Embora, um número de sessões de modelagem prática mostra que algumas vezes é necessário acrescentar componentes adicionais para o modelo, tais como, comentários, suposições, cenários, tarefas, entre outros. Se tal extensão é aprovada pelo grupo de modelagem, ela pode melhorar consideravelmente a expressividade e clareza do modelo. BUBENKO et al. (1998) explica cada componente:

O objetivo do negócio é o estado desejado do negócio a ser atingido. Ele é usado para expressar objetivos considerando o negócio ou o estado do negócio que se deseja alcançar. Objetivos expressam o que a organização e seus empregados querem alcançar, ou evitar e quando. Eles podem ser expressados como um conjunto de estados comensuráveis, ou como focos gerais, visões ou direções. Objetivos podem ter muitos significados tais como metas, intenções, necessidades, requisitos, estados desejados, entre outros. As sentenças devem iniciar-se como: "O objetivo é...". Os objetivos podem ter valores opcionais de prioridade e criticabilidade (com possíveis valores: alto, médio, baixo), que permitem às pessoas que estão modelando fixar diferentes níveis de prioridades e notar o nível de criticabilidade. A modelagem de objetivos requer que os participantes reflitam muito, e declarem suas metas a curto e a longo prazo na organização. Para tanto, é necessário que os participantes discutam e concordem sobre: a importância individual dos objetivos, a criatividade dos objetivos, a prioridade dos objetivos e as formas alternativas de atingir os objetivos.

O problema é usado para expressar que o ambiente está ou pode ficar em um estado não desejado que dificulte alcançar os objetivos. Para documentar problemas encontrados é criada uma base que detecta objetivos escondidos. Se um problema declarado não está impedindo nenhum objetivo, então o conjunto de objetivos está incompleto ou o problema realmente não é um problema da organização. Problemas podem ser especificados em dois sub-tipos:

$>$ Ponto fraco: um tipo de problema que descreve fatores que podem reduzir a possibilidade de atingir um objetivo. A organização tem os recursos e conhecimento para reduzir os efeitos do problema.

$>$ Ameaça: um tipo de problema para o qual a empresa tem recursos para reduzir seus efeitos, mas não tem o conhecimento requerido.

A causa é usada para expressar explicações ou razões para os problemas. Causas são usualmente situações ou estados, fora do controle do projeto, processo, ou da 
organização. Pode ser alguma coisa que é bem entendida e não precisa mais ser analisada. Tipicamente, a causa não pode ser afetada pela organização.

A restrição é usada para expressar restrições do negócio, leis, regras, ou políticas do mundo externo afetando componentes e ligações com o Modelo Organizacional. Regras internas do negócio e políticas da organização são definidas no Modelo de Regras do Negócio.

Uma oportunidade é usada para expressar recursos que podem tornar certos objetivos mais fáceis de alcançar. Estados alcançáveis não considerados como objetivos, ou mesmo para declarar novos objetivos da organização. Por exemplo, novas tecnologias da comunicação podem facilitar as possibilidades da organização alcançar um objetivo para ampliar o mercado internacional dos seus produtos. Oportunidades são situações em que se deseja obter vantagens. Sendo assim, a oportunidade deveria ser transformada em um objetivo.

\subsubsection{Ligações dentro do Modelo de Objetivos}

Os tipos de ligações, segundo BUBENKO et al. (1998), entre os componentes do Modelo de Objetivos são (figura 23):

$>$ Relacionamento de Apoio que é essencialmente visto como "vertical". É usado para refinar ou decompor objetivos e outros componentes.

Relacionamento de Impedimento que é usado para mostrar influências negativas entre componentes do Modelo de Objetivos, e pode ser considerado como o oposto do relacionamento de apoio.

Relacionamento de Conflito que é usado para definir situações que ao alcançar um objetivo haverá um conflito com outro. Por exemplo, o objetivo de uma biblioteca em atrair mais clientes ficando mais tempo funcionando, estará em conflito com o objetivo de economizar dinheiro nos custos dos salários dos funcionários.

Inicialmente o Modelo de Objetivos pode ter um alto nível de abstração. Para obter mais clareza e detalhes é necessário decompor ou refinar os objetivos em sub-objetivos. O refinamento é realizado usando relacionamento do tipo AND/OR. O relacionamento de refinamento AND representa um conjunto de sub-objetivos únicos que são necessários para satisfazer e apoiar o objetivo original. Se o Objetivo 1 for refinado em Objetivo 1.1, 1.2 e 1.3, demonstra-se, então, que para atingir o Objetivo 1 é necessário atingir o Objetivo 1.1, 1.2 e 1.3. A figura 21 ilustra o refinamento. 


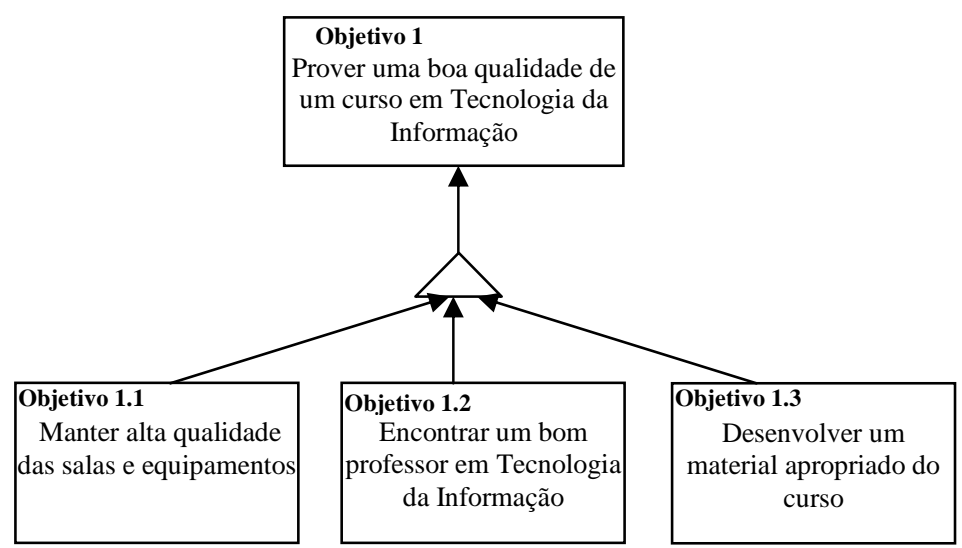

Figura 21 - Fração de um Modelo de Objetivos contendo relacionamento AND.

Fonte: BUBENKO et. al. (1998), p. 27.

O relacionamento de refinamento OR representa um conjunto de sub-objetivos alternativos. Para apoiar o objetivo original, é suficiente satisfazer apenas um objetivo do conjunto. A figura 22 exemplifica o refinamento OR.

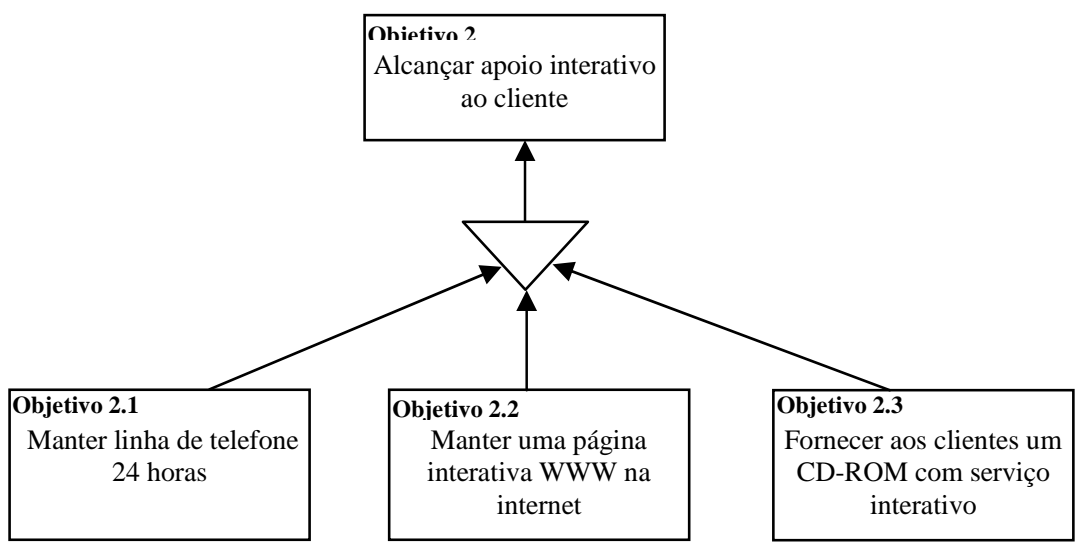

Figura 22 - Fração de um Modelo de Objetivos contendo relacionamento OR. Fonte: BUBENKO et al. (1998), p. 27. 


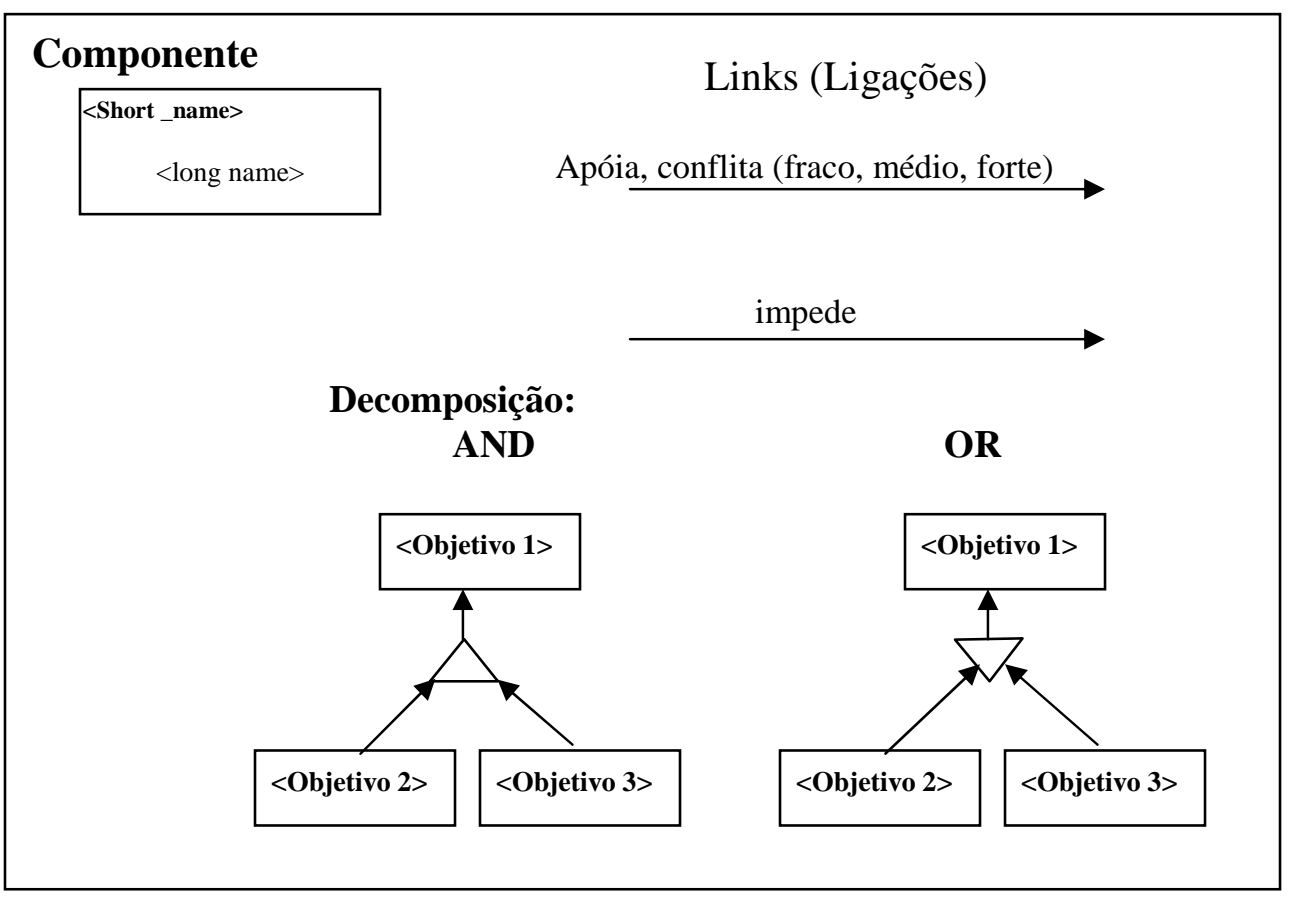

Figura 23 - Notações do Modelo de Objetivos.

Fonte: BUBENKO et al. (1998), p. 27.

\subsubsection{Desenvolvendo o Modelo de Objetivos}

BUBENKO et al., (1998) explicam que o MO deve ser desenvolvido inicialmente com a atividade de brainstorming. As visões e contribuições dos participantes devem ser consideradas, e normalmente essas visões fazem o produto inicial de modelagem desestruturado e difícil de entender. $\mathrm{O}$ passo seguinte inclui estruturação, classificação e operacionalização dos componentes do modelo de objetivos. Isso é normalmente feito pelos projetistas em uma forma interativa, onde os participantes são consultados continuamente para validar o progresso. Essa validação é muito importante para que o Modelo de Objetivos concentre-se nos objetivos do negócio e não no apoio ao sistema de informação e seus objetivos mais técnicos. Para apoiar o sistema de informação existe o Modelo de Requisitos e Componentes Técnicos. As regras estáticas e dinâmicas que governam os estados de mudança da organização são informalmente definidas no MO. Durante a modelagem algumas questões devem ser consideradas:

1. Quais são as estratégias dessa parte da organização?

2. Existem políticas declaradas que podem influenciar esse modelo? 
3. Quais convenções, regras, regulamentos e leis são relevantes?

4. O que a organização gostaria de alcançar?

5. Existe algum problema particular impedindo o objetivo?

6. Esse problema está relacionado com algum objetivo particular?

7. Qual é a causa desse problema?

8. Como esse problema poderia ser eliminado?

9. Existem algumas oportunidades particulares que poderiam ser usadas?

10. Quais ações poderiam ser tomadas para melhorar a situação?

11. Como esse objetivo pode ser alcançado?

12. Esse objetivo pode ser definido em termos operacionais, dando um número de subobjetivos de apoio?

Os objetivos devem ter sentenças completas para evitar ambigüidades ou incertezas. É importante evitar palavras com muitos significados, e palavras que podem ser mal-entendidas em diferentes situações. Deve-se evitar frases: "Ter um bom ABC", buscando utilizar termos mais tangíveis e comensuráveis como "Ter um sistema $\mathrm{ABC}$ que tenha baixo custo de produção e manutenção e uma interface multi-usuário" (BUBENKO et al., 1998).

\subsubsection{Refinamento e operacionalização dos objetivos}

A proposta de operacionalização de objetivos visa detalhar como o alto nível de objetivos pode ser satisfeito. A operacionalização do Modelo de Objetivos encoraja o desenvolvimento da rede de objetivos. Os aspectos chaves do processo de operacionalização de objetivos são:

$>$ Ênfase na criatividade: a operacionalização de objetivos reflete um pulo criativo dos fatos presentes para futuras possibilidades que trazem alguma coisa nova que previamente não existia.

Ênfase na natureza dinâmica do processo: o resultado do processo não é estático, mas depende das decisões de projeto e as visões das situações futuras durante o processo de operacionalização. Isso significa que o resultado do processo não é sempre o mesmo.

As principais atividades da operacionalização são refinamento dos objetivos e gerenciamento de conflitos. Durante o refinamento dos objetivos, novos objetivos são gerados através do detalhamento do alto nível. Nesse sentido, um objetivo de alto nível é refinado em um ou mais sub-objetivos, que 
podem tornar a ser refinados em novos sub-objetivos. O resultado desses refinamentos sucessivos é uma estrutura hierárquica multi-nível, iniciando-se de um objetivo de alto-nível vago, até objetivos operacionais específicos. No refinamento de objetivos é possível usar relacionamento AND/OR nas estruturas para refinar objetivos em muitas combinações alternativas de sub-objetivos, ou um subobjetivo que pode ser realizado por muitas alternativas de modelo de projeto.

O gerenciamento de conflitos consiste de um número de atividades:

Detecção de conflitos: visa a identificação de conflitos entre objetivos. Pode ser difícil relacionar novos objetivos com os objetivos existentes e determinar o efeito daqueles para estes. Para conseguir encontrar conflitos deve-se procurar exaustivamente no modelo de objetivo e comparar o novo objetivo para cada objetivo existente. Uma forma razoável de procurar por potenciais conflitos é usar os conflitos dos objetivos de alto nível que já foram identificados durante o estágio de aquisição.

Classificação de conflitos: enfoca a identificação do tipo de conflito que tem sido detectado. Conflito final ocorre quando dois objetivos contraditórios são desejados. Conflito de meios (means) ocorre quando os atores relacionados a objetivos idênticos querem usar o mesmo recurso. A classificação de conflitos pode ser usada por métodos de gerenciamento de conflitos para reagir de modo devido.

Para tratar conflitos, alguns dos seguintes tipos de tratamento podem ser usados:

Ignorar: quando o conflito não impede nenhum desenvolvimento, embora seja necessário não perder de vista o conflito em caso do impacto aumentar.

$>$ Amenizar: o balanceamento dos objetivos conflitantes pode não ser claro até que várias possibilidades de projeto sejam exploradas em termos de modelos alternativos de projetos. Essa forma de decisão é trocada para o estágio de geração do modelo de projeto, quando dados concretos sobre o caso estão disponíveis.

Resolver o conflito: freqüentemente um objetivo conflitante implica na indisponibilidade de uma alternativa específica para alcançar ambos objetivos. Nesse caso, o ranking de objetivos pode ser útil para decidir uma eventual omissão de um objetivo. Entretanto, alguns conflitos podem ser resultados:

Da redefinição de objetivos; 
$>$ Da especificação do contexto em que cada objetivo é alcançado ou

Do refinamento de objetivos alternativos.

Segundo BUBENKO et al. (1998), as duas questões chaves em gerenciamento de conflito são: conhecimento da trajetória do conflito e gravação das informações sobre esses conflitos, tais como as circunstâncias que levam a esses conflitos. Muito freqüentemente, os objetivos de alto nível, os problemas, regras do negócio, entre outros, adquiridos no estágio de aquisição, contêm um número de requisitos informais e imprecisos; é recomendado que a saída do Modelo de Objetivo inicial seja estruturada no estágio inicial. Essa tarefa envolve:

> Classificação de Objetivos: para melhorar a compreensão e entendimento de inúmeros objetivos, aconselha-se classificá-los em uma tabela matriz, onde eles podem ser categorizados de acordo com origem, stakeholder, função, domínio, etc. Isso permitirá a comparação, análise e talvez descobrir a necessidade de mais discussões baseadas na análise dos padrões dos objetivos (figura 24).

Priorização de Objetivos: possibilita a resolução dos conflitos entre objetivos. Um alto nível de objetivos age como uma restrição em um objetivo de baixo nível.

Correlação de Objetivos: é compreendida como interação positiva e negativa entre objetivos. Em geral, colaboração de objetivos é desejável, desde que a colaboração entre dois objetivos signifique que a satisfação de um objetivo apoiará a satisfação de outro objetivo; mostrando também um consenso entre objetivos e stakeholders. Por outro lado, a existência de objetivos antagônicos poderia impedir a satisfação dos objetivos. Além disso, falhas para reconhecer objetivos antagônicos poderiam causar confusão através do processo de projeto. Uma abordagem sistemática tem a função de revelar correlações de objetivos usando matrizes para assegurar que todas as interações possíveis sejam descobertas, e que os diagramas tornem claro o padrão dos relacionamentos (figura 25). 
Objetivos Categorias

\begin{tabular}{|l|c|c|c|c|c|}
\cline { 2 - 6 } & Categoria 1 & Categoria 2 & Categoria 3 & ... & etc \\
\hline Objetivo 1 & $\mathrm{X}$ & & & & \\
\hline Objetivo 2 & & $\mathrm{X}$ & $\mathrm{X}$ & & \\
\hline Objetivo 3 & & & $\mathrm{X}$ & & \\
\hline Objetivo 4 & & & $\mathrm{X}$ & & \\
\cline { 2 - 6 }
\end{tabular}

Figura 24 - Matriz de Classificação por categorias.

Fonte: LOUCOPOULOS et al. (1998), p. 14.

\begin{tabular}{|c|c|c|c|c|c|c|}
\hline & & & & & & \\
\hline Objetivos & & & & & & \\
\hline & Obj.1. & Obj. 2 & Obj. 3 & Obj. 4 & Obj. 5 & Obj.6 \\
\hline Obj. 1 & & - & + & + & + & \\
\hline & Obj. 2 & & - & & & \\
\hline & & Obj. 3 & & + & & \\
\hline & & & Obj. 4 & & & \\
\hline & & & & Obj. 5 & & + \\
\hline & & & & & Obj. 6 & \\
\hline
\end{tabular}

Figura 25: Matriz de correlação de objetivos.

Fonte: LOUCOPOULOS at al., (1998), p. 15.

Para ilustrar os principais aspectos do Modelo Organizacional será utilizado o exemplo de uma biblioteca pequena, como descrito em BUBENKO et al. (1998). Nas reuniões para modelagem da biblioteca muitos fatores foram identificados:

A biblioteca terá seu orçamento cortado $50 \%$ nos próximos 3 anos.

A biblioteca precisa encontrar fontes adicionais de recursos financeiros.

Existe a necessidade de melhorar o serviço.

Existe uma longa lista de espera para emprestar livros.

A biblioteca deveria fornecer um alto padrão de serviço. 
$>$ A biblioteca necessita de recursos financeiros externos de $\mathrm{R} \$ 500.000,00$ nos próximos três anos.

A lista de espera deverá ser minimizada.

A biblioteca precisa de mais clientes pagantes.

$>$ Existe um regulamento, segundo o qual a biblioteca não deveria cobrar de estudantes e acadêmicos.

$>$ Não existe um bom sistema de registro de todas as transações financeiras.

$>$ A biblioteca está situada na ELECTRUM que é um prédio para companhias de tecnologia da informação.

É freqüentemente possível determinar intuitivamente o tipo de um fato particular. Por exemplo, a sentença "a biblioteca deveria fornecer um serviço de alto nível" parece um objetivo que a gerência da biblioteca deveria alcançar no futuro. A sentença "A biblioteca precisa de mais clientes pagantes" é claramente entendida se é considerado que a biblioteca tem falta de recursos financeiros. Parte do Modelo de Objetivos está representada na figura 26. Este é apenas um modelo inicial baseado nas primeiras discussões. Pode ser elaborado e detalhado de muitas formas para atingir objetivos claros e operacionais e outros componentes do modelo. Geralmente, existem dois tipos principais de atividades no trabalho do Modelo de Objetivos: aquisição e operacionalização. 


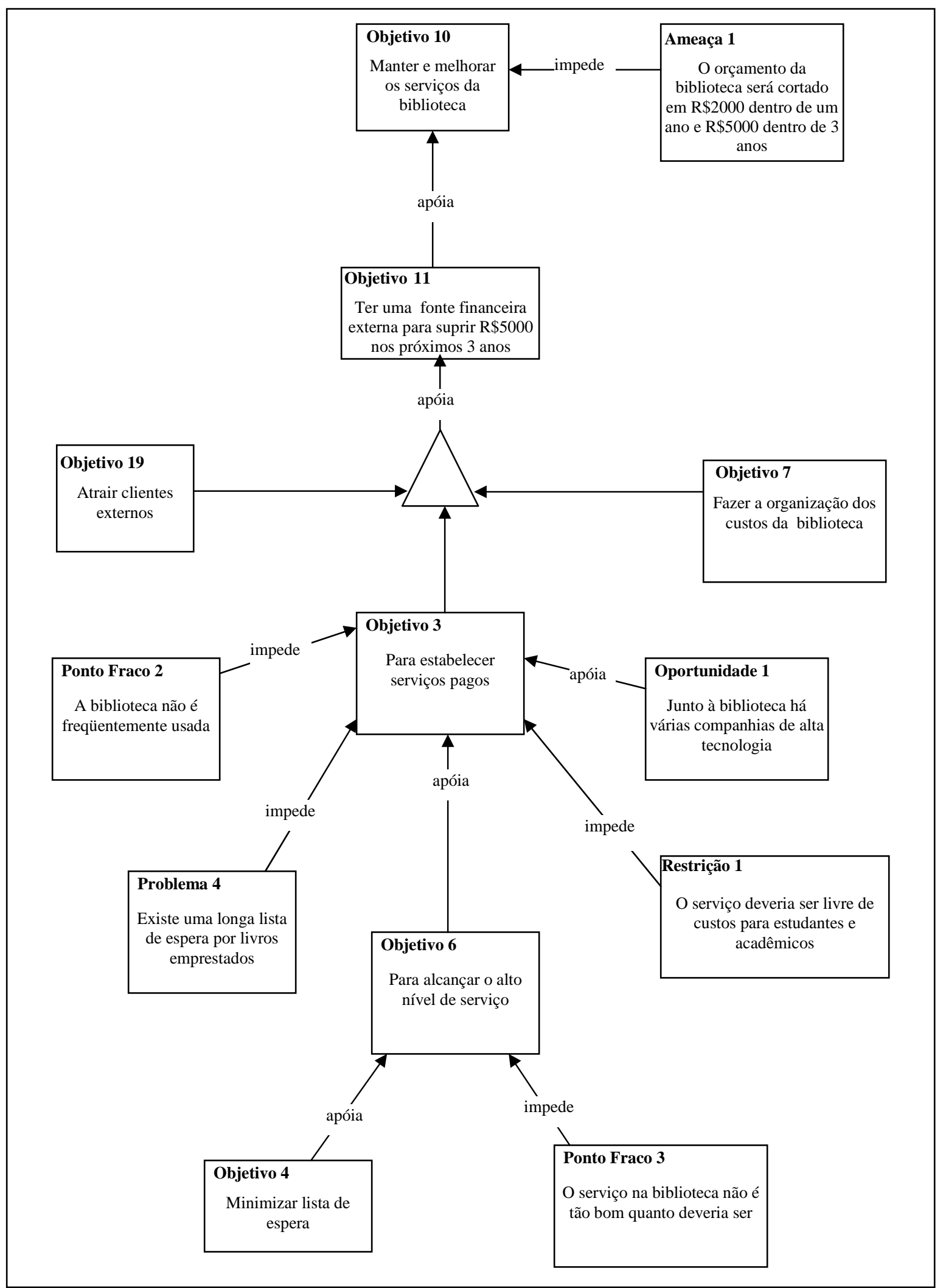

Figura 26- Parte de um Modelo de Objetivos de caso de uma biblioteca.

Fonte: BUBENKO et al. (1998), p. 29 


\subsubsection{Modelo de Regras do Negócio}

O Modelo de Regras do Negócio, de acordo com BUBENKO et al., (1998), é usado para definir e manter explicitamente regras do negócio formuladas, consistentes com o Modelo de Objetivos. Regras do Negócio podem ser vistas como operacionalização ou limites dos objetivos. Regras do Negócio são regras que controlam a organização no sentido de definir e restringir quais ações podem ser executadas em várias situações. Elas podem ser:

$>$ declarações precisas que descrevem o método escolhido pelo negócio para alcançar seus objetivos e implementar suas políticas

$>$ regras impostas externamente sobre o negócio, tais como regulamentos e leis.

Regras do negócio formam uma hierarquia onde o baixo nível de regras define a forma pelo qual o alto nível de regras ou objetivos são implementados. A modelagem de Regras do Negócio está intimamente relacionada com o Modelo de Objetivos. Regras são definidas por objetivos enquanto também afetam a realização de outros objetivos. Elas disparam processos de negócio e fazem referência a conceitos definidos no Modelo de Conceitos. Atores do Modelo de Atores são responsáveis por alcançar e definir regras do negócio. Regras do negócio requerem funcionalidade do sistema de informação. Componentes do Modelo de Requisitos e Componentes Técnicos podem ser motivados por regras do negócio.

Regras do Negócio podem ser categorizados, segundo BUBENKO et al. (1998), em Regras Derivadas, Regras de Evento-Ação e Regras de Restrição. Regras Derivadas são expressões que definem componentes derivados da estrutura da informação em termos de entidades que já estão presentes na base de informação do modelo da organização. Elas são introduzidas como um meio de capturar o domínio estrutural de conhecimento que não precisa estar armazenado e seus valores podem ser derivados dinamicamente usando valores existentes ou outras informações derivadas. Uma regra derivada é, por exemplo: "Um mau cliente de biblioteca é um cliente que não retorna o livro até a data limite por duas vezes consecutivas".

Regras de Evento-Ação estão relacionadas com a invocação de atividades. Em particular expressam as condições sobre as quais as atividades devem ser realizadas, como um conjunto de condições disparadoras e/ou um conjunto de pré-condições que devem ser satisfeitos antes da sua execução. Por exemplo: se o retorno de um empréstimo está quatro dias atrasado, envie um lembrete.

Regras de Restrição estão relacionadas à integridade da informação, à estrutura dos componentes, ou às atividades e comportamentos permitidos na organização. Uma restrição é, por exemplo: "o salário de um empregado não deve decrescer". As regras de restrição podem ser estáticas e de transição. As restrições estáticas aplicam-se a todo estado da base da informação e são independentes 
de tempo, como por exemplo: "a locação de cada cópia do livro é única e apenas uma". As restrições de transição definem um estado de transição na base de informação, desta maneira especificando restrições no comportamento do sistema. Uma restrição de transição é, por exemplo: "Uma cópia de livro está faltando, se o empréstimo dele está atrasado por mais de quatro semanas".

No Modelo de Regras do Negócio existem dois tipos de relacionamentos: de apoio e de impedimento. O relacionamento de apoio é essencialmente visto como vertical, podendo, por exemplo, ser usado para refinar ou decompor regras. O relacionamento de impedimento é usado para mostrar influências negativas entre componentes do Modelo de Regras do Negócio, e pode ser considerado como o oposto de apoio. Assim como no Modelo de Objetivos, também existem as estruturas de decomposição AND/OR no Modelo de Regras do Negócio. O relacionamento de refinamento AND representa um conjunto único de sub-regras, que são necessárias para satisfazer a regra original refinada. O relacionamento de refinamento OR representa um conjunto de sub-regras alternativas no qual, para apoiar uma regra original, é necessário satisfazer apenas uma regra do conjunto (BUBENKO et al., 1998).

BUBENKO et al. (1998) afirmam que todas as regras do negócio deveriam ser expressas de acordo com a figura 27. Entretanto, nem sempre é possível escrever regras do negócio usando esse padrão proposto. Geralmente existem três formas sob as quais as regras do negócio podem ser declaradas: informalmente, em linguagem natural; formalmente, utilizando o português estruturado; ou formalmente, usando linguagens especialmente para desenvolver regras, tal como TEMPORA ERL, que é uma notação técnica para expressar regras do negócio. As duas últimas formas de expressar regras de forma não-ambígua contribuem para facilitar a implementação delas no projeto de sistema de informação, como mostrado no capítulo 3.

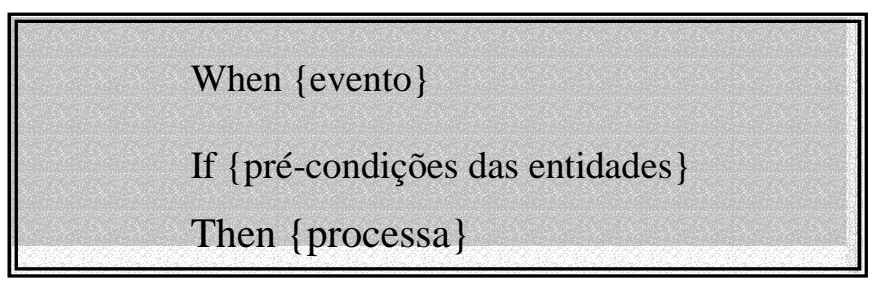

Figura 27 - Estrutura de Regras do Negócio.

Cada expressão de regras do negócio deveria ter apenas uma regra atômica, que é uma declaração específica e formal de uma simples restrição, fato, derivação, ou termo que não pode ser decomposto posteriormente. Por exemplo, a regra: "Clientes tornam-se Maus-Clientes se demorarem mais do que quatro semanas para entregarem o livro" será declarada da seguinte forma: 


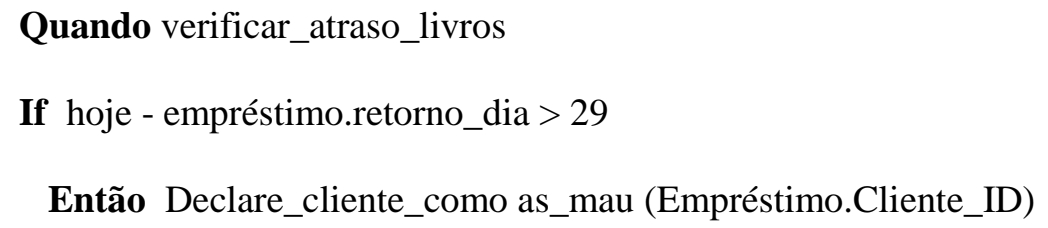

Através de uma regra escrita dessa forma (figura 28), os participantes e projetistas são capazes de obter informações mais precisas sobre:

Quais entidades ( Empréstimo, Cliente, Mau Cliente) estão envolvidas ou relacionadas na realização dessa regra;

Quais processos apoiam e são disparados (check_delay_books) por essa regra.

De acordo com BUBENKO et al. (1998), é possível formalmente expressar apenas regras atômicas. Regras que são mais complexas precisam ser expressas em linguagem natural ou semi-natural e, então, decompostas e refinadas usando relacionamentos AND/OR. Existem regras atômicas que são quase impossíveis de serem definidas de forma formal. Por exemplo, regras que são relacionadas a requisitos não-formais.

Ao modelar regras do negócio, é importante considerar as seguintes questões:

1. Existem regras declaradas e políticas com a companhia que podem influenciar esse modelo?

2. Por quais regras os objetivos da organização podem ser alcançados?

3. A regra está relacionada a um objetivo particular?

4. Como essa regra pode ser decomposta?

5. Como a organização pode ajustar-se à especificação dessa regra?

6. Como validar se a regra é cumprida?

7. Quais processos disparam essa regra?

8. Essa regra pode ser definida em uma forma operacional?

9. Pode uma regra ser decomposta em regras simples? 


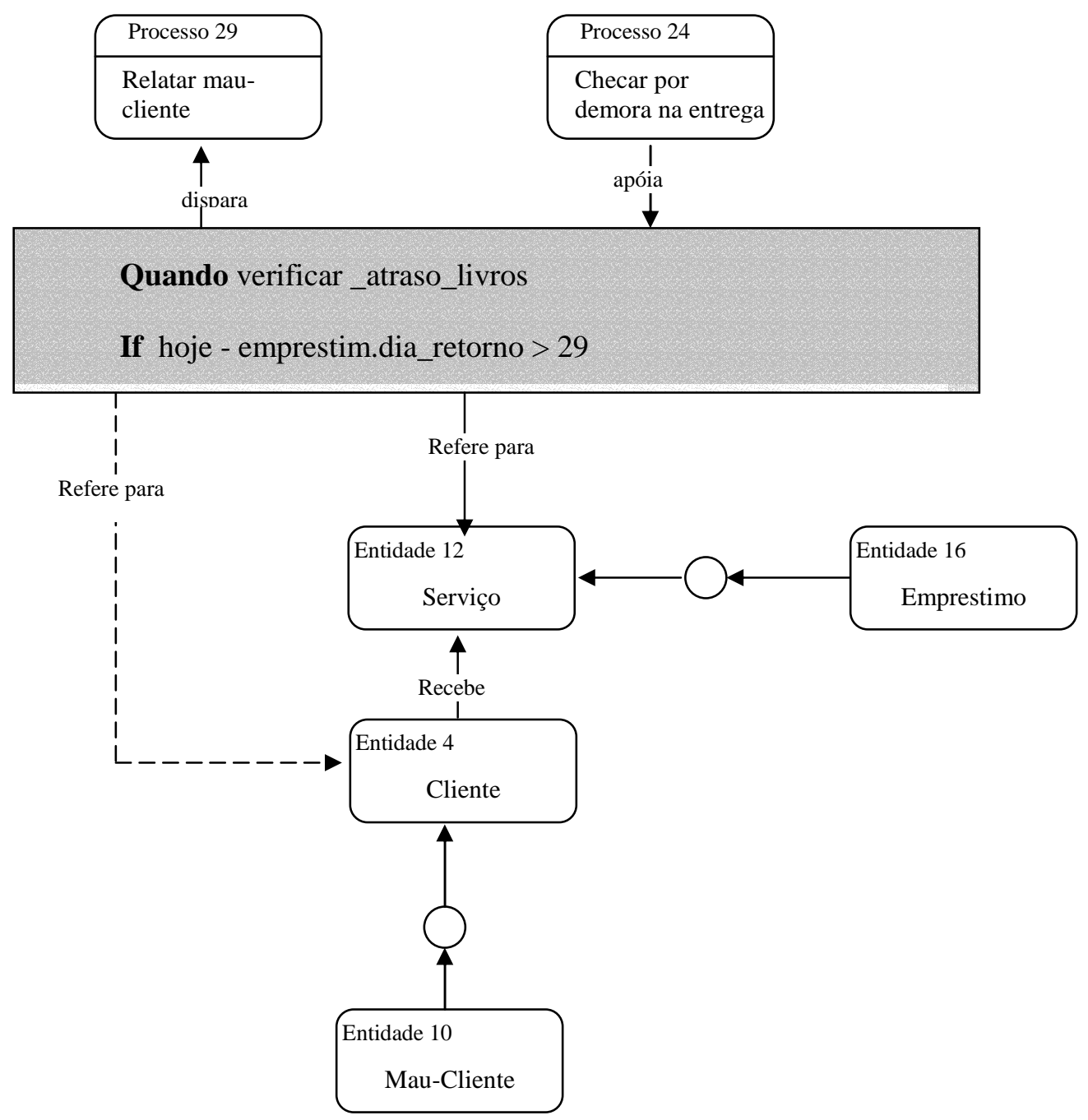

Figura 28- Regras referem-se a entidades do Modelo de Conceitos e são apoiadas por processos no Modelo de Processos do Negócio.

Fonte: BUBENKO et al. (1998), p. 39.

De acordo com o trabalho de BUBENKO et al. (1998), considerando novamente o caso da biblioteca, é possível formular muitas regras e representá-las graficamente (figura 29):

D Clientes devem ser considerados como maus clientes se eles atrasarem a entrega do livro em ocasiões consecutivas ou em quatro semanas.

Clientes deveriam pagar multas se o livro está atrasado, independente de qualquer privilégio que eles tenham.

Maus-clientes que não são clientes pagantes não deveriam ser habilitados a pedir livros de outras bibliotecas. 
$>$ Clientes pagantes não deveriam ter prioridade na lista de espera.

O catálogo da biblioteca deveria ser atualizado logo que as mudanças ocorressem.

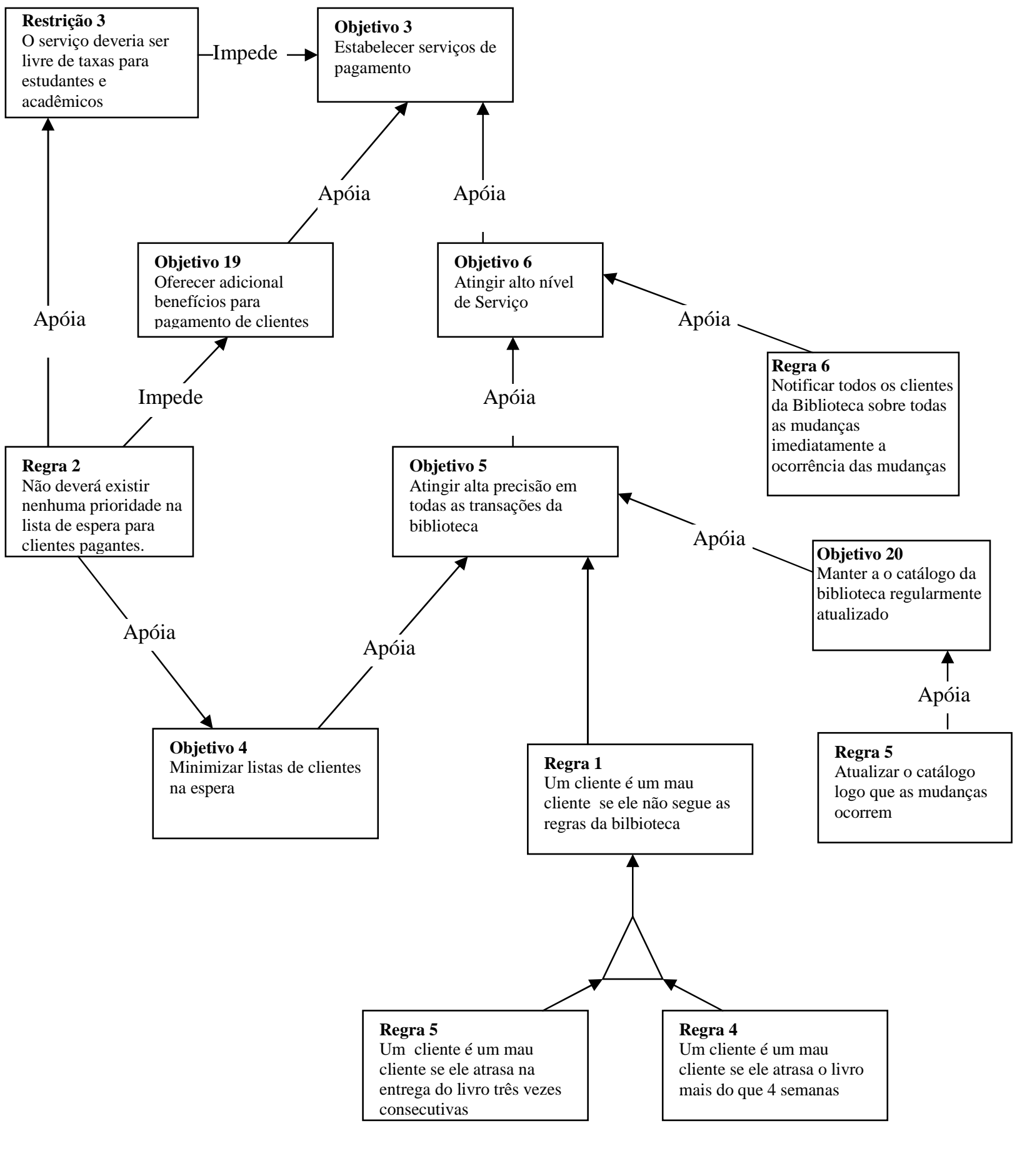

Figura 29- Interação entre o Modelo de Regras do Negócio e componentes do Modelos de Objetivos.

Fonte: BUBENKO et al. (1998), p. 37. 


\subsubsection{Modelo de Conceitos}

De acordo com BUBENKO et al. (1998), o Modelo de Conceitos é usado estritamente para definir "coisas" e "fenômenos" que estão em outros modelos, além de definir entidades e dados da aplicação em um nível conceitual, servindo como um dicionário. O Modelo Conceitual deve, ao menos, incluir componentes pelos quais se pode descrever o conteúdo de diferentes conjuntos de informação e fluxos do Modelo de Processos do Negócio. Por exemplo, a expressão do objetivo: "Manter e melhorar o serviço da biblioteca", requer a definição do conceito "serviço da biblioteca" no Modelo de Conceitos. É importante que todas as entidades usadas nos outros modelos sejam definidas aqui para evitar a possibilidade de mal-entendidos entre os participantes e stakeholders. Por essa razão, inconsistências são evitadas.

O Modelo de Conceitos inclui componentes tais como: entidades, relacionamentos binários e atributos de informação. Os relacionamentos ISA e PartOF são incluídos no Modelo de Conceitos para permitir a modelagem de generalização e de componentes complexos. O Modelo de Conceitos permite definir diferentes "grupos de Componentes de Modelo de Conceitos". Esse grupo é simplesmente uma visão de uma parte de um modelo de conceitos, e inclui um sub-conjunto de entidades do Modelo de Conceitos, relacionamentos e atributos. Um grupo pode ser um membro de outro grupo. Entidade é alguma coisa do domínio de interesse e aplicação que deve ser entendida, caracterizada e definida usando relacionamento para outras entidades. Atributo é uma entidade usada apenas para caracterizar outra entidade. É uma propriedade de um tipo de objeto. As entidades podem ser relacionadas por meio de relacionamento semântico, tais como: relacionamento binário, relacionamento generalização/especialização (ISA), e relacionamento de agregação (PartOF).

Para KIRIKOVA (2000), todos os elementos da estrutura ISA não refletem apenas por elementos da área e recursos do negócio, mas também por elementos relacionados diretamente e indiretamente. A intenção aqui não é mostrar estruturas de conhecimento correspondente, mas convencer de que a estrutura fornece uma possibilidade de representar o conhecimento requerido.

O relacionamento binário é uma semântica entre duas entidades ou com uma entidade. Relacionamentos binários são inerentemente bi-direcionais. A cada direção pode ser dado um nome, preferivelmente em forma de uma frase verbal. A direção indicada pela seta pode ser chamada de forward (para frente) ou primária, e a direção oposta como direção inversa. Um exemplo de relacionamento binário é dado na figura 30. As entidades participantes no relacionamento podem executar certas tarefas no relacionamento. No relacionamento "Editor imprime Livro/Livro é impresso pelo Editor", o Editor é quem imprime, enquanto o livro é o que é impresso pelo Editor (BUBENKO et al., 1998). 


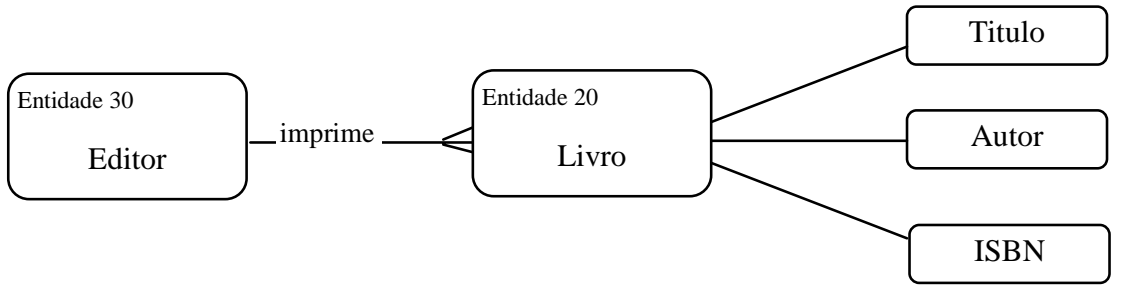

Figura 30 - Exemplo de Relacionamento Binário.

Fonte: BUBENKO et al. (1998) pg. 41.

O relacionamento ISA é um tipo específico de relacionamento semântico entre entidades. Se "A" ISA "B", então "B" é o conceito mais genérico e A é o conceito específico. Esse tipo de relacionamento é também referenciado como generalização. $\mathrm{O}$ oposto ou inverso de generalização é chamado especialização (figura 31). A propriedade mais significante de um relacionamento ISA é a herança. Tudo que é especificado para ser verdadeiro sobre um conceito genérico é também verdade para um conceito específico, significando que todos atributos, seus valores e restrições são herdados de um nível mais genérico de conceito para um nível mais específico. Os sub-tipos que resultam de uma especialização particular de um tipo de objeto podem não coincidir. Considerando a especialização de Cliente como Individual e Organizacional, um simples cliente não pode ser individual e organizacional ao mesmo tempo. Tais tipos de especificação é chamada total. Existe uma diferença no modelo entre cliente "organizacional" e cliente "individual". Se se espera relatar alguma coisa específica sobre um mau cliente que não está relacionado a um tipo geral de cliente, é necessário introduzir um conceito separado para ele. A especificação é parcial porque não estão sendo especificados outros subtipos de clientes, que poderiam ser, por exemplo, freqüente ou normal. A especialização é total quando todas as instâncias de um tipo genérico são membros de um tipo específico. Isso ocorre quando a especialização é uma partição de um tipo genérico. Quando a especialização é parcial existem instâncias de um conceito genérico que não é membro de nenhum sub-tipo. 


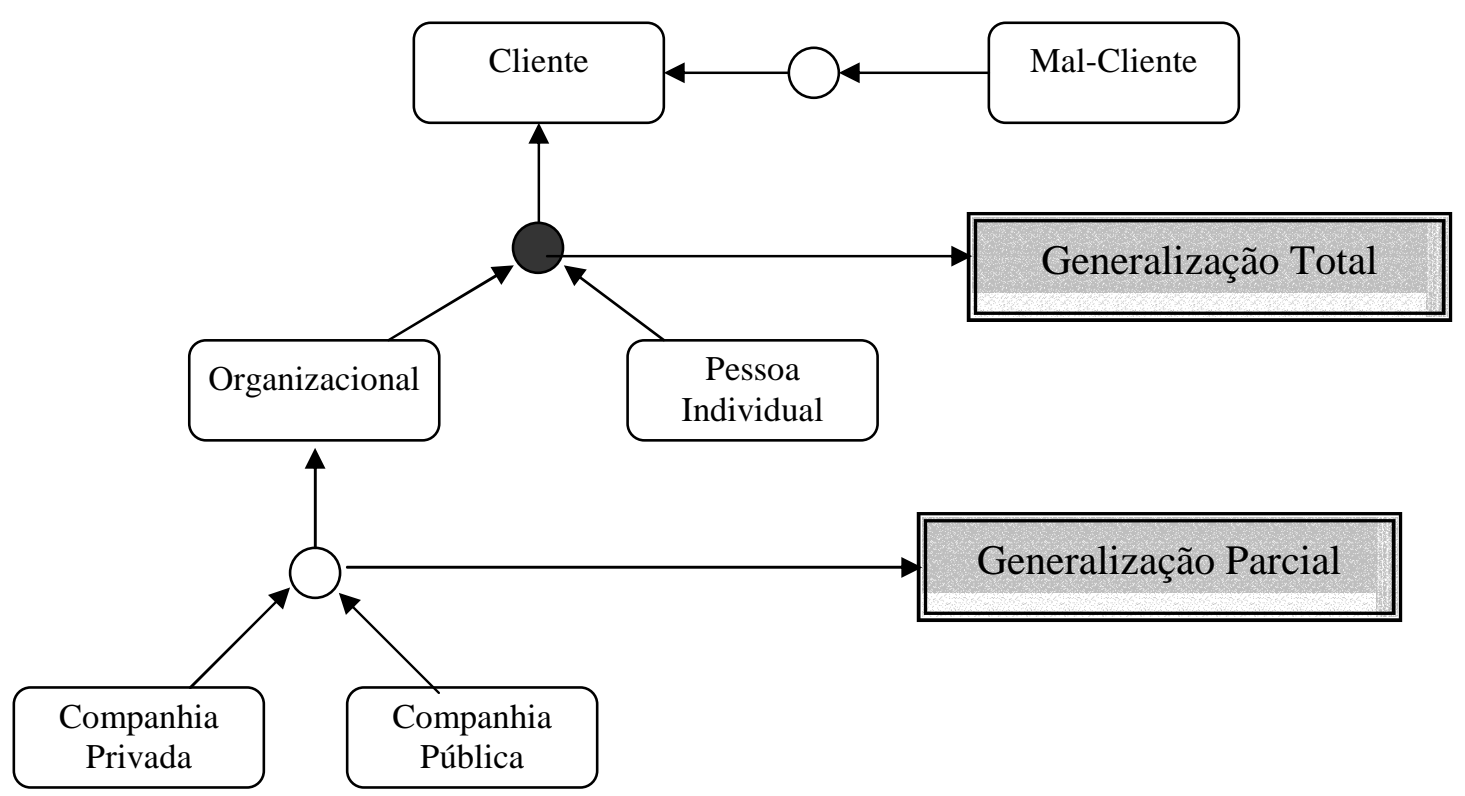

Figura 31 - O conceito de "Cliente" pode ser especializado de formas diferentes.

Fonte: BUBENKO et al. (1998) pg. 42.

O relacionamento PartOF ou uma agregação (figura 32) é uma forma especial de relacionamento semântico, onde as entidades inter-relacionadas são "fortemente e firmemente acopladas" umas as outras. O objeto agregado é uma reunião de partes, e as partes são componentes de agregação. Os objetos componentes são freqüentemente subordinados ao objeto agregado. O exemplo mais típico de agregação é uma exposição de uma parte, onde a parte em um nível mais superior tem um número de componentes, e onde alguns desses componentes no próximo nível são vistos como agregados, que por sua vez é composto de partes. A construção do relacionamento PartOF é incluída em um Modelo de Conceitos por razões de conveniências, de forma que será possível usá-la sempre que for natural e compensador, ver e operar o relacionamento sobre algo como parte de uma hierarquia ou estrutura de componentes. A figura 32 mostra que um documento é uma estrutura de componentes: um cabeçalho e um corpo de documento. O corpo do documento tem um ou mais capítulos e apêndices como componentes. 




Figura 32- Exemplo de Relacionamento PartOF.

Fonte: BUBENKO et al., 1998.pg. 42

No Modelo de Conceitos incluem componentes que representam a informação necessária ou produzida pelos processos do Modelo de Processos do Negócio. Portanto, se existe a necessidade de algum processo do Modelo de Processo de Negócio tal como, "Procurar a disponibilidade de um livro no Catálogo da Biblioteca", então o livro e suas cópias devem ser incluídos no Modelo de Conceitos e seus atributos relevantes devem ser declarados. A inclusão da informação no Modelo de Conceitos não implica na realização de um sistema de informação computadorizado.

O catálogo da biblioteca pode ser visto como um processo de alto nível do Modelo de Processos de Negócio, mesmo se for usado outro nome, como "Catalogamento de Livros". Esse processo do Modelo de Processos do Negócio conterá todos os sub-processos que podem ser vistos como parte do "processo de alto nível" Catalogação de Livros.

Um conceito pode ter diferentes interpretações e diferentes usos; e pode aparecer em diferentes submodelos. Isso é importante para distinguir claramente os diferentes usos e colocar componentes em um modelo apropriado no início, antes que o modelo cresça muito e fique confuso. A notação para a modelagem de componentes e relacionamentos do modelo de conceitos é ilustrada pela figura 33. 
Segundo BUBENKO et al., (1998), no Modelo de Conceitos pode-se usar "entidades reais". A experiência tem mostrado que o modelo de operações pode ser muito ilustrativo e apoiar o entendimento humano. Palavras com significados específicos podem algumas vezes ser necessárias para documentação, e ter seus relacionamentos discutidos. Pode acontecer dessas entidades serem introduzidas em textos de declaração de objetivos no Modelo de Objetivos, e precisarem de mais definição e discussão. Ao modelar entidades muitas questões devem ser consideradas para facilitar o trabalho, tais como:

1. Quais são as principais entidades da aplicação?

2. Como essas entidades são relacionadas?

3. Por que essa entidade é necessária?

4. O que é necessário saber sobre o conceito da aplicação? Quando e onde surgirá a necessidade dessa entidade?

5. Quantas instâncias dessa entidade existem?

6. Quando essa instância deixa de existir?

7. Quais situações acima refletem no Modelo de Processos de Negócio?

8. Os atributos da entidade são totais ou parciais?

9. Os atributos são simples ou multi-valorados?

10. O tipo de entidade é geralmente relacionado a algum outro tipo?

11. Existe a necessidade de algum dado histórico sobre entidades, relacionamentos ou atributos?

12. O relacionamento é estável ou varia de acordo com o tempo?

13. Como as entidades variam de acordo com o tempo?

14. Existem características temporais dos atributos? 


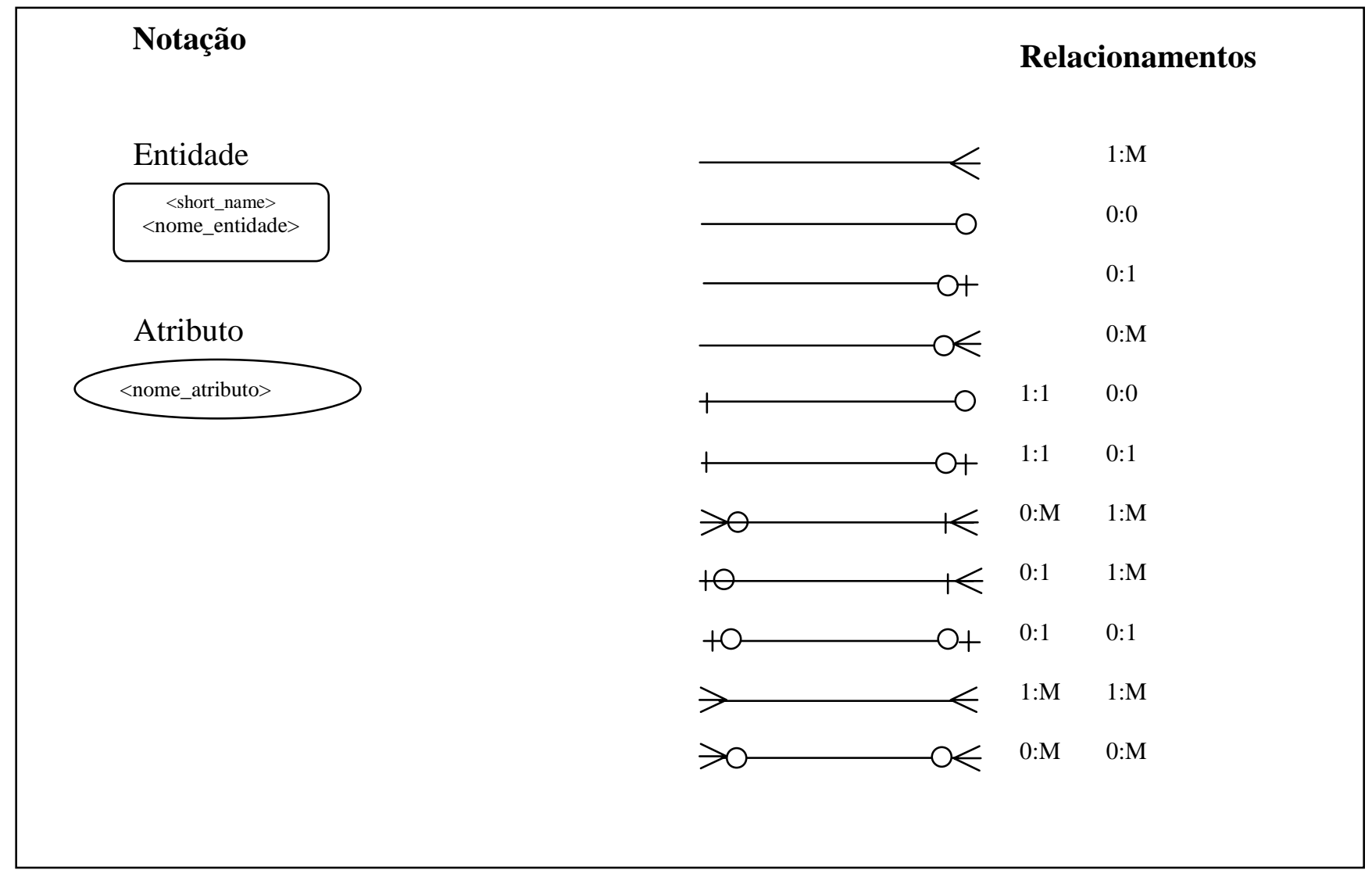

Figura 33 - Notação para modelagem do Modelo de Conceitos

\subsubsection{Modelo de Processo do Negócio}

De acordo com BUBENKO et al. (1998), o Modelo de Processo de Negócio destina-se a analisar o processo e fluxo de informação e material da organização. Processos podem ser decompostos em sub-processos. Componentes do Modelo de Processos de Negócio são, primariamente, motivados pelos componentes do Modelo de Objetivos e também possibilitam que objetivos do Modelo de Objetivos sejam alcançados. O Modelo de Processos de Negócio descreve as atividades organizacionais (funções e processos da organização). O núcleo da organização é o conjunto de processos, contribuindo para os valores da organização. Para alcançar uma boa abstração, o Modelo de Processos de Negócio permite total liberdade no processo de decomposição em sub-processos (figura 34 e 35). Dependendo do propósito da modelagem, os processos descritos podem ser existentes ou futuros (processos planejados). Um exemplo de um processo de negócio é o "Gerenciamento de retornos de empréstimos" que pode ser decomposto em "registro de retorno", "checar se o livro está reservado" e "retornar à prateleira".

Os componentes do Modelo de Processos de Negócio são processos, processos externos e conjunto de materiais e informações. Processo é uma coleção de atividades que: 
$>$ consome entradas e produz saídas em termos de informação ou material;

$>$ é controlada por um conjunto de regras, indicando como processar as entradas e produzir as saídas;

$>$ tem um relacionamento com o Modelo de Atores e Recursos, em termos do executor ou responsável pelo processo e

$>$ como uma instância do Modelo de Processos de Negócio é esperado para consumir, quando iniciado, um montante finito de recursos e tempo.

Processos externos representam uma coleção de atividades que:

$>$ são localizadas fora do escopo da área da atividade organizacional;

$>$ comunicam-se com processos ou atividades da área do domínio do problema

$>$ são essenciais para documentar.

Processos externos algumas vezes podem ser considerados como fluxo de entrada ou saída de alguma informação e material. Um exemplo típico de processo externo pode ser o de um cliente que pede ou recebe algum serviço da biblioteca. Conjunto de material ou informação é um conjunto de informação ou material enviado de um Processo ou Processo Externo para outro. O conteúdo do fluxo de material e informação são descritos no Modelo de Conceitos, onde eles são decompostos se necessário. O fluxo de material e informação deve ter ao menos um envio de processos ou processos externos e ao menos um recebimento de processo ou processo externo. Os processos de alto nível deveriam ser separados dos processos de baixo nível com o mecanismo de decomposição. Igualmente, se não existir nenhum nível máximo de intensidade de decomposição, a restrição é desejada pois evita estruturas complexas desnecessárias (BUBENKO et al., 1998)

Um exemplo de decomposição é realizado de um simples processo de verificação que tem como entrada "Endereço" e duas saídas "Endereço Inválido" e "Endereço Válido" (figura 35). Na figura 36 o processo é decomposto em quatro sub-processos. Cada um desses sub-processos tem um fluxo de dados de entrada. No exemplo considera-se que "Endereço" é um fluxo de informação complexa sendo, então, dividido em vários componentes. No caso da biblioteca existem vários processos como: emprestar e devolver livros, recebimento entre outros. Todos eles podem ser decompostos. A figura 36 mostra um modelo para empréstimo de livros. Nesse exemplo, o processo de empréstimo de livros é disparado. São mostrados partes do Modelo de Atores e Recursos que realizam o processo Negociação com o Cliente. Ligações entre fluxo de informação e entidade, indicam o relacionamento entre Modelo de Processos de Negócio e Modelo de Conceitos. Não existe a necessidade de mostrar todos os possíveis 
relacionamentos entre Modelo de Processos de Negócio e outros submodelos do Modelo Organizacional, apenas as ligações mais importantes, para reduzir a complexidade do modelo.

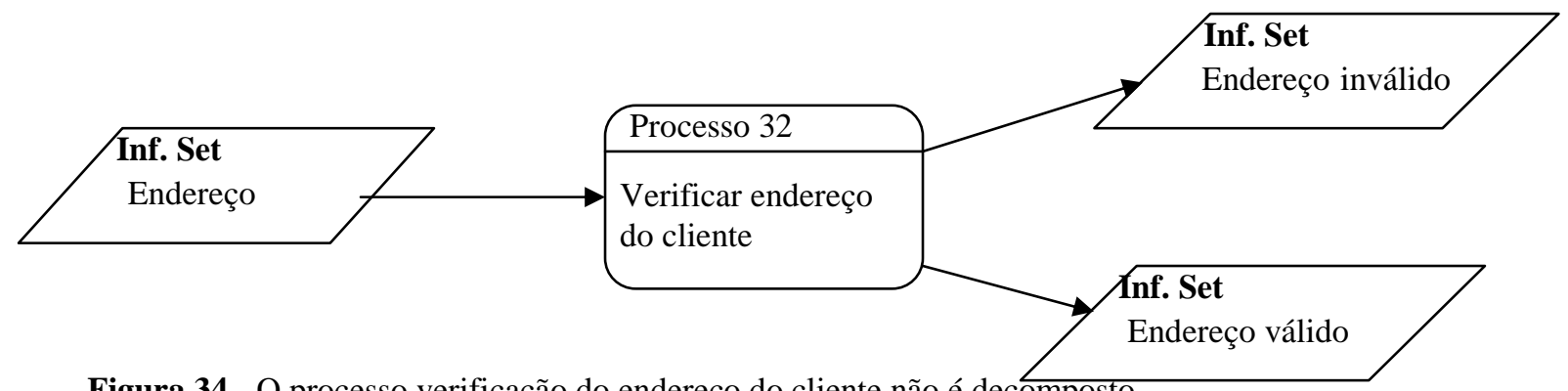

Figura 34- O processo verificação do endereço do cliente não é decomposto.

Fonte: BUBENKO et al. (1998), p. 51.

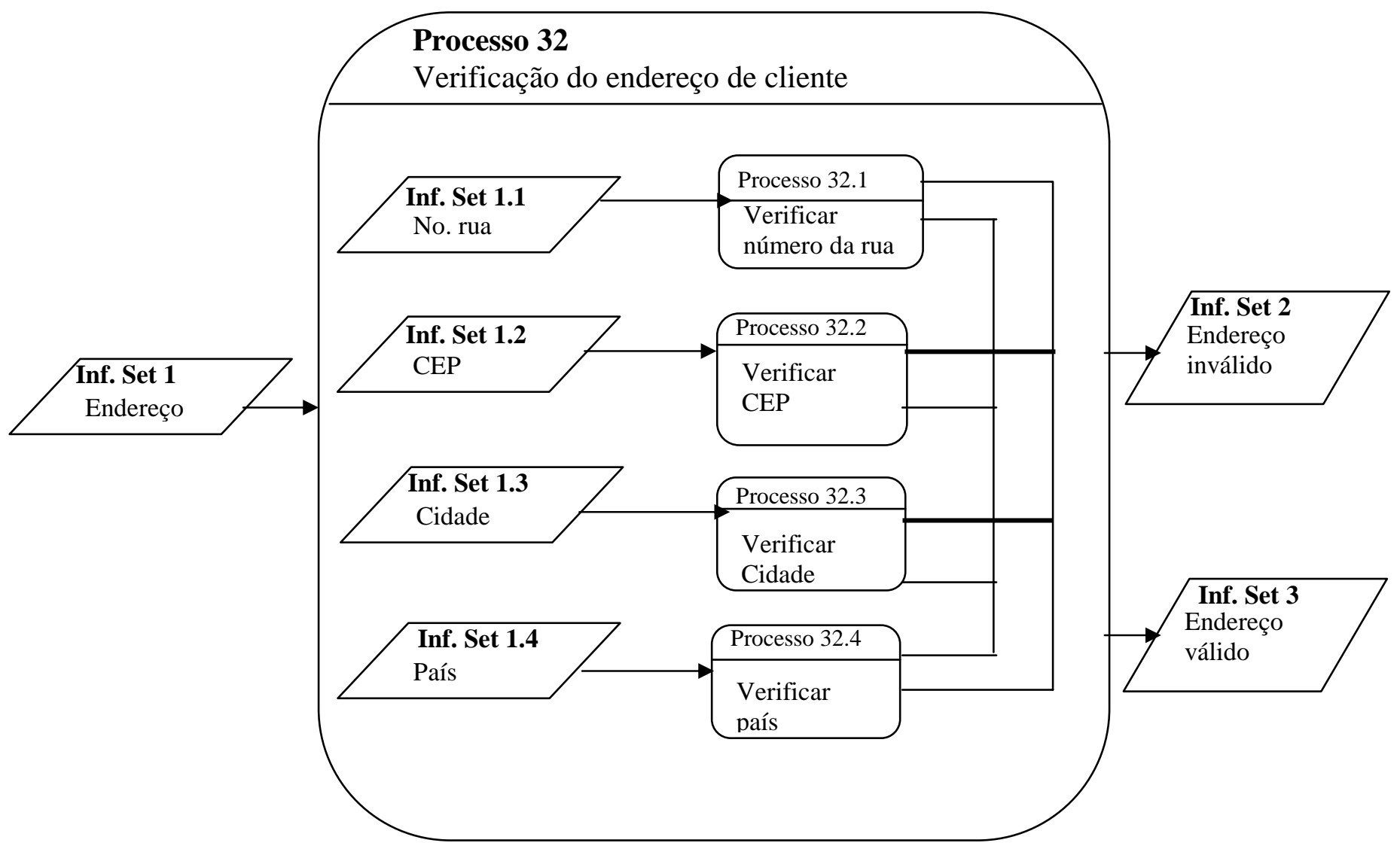

Figura 35- O processo verificação de endereço é decomposto em quatro sub-processos.

Fonte: BUBENKO et al. (1998), p. 51. 


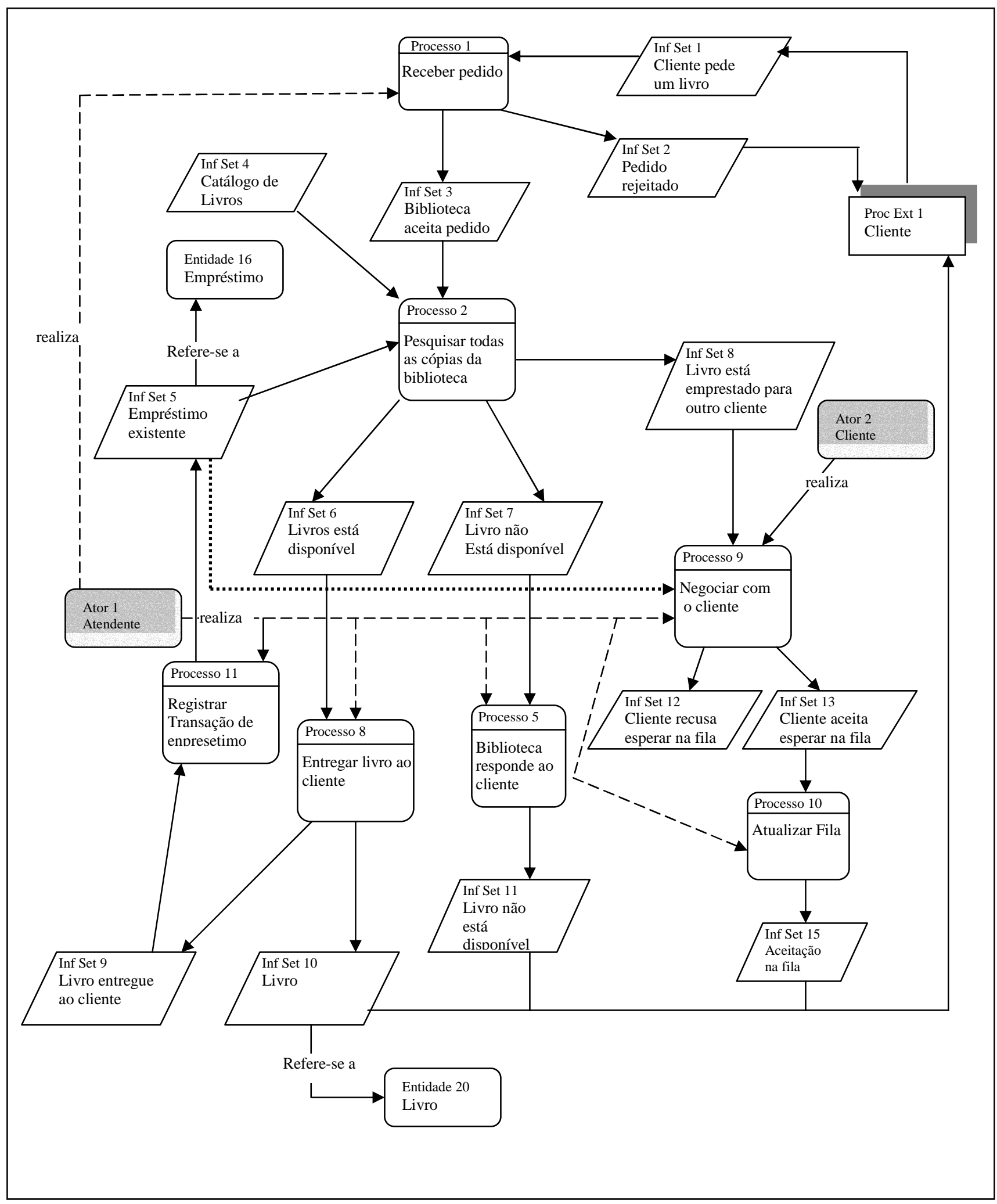

Figura 36- Um exemplo de Modelo de Processos de Negócio.

Fonte: BUBENKO et al. (1998), p. 50.

Os componentes do Modelo de Processos do Negócio devem ser motivados pelos objetivos da organização definidos no Modelo de Objetivos. Processos do Modelo de Processos de Negócio são 
realizados em, ou com a informação descrita pelos componentes do Modelo de Conceitos. Tais como, entidades, atributos e relacionamentos ou grupos de componentes do Modelo de Conceitos. Os componentes do Modelo de Processos do Negócio também estão intimamente relacionados com todos componentes do Modelo de Atores e Recursos. O relacionamento entre o Modelo de Processo de Negócio e Modelo de Atores e Recursos pode ser de diferentes tipos, tais como:

Ator A realiza processo P;

$>$ Ator A é_responsável_por_processo P;

$>$ Ator A apóia processo $\mathrm{P}$ ou

Ator A é_um_consultante_para_processo P.

Em geral, de acordo com BUBENKO et al. (1998), cada componente do Modelo de Processos do Negócio deve, ao menos no nível de decomposição, ter um relacionamento definido no Modelo de Atores e Recursos. É importante observar que o Modelo de Processos do Negócio descreve processos da área do negócio, e não unidades organizacionais e sistema. Para um componente ser qualificado para inclusão no Modelo de Processos de Negócio, deve-se descrever um conjunto de possíveis processos com um tempo de início e fim. Em um alto nível de abstração, esse conjunto de processos pode ser razoavelmente bem definido. As principais distinções entre um processo (tipo) e um componente do Modelo de Atores e Recursos são:

\section{Temporal:}

um componente Modelo de Recursos e Atores é criado. Ele existe até se desfazer ou ser excluído pelo ambiente.

$>$ O Modelo de Processos de Negócio descreve tipos de processos, cujas instâncias existem por um tempo limitado.

Instanciação:

O Modelo de Atores e Recursos contém componentes em um nível de instância, como unidades organizacionais, recursos individuais ou atores humanos e tarefas.

$>$ O Modelo de Processos de Negócio descreve processos em um nível de classe.

Seguindo esta abordagem, algumas questões devem ser consideradas na modelagem dos processos de negócio:

1. Quais são os principais processos da organização? 
2. Como esses processos são relacionados?

3. Por que esse processo é necessário?

4. Quais informações e fluxos de material são necessários?

5. Quais fluxos de informação e material não são necessários?

6. O que o fluxo de informação e material produzem?

7. Eles são representados no Modelo de Conceitos?

8. As situações que "criam" e "destroem" esses conjuntos de informações ou material são refletidas no Modelo de Processo de Negócio?

9. Quais regras disparam esse processo?

10. Quais atores são responsáveis por realizar e apoiar esse processo? 


\subsubsection{Modelo de Atores e Recursos}

O Modelo de Atores e Recursos (MAR) define que tipo de atores e recursos, ou quais atores individuais estão envolvidos nas atividades organizacionais. MAR descreve:

Como diferentes atores e recursos são relacionados entre si e como são relacionados com componentes do Modelo de Objetivos;

$>$ E de que forma os objetivos estão relacionados aos processos do Modelo de Processos de Negócio.

MAR descreve o sistema do negócio existente ou futuro, contendo recursos humanos e nãohumanos. Isso permite a inclusão, como parte da engenharia de requisitos, a descrição de um sistema sócio-técnico para ser desenvolvido. Essa descrição não pode ser feita pelo Modelo de Processos de Negócio e Modelo de Conceitos. Um ator do Modelo de Atores e Recursos pode ser dependente de um número de outros atores para a realização de certas tarefas ou processos.

Os componentes do Modelo de Atores e Recursos definem atores e recursos envolvidos nas atividades empresariais, articulados no Modelo de Processo de Negócio, ou atores relacionados com outros modelos ou para o desenvolvimento do sistema. Ator e recurso podem ser:

> Individual: denota uma pessoa da organização. Por exemplo: Ana Polare ou João Cardoso. Indivíduos são identificados pelo seu nome. Entretanto como os nomes podem não ser únicos, devem ser usados com moderação. Pessoas essenciais com habilidades ou tarefas específicas são incluídas no Modelo de Atores e Recursos, uma vez que elas esclarecem e adicionam significado ao modelo e seus relacionamentos. Indivíduos podem executar tarefas e pertencer a unidades organizacionais. Por exemplo, o indivíduo Ana Polare executa a tarefa "gerenciar biblioteca" e pertence a uma Unidade Organizacional "Biblioteca Central". Indivíduos podem, entretanto, ser relacionados com outros indivíduos, tarefas, unidades organizacionais e recursos não-humanos, por relacionamentos binários semânticos. Os relacionamentos ISA e PartOF não são relevantes para indivíduos.

Unidade Organizacional: pode representar toda a estrutura organizacional na organização tais como grupo, departamento, divisão, projeto, time, subsidiário, entre outros. Sendo atores, Unidades Organizacionais podem ter sub-unidades. Eles podem também executar tarefas e ter outros atores. Unidades organizacionais podem estar 
relacionadas a outras unidades organizacionais, a indivíduos, tarefas, e recursos nãohumanos por relacionamento binário semântico.

Recursos não-humanos: podem ser tipos de máquinas, sistemas e equipamentos. Sendo atores, recursos não-humanos podem ter componentes, ser generalizados ou especializados e executar tarefas. Naturalmente, a mesma tarefa em situações diferentes pode ser executada por diferentes recursos não-humanos. Recursos não-humanos podem ser recursos para processos. Eles podem também ser relacionados a outros recursos nãohumanos, a indivíduos, unidades organizacionais e tarefas em relacionamentos semânticos e binários.

Tarefas ${ }^{1}$ podem ser executadas por unidades organizacionais em contextos diferentes. Uma unidade organizacional pode, por exemplo, executar tarefas de administrador e autorização no mesmo contexto. Isso pode ser importante para identificar requisitos dependendo da tarefa que eles têm. Por exemplo: Ator, Supervisor, Gerente, entre outras. As tarefas podem pertencer a uma ou mais unidades organizacionais, e ser relacionadas a outras tarefas, indivíduos, unidades organizacionais e recursos nãohumanos por relacionamento binário (com nome do usuário). Tarefas podem ser generalizadas ou especializadas e ser tarefas componentes, podem realizar processos e ser responsável pela realização dos processos e objetivos alcançados. Elas podem também definir objetivos.

Relacionamento binário é usado para descrever tipos diferentes de relacionamentos entre seus componentes. Os dois principais propósitos para relacionamento binário entre os componentes do Modelo de Atores e Recursos e componentes de outros submodelos são definidos por:

Responsabilidade: é um relacionamento entre atores e processos de negócio, regras do negócio e objetivos. Responsabilidade pode ser delegada ou transferida entre atores. Responsabilidade pode ser organizacional ou operacional. A responsabilidade organizacional é relacionada à liberdade de um ator tomar decisões por outras entidades da organização, como objetivos, regras, recursos, processos de negócios e outros atores. Responsabilidades organizacionais podem ser representadas com os relacionamentos da tabela abaixo.

\footnotetext{
${ }^{1}$ Tarefa tem também o sentido de papel.
} 
Tabela 3 - Responsabilidades organizacionais

- Ator_define_objetivo

- Ator_é_responsável_por_objetivo

- Ator_é_responsável_por regra

- Ator_é_responsável_por_recurso

- Ator_é_responsável_por processo_de_negócio

- Ator_proprietário_recurso

- Ator_monitora_outro ator

A responsabilidade operacional é relacionada principalmente com a execução de tarefas e indica que um ator é alocado para realizar um processo de negócio ou que o processo de negócio é fixado por um ator. A responsabilidade operacional pode ser representada como "ator realiza processo", significando que o realizador da tarefa tem uma responsabilidade operacional.

- Dependência é uma relação entre atores da organização. Um ator depende de outro para alguma coisa que pode ser um recurso ou um processo de negócio. Dois tipos de dependências podem ser identificados: operacional e autoridade. A dependência pode ser simultaneamente do tipo operacional e de autoridade. A dependência operacional diz respeito a dependências criadas no fluxo de trabalho. Por exemplo, atores dependem de outros para usarem recursos que são necessários ao processo de negócio que eles realizam, ou um ator pode esperar por uma saída de outro processo de atores. A dependência de autoridade está relacionada com a dependência criada por causa das regras organizacionais, regulamentos, ou relacionamentos de autoridades e poder. Por exemplo, um usuário precisa de uma senha para trabalhar em um sistema computacional, um vendedor precisa de permissão para usar linhas internacionais.

A notação do Modelo de Atores e Recursos é apresentada na figura 37. Dois tipos específicos de relacionamentos fazem parte do Modelo de Atores e Recursos (MAR): ISA e PartOF. ISA é usado para descrever relacionamentos de generalização entre tarefas do Modelo de Atores e Recursos. A expressão "A ISA B" declara que componentes que executam a tarefa B também executam a tarefa A, como "Mau-Cliente ISA Cliente". Propriedades e relacionamentos de A são herdados por B. Isso significa que se $\mathrm{A}$ está operando processo $\mathrm{P}$, então $\mathrm{B}$ também está operando processo P. PartOF é usado como "B PartOF A", e declara que B é um componente de A. Esse tipo de relacionamento pode expressar relacionamentos de componentes de sistemas técnicos ou ser útil na modelagem das hierarquias organizacionais, por exemplo, a unidade organizacional X é PartOF de Y. 


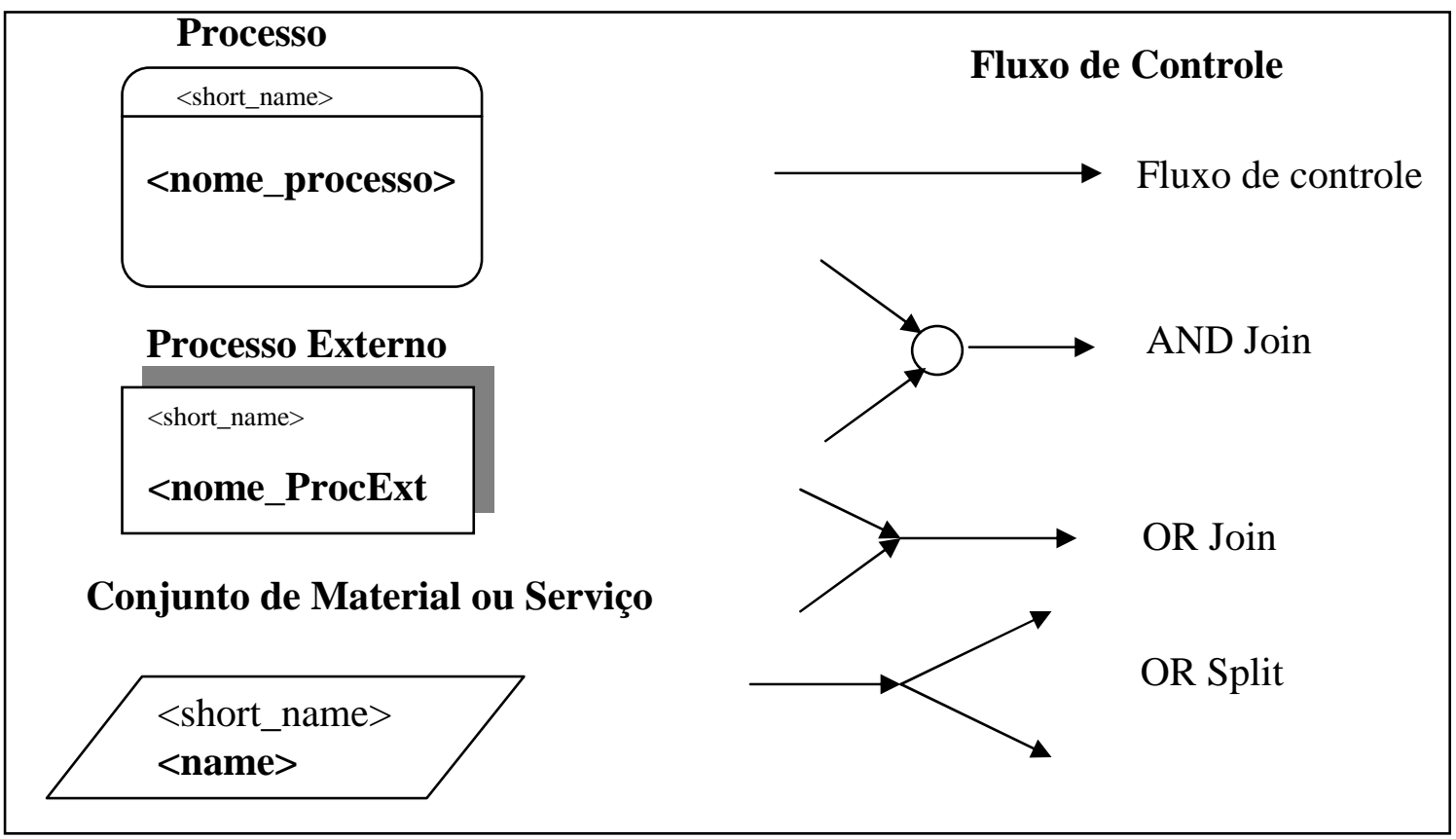

Figura 37- Notação do Modelo de Atores e Recursos.

Fonte: BUBENKO et al. (1998), p. 49

Ligações entre os componentes do Modelo de Processos do Negócio e o Modelo de Atores e Recursos descrevem o tipo de relacionamento que existe entre um particular processo de um ator ou recurso. Para facilitar o processo de modelagem e melhorar a qualidade do modelo, as seguintes questões devem ser consideradas:

1. Quais são os principais atores dessa aplicação?

2. Como os atores estão relacionados?

3. Por que o ator é necessário?

4. Qual é o seu propósito?

5. Esse ator é representado no Modelo de Conceitos?

6. Por quais processos o ator é responsável?

7. Quais processos esse ator realiza?

8. Quais objetivos são definidos por esse ator?

9. Quais regras do negócio são definidas por esse ator?

10. Por quais regras do negócio esse ator é responsável?

11. De quais recursos esse ator é proprietário? 
12. Por quais recursos esse ator é responsável?

Referenciando o caso da biblioteca, foi encontrado, entre outras, as seguintes tarefas (papéis) e relacionamentos binários: a) a tarefa de prover serviços para clientes; b) a empresa KTH financia a biblioteca; c) estudante faz o papel de cliente não-pagante. d) o atendente trabalha na biblioteca. A figura 38 mostra apenas o Modelo de Atores e Recursos. Entretanto, os componentes do Modelo de Atores e Recursos também podem ser relacionados a outros modelos. Por exemplo, no Modelo de Processos de Negócio (figura 36) existem dois executores Atendente da Biblioteca e Cliente que realizam alguns processos.

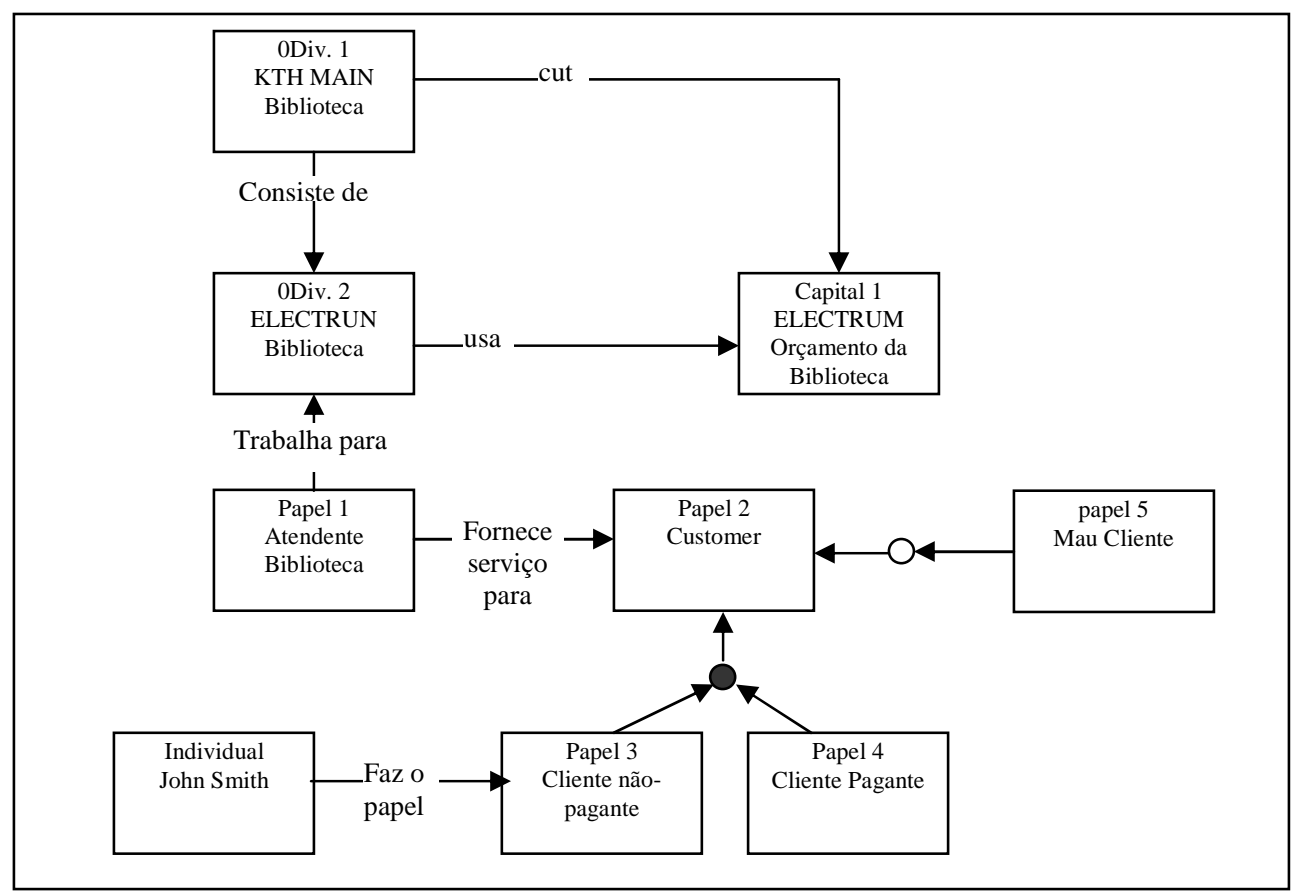

Figura 38- Um exemplo de Modelo de Recursos e Atores de uma Biblioteca.

Fonte: BUBENKO et al. (1998), p. 57

\subsubsection{Modelo de Requisitos e Componentes Técnicos}

O que foi elaborado pelo Modelo de Objetivos, Modelo de Regras do Negócio, Modelo de Conceitos, Modelo de Processos de Negócio e Modelo de Atores e Recursos é uma descrição inicial dos objetivos da organização, das regras do negócio, dos processos, do sistema de atores, das entidades de informação, de modo que os processos de negócio devam contribuir com os objetivos declarados. Se o objetivo é desenvolver um sistema de informação para apoiar processos, 
então existe a necessidade de tratar dos requisitos técnicos do sistema de informação, inicialmente de uma forma menos formal.

A abordagem EKD inclui um submodelo simples para descrever e para relacionar entre si, requisitos iniciais e não claros do sistema de informação. O Modelo de Requisitos e Componentes Técnicos se parece com a estrutura do Modelo de Objetivos e indiretamente com o Modelo de Sistemas de Informação. Inicialmente é necessário desenvolver um conjunto de requisitos ou objetivos de alto nível para o sistema de informação como um todo. Baseado nesse conjunto, o sistema de informação é estruturado em um número de sub-sistemas ou componentes técnicos. Para cada sub-sistema, é necessário definir um conjunto de objetivos e requisitos que são mais específicos. Esses objetivos e requisitos devem ser derivados e consistentes com os outros submodelos descritos anteriormente. O Modelo de Requisitos e Componentes Técnicos é uma tentativa inicial de se definir as estruturas e propriedades do sistema de informação para apoiar as atividades do negócio, como definido no Modelo de Processos do Negócio.

Segundo BUBENKO et al. (1998), os componentes presentes no Modelo de Requisitos e Componentes Técnicos são: Objetivos do Sistema de Informação, Problemas do Sistema de Informação e Requisitos do Sistema de Informação. Os Objetivos do Sistema de Informação são usados para expressar o alto nível de objetivos com relação ao sistema de informação e ou/subsistema ou componentes. Eles podem ser expressos com propriedades mensuráveis ou não mensuráveis, focos, visões, ou direções. Os objetivos do Sistema de Informação são tipicamente motivados por atividades do Modelo de Processos do Negócio, e podem ser motivados pelos objetivos do Modelo de Objetivos. Os Problemas do Sistema de Informação são usados para expressar estados não desejáveis do negócio ou do ambiente, ou fatos problemáticos sobre a situação corrente com respeito ao sistema de informação a ser desenvolvido. Os problemas do sistema de informação normalmente impedem os objetivos do sistema de informação. Os Requisitos do Sistema de Informação expressam requisitos a serem designados para propriedades do sistema de informação. A propriedade pode ser funcional ou não-funcional. Uma expressão de requisitos sempre refere-se a componentes do Modelo de Processos de Negócio e pode referir-se a componentes do Modelo de Atores e Recursos e Modelo de Conceitos. Os requisitos do sistema de informação podem apoiar ou impedir os requisitos funcionais e não funcionais do sistema de informação.

Os requisitos funcionais do sistema de informação são usados para expressar requisitos definitivos com relação a propriedade funcional do sistema de informação ou algum sub-sistema. Requisitos funcionais devem ser claramente definidos com referência ao Modelo de Conceitos. Preferivelmente, um requisito deve ser expresso de uma forma formal ou ao menos semiformal. 
Todos os conceitos de dados referentes aos requisitos funcionais devem ser definidos como um componente do Modelo de Conceitos. Requisitos funcionais podem ser diretamente apoiados pelos objetivos do sistema de informação, mas são mais freqüentemente vistos como refinamentos dos requisitos do sistema de informação. Requisitos funcionais são apoiados por componentes de outros submodelos, em particular o Modelo de Processos do Negócio, e também pelo Modelo de Objetivos. Um requisito funcional deve ser relacionado a um processo ou a um sub-processo, definido no Modelo de Processos do Negócio.

Os requisitos não funcionais do sistema de informação são usados para expressar um tipo de requisito e restrição, considerando o sistema de informação a ser construído ou o processo de construí-lo. Requisitos não funcionais nem sempre são definitivos e podem algumas vezes ser negociados. Pode acontecer, por exemplo, de dois requisitos não funcionais não serem satisfeitos no mesmo nível completo, devido a alguma restrição financeira. Nesse caso, o nível de realização desses requisitos deve ser negociado. Alguns requisitos não funcionais podem impedir outros requisitos não funcionais, objetivos e problemas do sistema de informação. Eles podem ser apoiados ou apoiar objetivos e requisitos do sistema de informação. Eles podem ser relacionados ou apoiados pelos componentes do Modelo de Objetivos, e processos do Modelo de Processos do Negócio. Um requisito não funcional pode ser relacionado para um componente no Modelo de Atores e Recursos com o relacionamento "ator_envolvido".

Os componentes da modelagem dos Objetivos e Problemas do Sistema de Informação são do mesmo tipo dos componentes do Modelo de Objetivos. Eles têm regras similares para nomeação e definição dos componentes do Modelo de Objetivos. Os objetivos do Sistema de Informação também deveriam iniciar com "O objetivo é...". Entretanto, ao modelar os requisitos do Sistema de Informação, é importante enfocar nos requisitos e componentes do sistema de informação, e não na organização ou questões gerais. Os componentes desse submodelo também devem ser mensuráveis e fáceis de realizar verificação, para que eles formem a base do projeto do Sistema de Informação. Expressões como "melhor do que", "maior do que", e "o melhor", normalmente não contribuem para o entendimento de um requisito particular. Os componentes desse submodelo devem ser intimamente relacionados com os componentes do Modelo do Processo de Negócio, Modelo de Objetivos ou Modelo de Regras do Negócio.

No exemplo apresentado na figura 39 assume-se que o sistema de informação pode apoiar requisitos funcionais e não funcionais. $\mathrm{O}$ requisito funcional refere-se a uma propriedade funcional do sistema de informação como armazenar dados sobre os livros pedidos na biblioteca e para responder a consulta "listar todas as publicações sobre Linhas de transmissão de alta voltagem publicado depois de 1994". Um requisito não funcional pode ser de vários tipos diferentes tais 
como, restrições de operações, restrições políticas, restrições econômicas, restrições de segurança de informações. Um exemplo seria: a pesquisa do catálogo da biblioteca deve ser implementada em um sistema computacional XYZ existente.

Os requisitos do sistema de informação devem apoiar os objetivos e processos da organização. O Modelo de Requisitos e Componentes Técnicos é usado como base para a Modelagem do Sistema de Informação. MRCT permite a discussão de: métricas; operações para criar, modificar e deletar objetos e relacionamentos; consultas e objetos de pesquisa e relacionamentos e a funcionalidade para checagem e análise de dados.

As seguintes questões devem ser consideradas na elaboração do Modelo de Requisitos e Componentes Técnicos:

1. Quais restrições e padrões existem considerando a comunicação com sistemas ou hardware existentes?

2. Quais são os requisitos importantes considerando requisitos não funcionais tipo segurança, disponibilidade, usabilidade, entre outros?

3. Quais restrições estão sendo consideradas no software existente ou nos sistemas que estão sendo desenvolvidos?

4. Quais restrições econômicas, pessoais, políticas, ou outras, existem?

5. Existem restrições legais para desenvolvimento do sistema?

6. Esse requisito pode ser refinado mais claramente (talvez decomposto) em uma forma que possa ser verificado e mensurado? 


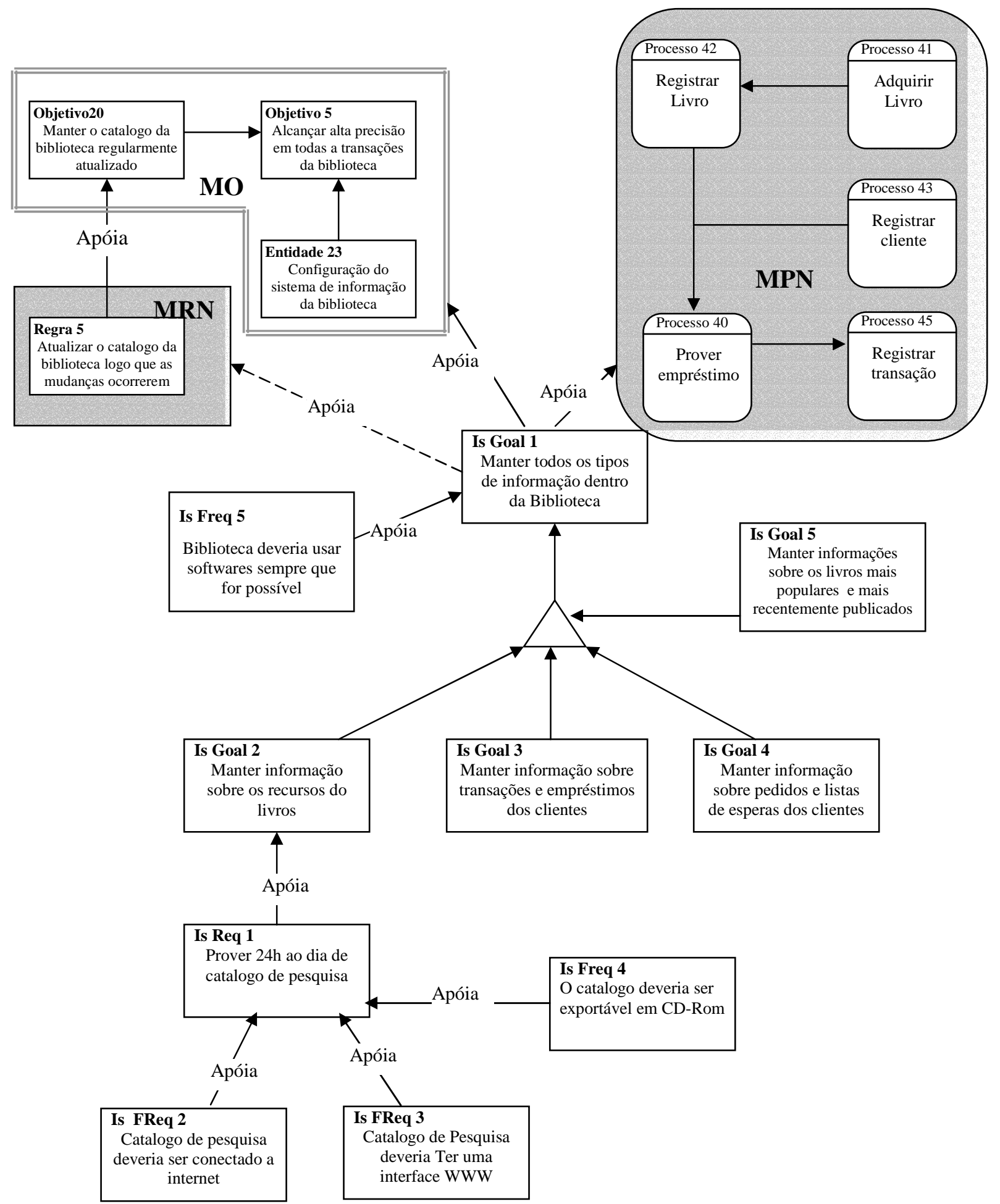

Figura 39 - Exemplo de um Modelo de Requisitos e Componentes Técnicos.

Fonte: BUBENKO et al. (1998), p. 61 


\subsubsection{Relacionamentos entre os submodelos}

BUBENKO et al. (1998), explicam que no desenvolvimento de um modelo organizacional completo, as ligações entre os componentes de diferentes submodelos executam um tarefa essencial. Por exemplo, declarações no Modelo de Objetivos permitem que conceitos diferentes sejam definidos mais claramente no Modelo de Conceitos, no qual uma ligação é especificada entre o componente correspondente no Modelo de Objetivos e o conceito no Modelo de Conceitos. Da mesma forma, objetivos no Modelo de Objetivos motivam processos particulares no Modelo de Processos do Negócio. Os processos são necessários para alcançar os objetivos declarados. Assim, uma ligação é definida entre o objetivo e o processo que deverá ser realizado para cumpri-lo. Ligações entre modelos tornam o conhecimento mais disponível, sendo possível ver por que certos processos e requisitos do sistema de informação têm que ser introduzidos. De acordo com a figura 40, as ligações entre os submodelos do Modelo Organizacional são explicadas a seguir:

Ligações entre o Modelo de Objetivos e o Modelo de Conceitos são normalmente usadas para descrever componentes do Modelo de Objetivos que referenciam entidades do Modelo de Conceitos Por exemplo, o objetivo: "Melhorar a satisfação do cliente" deveria referenciar o conceito "Cliente" no Modelo de Conceitos.

Ligações entre o Modelo de Objetivos e o Modelo de Processos de Negócio tipicamente relacionam objetivos do Modelo de Objetivos a processos do Modelo de Processos de Negócios com o relacionamento "motiva". Exemplo: "Melhorar a satisfação do cliente" poderia inicialmente motivar um particular processo de alto nível da organização como "Monitoramento das Relações com Cliente".

Ligações entre o Modelo de Objetivos e o Modelo de Atores e Recursos podem significar várias coisas: podem motivar ou requerer a introdução de novos atores particulares, como: Agentes de Relações de Clientes (motivado pelo objetivo de melhorar relacionamentos com clientes), ou elas podem descrever quais componentes do Modelo de Atores e Recursos são responsáveis para alcançar um particular objetivo ou defini-lo.

Ligações entre o Modelo de Objetivos e o Modelo de Regras do Negócio tipicamente descrevem como componentes diferentes do Modelo de Objetivos são implementados em termos de regras do negócio no Modelo de Regras do Negócio. Por exemplo, o objetivo "Registrar Maus Clientes" declarado no Modelo de Objetivos requer uma regra do negócio no Modelo de Regras do Negócio, que declara como exatamente 
isso deveria ser distinguido, como "Cliente é considerado mau cliente se demorar mais do que quatro semanas para entregar um livro".

Ligações entre o Modelo de Regras do Negócio e o Modelo de Processos de Negócio normalmente descrevem como processos do Modelo de Processos de Negócio são disparados pelas regras do negócio do Modelo de Regras do Negócio. Por exemplo, se existe uma regra que declara "Clientes são registrados como maus clientes se demorarem mais do que quatro semanas para entregarem o livro", então essa regra dispara o processo que realiza o registro de maus clientes.

Ligações entre o Modelo de Processos de Negócio e o Modelo de Conceito estão tipicamente entre o conjunto de informação do Modelo de Processos do Negócio e componentes do Modelo de Conceitos. Por exemplo, o Conjunto de Informação "vôo esperados" deveria referir-se a entidades incluindo atributos e relacionamentos como Vôo, Linha Área, Piloto e dados temporais sobre chegadas.

Ligações entre Modelo de Processos de Negócio e Modelo de Atores e Recursos tipicamente descrevem como componentes distintos do Modelo de Atores são relacionados ou envolvidos nos processos do Modelo de Processos de Negócio. Exemplos de nomes de ligações são: realiza, é_responsável_por, e apóia. Por exemplo, ator Auxiliar de Biblioteca realiza o processo entrega livro para clientes.

Ligações entre o Modelo de Atores e Recursos e o Modelo de Regras do Negócio normalmente descrevem como componentes diferentes do Modelo de Atores e Recursos são relacionados a Regras do Negócio do Modelo de Processos de Negócio. Exemplos de nomes de ligações são: define, é responsável por.

Ligações entre o Modelo de Requisitos e Componentes Técnicos e outros componentes do modelo podem ser mais complexas do que os relacionamentos binários normais. Mais tipicamente, o Modelo de Processos do Negócio motiva os objetivos do sistema de informação e os requisitos do sistema de informação. Simples declarações binárias, tais como "O Sistema de Catálogo da Biblioteca deve ser capaz de manusear X pedidos simultaneamente", mas pode também ter declarações mais complexas, tais como, "O tempo de resposta para o usuário do tipo $\mathrm{X}$, quando estiver realizando o processo $\mathrm{P}$, na data definida como $\mathrm{C}$, deve ser menor do que $\mathrm{Z}$ segundos".

Os componentes do Modelo devem ser ligados de muitas formas. As ligações que devem ser estabelecidas dependem do propósito de um projeto EKD particular. Cada Modelo 
Organizacional tem um propósito e um foco que as ligações de cada modelo devem refletir. Toda ligação representa uma declaração feita sobre a organização e, possivelmente, seus requisitos do sistema de informação. A semântica de todas ligações deveria ser analisada cuidadosamente. Existe, entretanto, um conjunto mínimo de ligações que deveria ser definido pela representação para ser considerado completo.

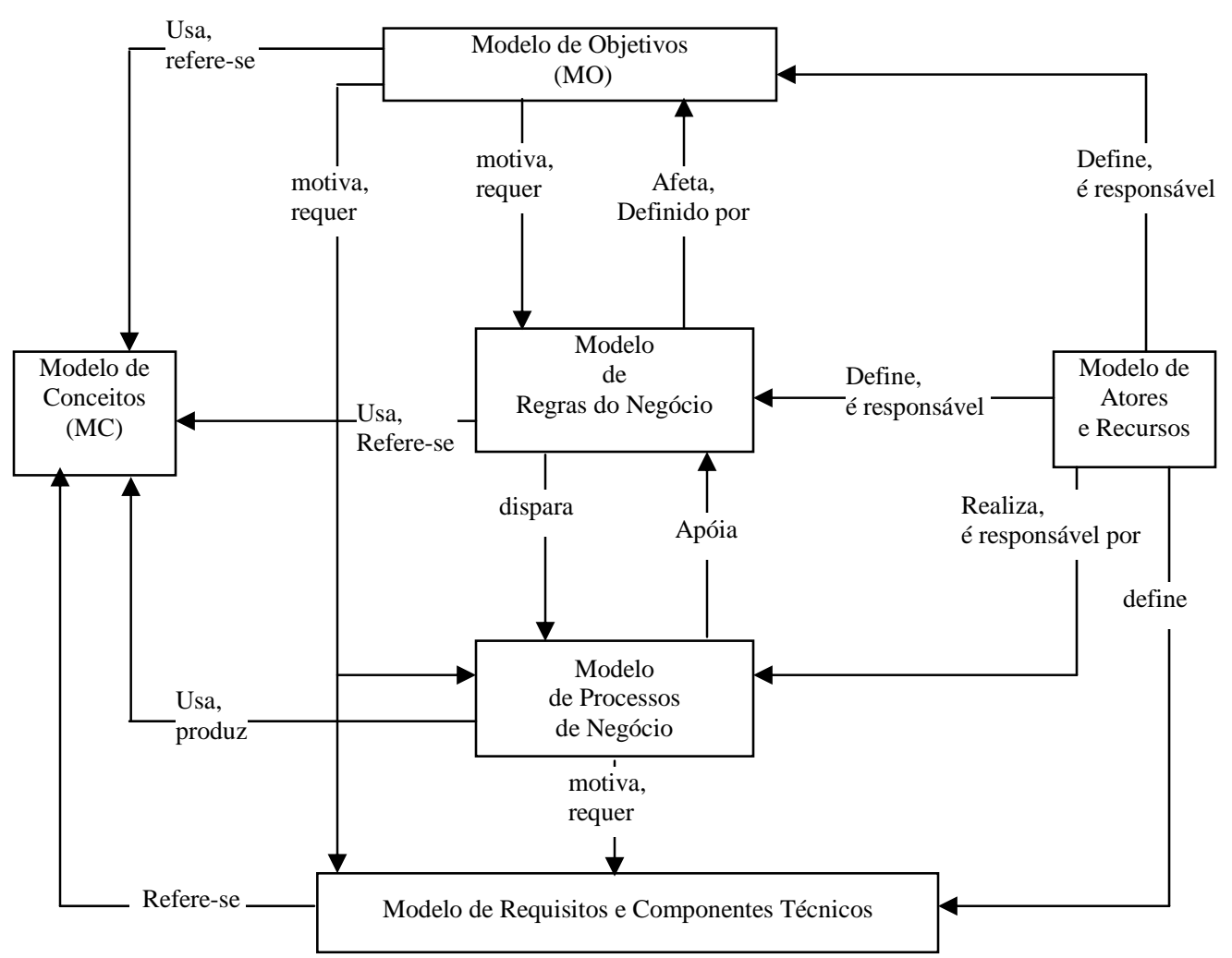

Figura 40- Relações entre submodelos

Fonte: BUBENKO et al. (1998), p. 65

\subsection{Componentes para auxiliar a modelagem}

BUBENKO et al. (1998) esclarecem que algumas vezes é interessante estender o Modelo Organizacional com alguns componentes adicionais ou "ordinários". As razões para usar esses componentes variam. Uma razão é, por exemplo, melhorar a expressividade do modelo, ou permitir mais liberdade para o grupo de desenvolvimento. Isso é mais comum nas primeiras sessões de modelagem, onde a tarefa mais importante é gerar idéias e tornar os participantes familiarizados 
com o processo de modelagem. Os tipos de componentes que podem ser adicionados aos submodelos do MO não são estritamente prescritos ou definidos. Os requisitos básicos para adicionar componentes são: que todos os participantes do grupo aceitem e entendam o significado de cada componente, e que o facilitador de modelagem aceite a extensão como benéfica. Alguns dos componentes adicionados podem ser mais tarde reformulados e usados como tipos de componentes regulares.

Os componentes adicionados mais comumente são comentários, ações para desenvolvimento do modelo, suposições e cenários. Os Comentários normalmente esclarecem alguns componentes de modelagem, ou todo o modelo. Podem ainda conter alguma informação que o grupo de modelagem acha importante, embora seja difícil expressar em termos de modelagem de componentes ordinários. Comentários podem também conter dicas para melhor elaboração do modelo. Se os comentários enfocam em algum componente de modelagem particular, estes são, então, interligados por setas. As ações para o desenvolvimento do modelo são usadas para expressar ações concretas ao desenvolvimento do modelo, ou refinamento de um componente particular de modelagem ou um grupo de componentes. As suposições expressam tipos hipotéticos de fatos, que podem ser preparados para um outro tipo de componente de modelagem por tipos de ligações tais como, motiva, apóia, impede, conflito, entre outros. Depois, durante a fase de elaboração e refinamento do modelo, as suposições podem ser transformadas em oportunidades, problemas, fraquezas, ameaças, objetivos, processos, requisitos do sistema de informação. Os cenários são usados para representar uma série de eventos alternativos possíveis, processos, ou questões, os quais podem ser descritos ou elaborados no modelo.

Um outro tipo de prática de modelagem apresentada por BUBENKO et al. (1998), é colocar os componentes de modelagem em grupos. Essa prática é comum na sessão intermediária de modelagem, quando há uma estrutura dos componentes de modelagem solta, sem relacionamento com as outras estruturas, uma situação comum que surge quando uma sessão de modelagem é muito pequena, ou o modelo não é completo por alguma razão. Existem muitas formas de agrupar categorias como por conteúdo (por exemplo, problemas de falta de competitividade, problemas de produção), por prioridade (como processos críticos do negócio) e por natureza (objetivos para mudanças, objetivos para estado futuro do negócio). Por exemplo, depois de uma reestruturação inicial do Modelo de Objetivos, é possível incluir grupos de objetivos estratégicos, objetivos de marketing e objetivos de produção. Depois, cada um desses grupos pode ser reposto como um simples objetivo, decomposto em um grupo separado contendo sub-objetivos que são membros do grupo, ou conectados juntos de qualquer forma. 


\subsection{Utilização da Abordagem EKD}

Segundo BUBENKO et al. (1998), a abordagem EKD está longe de ser constituída de apenas um produto, o Modelo Organizacional e seus submodelos. O sucesso da aplicação do EKD depende inteiramente da forma pela qual é introduzido na organização e na forma em que o processo de desenvolvimento é conduzido. No trabalho de BUBENKO et al. (1998) são apresentadas algumas diretrizes para introduzir e usar a abordagem EKD. Mesmo a abordagem e seus predecessores tendo sido aplicados por muitos anos, muito conhecimento novo é ainda observado e desenvolvido, considerando-se a aplicação da abordagem. Essas diretrizes devem ser consideradas como conhecimento em constante evolução e extensão. Um grande número de experiências em Modelagem Organizacional (ou Modelagem de Negócio) tem sido feito na Suécia e resultou em:

- Descrições claras e com rigor adicional;

- Uma evolução na aprendizagem organizacional;

- Aceitabilidade na realização de mudanças e no processo de reengenharia na organização.

Foi observado por BUBENKO et al. (1998), que a abordagem é difícil de explicar, e que existe um risco de levar crenças em mudanças mágicas na organização, ou seja, acreditar que a abordagem automaticamente ajudará a resolver todos os problemas da organização. Existe a necessidade de muita disciplina para mover-se da fase inicial até versões de modelos melhorados usando ferramentas computacionais. A abordagem EKD pode ser aplicada por muitas razões diferentes e, sendo assim, proporcionará saídas e resultados diferentes. A saída desejada é chamada de alvo na abordagem EKD. Em BUBENKO et al. (1998), diferentes alvos são descritos:

1. Uma companhia deseja desenvolver uma estratégia para desenvolvimento em longo prazo de seus recursos humanos. Essa aplicação irá concentrar-se no Modelo de Objetivos. Quais são os objetivos gerais em longo prazo? Quais objetivos considerando recursos humanos são reconhecidos e como esses objetivos estão relacionados aos objetivos em longo prazo da organização? Quais problemas são enfrentados e quais ameaças e restrições existem? Mas esse tipo de análise pode muito bem introduzir a necessidade de melhorar a análise conceitual e modelagem de conceitos essenciais para o problema em questão. Por exemplo, o que se entende por recursos humanos, como avaliá-los, o que se entende por competência e como avaliála, que tipo de competência será necessária no futuro, considerando os objetivos 
declarados. Essa análise poderá trazer o desenvolvimento do Modelo de Processos do Negócio. Novos tipos de posições, tarefas, e habilidade podem requerer ainda o desenvolvimento do Modelo de Atores e Recursos.

2. Uma questão geral pode ser formulada como "o sistema corrente satisfaz a necessidade de apoio de informações para a série de estratégias em longo prazo. Se não, o que deve ser mudado para alcançar uma solução satisfatória?" Inicialmente, os objetivos da situação futura devem ser analisados. Depois, baseado nesse conjunto de objetivos, o conjunto de processos e regras do negócio deve ser examinado e reprojetado. Um novo Modelo de Atores e Recursos será provavelmente desenvolvido. O conjunto atual de sistemas de informação deve ser descrito e suas propriedades gerais dadas no Modelo de Requisitos e Componentes Técnicos (MRCT). Um modelo do futuro conjunto de componentes técnicos necessários e seus requisitos devem ser desenvolvidos baseados na documentação de objetivos, processos, conceitos e atores para um futuro sistema de negócio. Uma comparação entre as propriedades do sistema atual técnico MRCT e requisitos do futuro conjunto de sistema de informação fornece a base para análise das necessidades para mudanças. Claramente, em muito casos, alternativas diferentes do futuro sistema de informação podem ser analisadas.

A seguir, algumas dicas, segundo BUBENKO et al. (1998) serão apresentadas dando uma pequena noção de vários problemas que poderão surgir:

1. Para introduzir a abordagem na companhia, é importante que esta seja aceita por todos. Para isso a gerência ou o responsável pelo orçamento deve estar convencido dos efeitos benéficos da abordagem. Outros funcionários da companhia, importantes para o projeto, devem ser convencidos de que o processo EKD não ameaçará seu emprego e posição. Aplicações custarão tempo e recursos humanos. Parece ser razoável entender que pessoas são em geral, cuidadosas em aceitar uma nova forma de trabalho, considerando as centenas oferecidas por firmas de consultorias. Nesse estágio inicial, pode ser útil mostrar histórias de sucesso referente a companhias que usaram EKD.

2. O projeto EKD deve ter uma missão e expectativas de resultados bem definidos. A proposta deve ser clara a todos os envolvidos.

3. O projeto EKD não pode ser executado com sucesso sem recursos suficientes e autoridade. Pessoas envolvidas devem ter tempo para participar e recursos computacionais (entre outros) devem ser alocados. 
4. Um projeto EKD tipicamente envolve um número variado de atores, tais como, gerente de projeto, o comitê de direção, grupo de referência, participantes da modelagem (tipicamente de 5 a 8 pessoas), facilitador da modelagem, técnicos na modelagem e outros. Entretanto, em um projeto pequeno não são necessários todos esses atores.

5. Ninguém pode conhecer todos os aspetos possíveis de um problema de projeto. Deve-se tentar compor um grupo abrangente para cobrir aspectos diferentes do problema em questão.

6. Não é aconselhado iniciar a primeira sessão de modelagem sem primeiro reunir os membros do grupo de modelagem individualmente. A reunião pode preferivelmente ser conduzida como uma entrevista. $\mathrm{O}$ entrevistador deveria ser o gerente do projeto ou facilitador. A entrevista normalmente dá um entendimento melhorado do que deveria (ou poderia) ser feito no primeiro seminário de modelagem.

7. Baseado nas entrevistas realizadas, o gerente de projeto e o facilitador da modelagem juntamente com outros membros do time técnico, devem preparar um plano de ação do primeiro seminário de modelagem. Esse plano deveria incluir as maiores questões para serem passadas ao grupo e ser realizada uma análise dos possíveis resultados e como estruturá-los. Possíveis obstáculos e conflitos devem ser analisados.

8. O primeiro seminário é realizado usando uma grande tela para anotações na parede, onde os participantes colocam suas idéias de diferentes componentes dos modelos usados, tais como: objetivos, problemas e oportunidades. A primeira sessão é normalmente iniciada com uma pequena introdução dos submodelos EKD e como o processo de modelagem será procedido. As diretrizes mostram como formular objetivos, problemas, entre outros. O primeiro seminário não deveria ter um tempo menor de 3 ou 4 horas. $\mathrm{O}$ resultado desse seminário é normalmente um gráfico não estruturado cobrindo alguns dos vários submodelos.

9. A tarefa dos técnicos em modelagem é, primeiramente, transportar o modelo da tela para um modelo computadorizado. Depois, o modelo é analisado e reestruturado. Declarações redundantes são eliminadas, componentes fortemente relacionados são aproximados. Descrições e relacionamentos são analisados criticamente. Componentes são generalizados e especializados (detalhados). Questões e comentários críticos são documentados. 
10. Depois de refinar o modelo, os técnicos têm que consultar os participantes da modelagem usando questões e comentários críticos do passo anterior. Possíveis mudanças e a extensão do modelo são discutidas com participantes individualmente.

11. As discussões do passo anterior fornecem informações para que os técnicos em modelagem possam melhorar o modelo. Esse é um estágio também necessário para desenvolver uma descrição do modelo e familiarizar os participantes de modelagem e para outras pessoas envolvidas.

12. Depois que a nova versão do modelo foi concluída, incluindo textos e gráficos que agregados estão no computador, o seminário walkthrough deverá ser realizado em um laboratório equipado com meios suficientes para expor o resultado do grupo de pessoas. O local do seminário deve ter um projetor com uma boa resolução. A tarefa do facilitador do walkthrough é agora expor os resultados obtidos para o grupo de modelagem, e convidá-lo para criticar e dar comentários construtivos e sugestões para mudanças. Todos os comentários e sugestões são documentados.

13. O trabalho baseado em dois seminários de modelagem normalmente não resulta em um modelo suficiente e completo. Análises adicionais e trabalho de reestruturação e walkthrough adicionais são necessários para alcançar um resultado útil. Trabalho contínuo, entretanto, tipicamente precede como interações incluindo trabalho entre o primeiro seminário e o walkthrough. A regra de parada é um conjunto de modelos descritos em detalhes suficientes que podem ser usados como base para um trabalho contínuo de implementação das sugestões dos modelos.

Em BUBENKO et al. (1998) é apresentado um conjunto de pré-condições para organizar a aplicação de um projeto EKD:

1. Deve ser passada uma missão clara para todo o time de modelagem.

2. Devem ser alocados tempo e recursos suficientes para a atividade.

3. A composição do grupo de modelagem deve ser baseada na idéia de que o time, coletivamente, tenha conhecimento em todos os campos necessários tais como: estratégias de negócio, objetivos, computação, software, sistema de informação, gerenciamento, questões operacionais, entre outras.

4. O grupo de modelagem deve ter a autoridade para reprojetar a organização;

5. Responsabilidades devem ser designadas considerando a documentação, uso e manutenção do Modelo Organizacional a ser desenvolvido. 
6. A atividade de modelagem tem que ser bem planejada com consideração:

$>$ às questões a serem discutidas;

aos participantes envolvidos;

$>$ à alocação de tarefa;

$>$ aos participantes sendo alocados em tempo;

$>$ às expectativas para ser completadas;

$>$ aos participantes recebendo treinamento no uso da Modelagem Organizacional antes do início da sessão de modelagem e

à participação de um facilitador experiente.

O gerente e os participantes do processo de modelagem devem entender completamente e concordar com todos os aspectos do projeto. O propósito, objetivos e escopo do projeto devem ser documentados. A alocação de recursos (pessoal, responsabilidade, tempo, dinheiro, recursos computacionais) deve ser determinada. Garantia de qualidade em termos de resultados e validação deve ser mantida e registrada.

As seguintes habilidades (algumas delas podem ser executadas por uma pessoa) são necessárias no projeto de modelagem:

1. O gerente de projeto, sendo da organização será responsável por:

$>$ Planejamento de Projeto;

$>$ Liderar o projeto e

$>$ Informar a gerência e o comitê de direção.

2. Comitê de Direção será tipicamente responsável por:

Apoio e "venda" do projeto dentro da organização;

$>$ Plano de trabalho;

$>$ Alocação de recursos;

Controle de qualidade e

Avaliação.

3. Grupo de referência, é geralmente formado por pessoas com conhecimento no domínio e outros stakeholders do projeto, que são responsáveis por:

$>$ Suprir o domínio de conhecimento e informação; 
$>$ Ajudar o facilitador com a estruturação de descrição dos modelos;

$>$ O grupo deve ser composto por pessoas:

$>$ De várias partes da organização com conhecimento e visões de abrangências muito amplas;

Due consigam sugerir mudanças organizacionais;

$>$ Entusiasmadas, de mente abertas e cooperativas.

4. O facilitador (pode ser recrutado de fora da organização), uma ou duas pessoas que:

Lidera $(\mathrm{m})$ e adverte $(\mathrm{m})$ durante as sessões de modelagem e

Apóia(m) cada um na aquisição de conhecimento e idéias do grupo de aplicação.

5. "Equilibrista" de Ferramenta é uma pessoa que tenha facilidade para lidar com ferramentas computacionais o suficiente para ajudar o facilitador na sessão de walkthrough.

6. O projeto também precisa de um Especialista em Ferramenta, responsável por modelar todo o desenvolvimento e realizar possíveis adaptações.

7. Um "Contador de Histórias" ou apresentador é necessário para fornecer aos participantes de modelagem introdução eficiente para as principais questões apresentadas no modelo.

8. Projetistas são importantes pela habilidade de ilustrar resultados essenciais das sessões de modelagem.

9. Especialista em Comunicação é responsável por desenvolver e adaptar técnicas e ferramentas para o trabalho síncrono ou assíncrono nos ambientes distribuído para indivíduos e grupos.

O primeiro seminário não deve falhar. Caso falhe, será difícil convencer o grupo a continuar a se dedicar. Por essa razão deve ser bem preparado. Se o projeto é aceito pela gerência e as pré-condições necessárias são encontradas, algumas questões devem ser tratadas no estágio de preparação. As linhas gerais são apresentadas de acordo com BUBENKO et al. (1998):

1. Selecionar as pessoas que sejam familiarizadas com o problema. Algumas vezes pode ser benéfico ter o lado do "consumidor" e do "produtor" representando uma visão mais abrangente. Em alguns estágios do projeto, pode ser necessário associar especialista de certas áreas do projeto. Esses especialistas podem sugerir soluções 
organizacionais ou de Tecnologia da Informação para satisfazer objetivos específicos declarados, como a reengenharia de alguns processos de negócio, ou desenvolvimento de alguns tipos de soluções de Tecnologia da Informação.

$\mathrm{Na}$ abordagem "top-down", o ponto inicial é a modelagem dos objetivos, na qual é necessário muito raciocínio para discutir o que se deseja alcançar. Por isso, é necessário que os participantes estejam diretamente envolvidos ou tenham conhecimento da tomada de decisão e formulação dos objetivos em um nível pertinente da organização, sendo operacional ou estratégico. Por outro lado, a abordagem "bottom-up", tipicamente usada na reestruturação de processos, deve ser iniciada com o processo de modelagem e pode requerer a participação de pessoas envolvidas nos processos para descrever e documentar processos organizacionais. Em todas as situações no entanto, pode ser necessário mudar membros de um grupo, uma vez que as discussões e modelos movem de uma área para outra, sendo necessário pessoas com conhecimentos diferentes.

Não é aconselhável ter um grupo em que os integrantes trabalhem juntos como a mesma atividade. Essa situação não permite o pensamento criativo, e até certo ponto ocorre uma repetição de idéias e visões conhecidas. O mesmo problema pode surgir se um superior direto estiver participando do grupo.

É aconselhável que os membros do grupo não se conheçam para estimular a troca de novas idéias, e deve-se evitar grandes diferenças de idades que podem estimular preconceitos ou conflitos de geração.

2. Entrevistar os especialistas em aplicações. O objetivo do seminário de modelagem é chegar a um consenso coletivo orientado às decisões. Isso deveria ser herdado com preparação adequada. $\mathrm{O}$ facilitador deveria entrevistar os participantes para:

Preparar-se e tornar-se familiarizado com cada participante;

Ganhar conhecimento do domínio do problema e de questões essenciais relacionadas;

Obter informações para permitir um cenário de questões dirigidas;

Adquirir informações que irão melhorar a sua habilidade em conduzir os seminários de modelagem, conseguindo apresentar diretrizes para os participantes concentrarem-se nas questões. 
Preparar-se para possíveis conflitos e para a necessidade de balancear um grupo ou pessoas dominantes que inibem a participação de outros.

3. A entrevista deveria focalizar as visões do entrevistado, os objetivos, suposições, os problemas enfrentados e as restrições observadas na área em questão. Supondo que a companhia tem o nome de COMP, uma divisão da companhia chamada DIV com uma particular função chamada F. Assume-se aqui que a proposta do projeto é analisar F e sugerir diferentes possibilidades de melhoramentos. As seguintes questões podem ser consideradas:

$>$ Como você descreveria a função $\mathrm{F}$, suas tarefas e atividades correntes dentro de DIV e COMP?

$>$ De acordo com sua opinião, descreva algumas questões importantes em F a fim de sejam consideradas nos próximos 3 a 5 anos.

$>$ Descreva alguns problemas correntemente experimentados por DIV com a função $F$.

Sugira objetivos de pequena e grande abrangências para a função F.

$>$ O que faz de F uma função necessária em DIV?

$>$ Em sua opinião quais são as forças e fraquezas atuais da função F?

$>$ Quais oportunidades existem na área de F?

> Quais restrições externas você gostaria de mencionar considerando F?

> Quais tendências externas podem influenciar a operação de F? Como?

$>$ Quais gerenciamentos deveriam estar particularmente preocupados com a operação de F?

$>$ Quais decisões importantes, com conseqüências abrangentes, nós teremos que tomar dentro de um ano considerando F?

> Você vê algum problema em realizar essas decisões?

4. As entrevistas fornecem ao gerente do projeto e facilitador uma visão melhorada das pessoas que participam nas sessões de modelagem e de suas visões, problemas, esperanças, preconceitos e sentimentos. Possibilitando ao facilitador a oportunidade de planejar o início de uma sessão de modelagem, como conduzi-la, e como lidar com situações inesperadas. 
5. Em geral o primeiro seminário deveria ser organizado de tal forma que promovesse trabalho concentrado. Sendo interessante que o local seja diferente daquele em que, usualmente, o grupo se reúne, ou que não seja associado à organização, passando uma atmosfera mais tranqüila e sem interrupções.

6. A sala deve conter:

Ao menos uma parede livre ( $3 \mathrm{~m}$ x $2 \mathrm{~m}$ ) para fixar uma tela para anotações.

> Cadeiras e mesas para todos os participantes, bem distribuídas na sala, de forma que ninguém fique escondido ou impossibilitado de acompanhar o seminário. Não deve haver distrações, como telefone.

$>$ Canetas (com tintas não permanentes) de cores diferentes para cada participante para facilitar a identificação.

Apagador e tesoura.

$>$ Papeis com adesivos (para anexar na tela para anotações)

$>$ Folhas com os nomes dos componentes para fazer anotações.

Uma pequena introdução deve ser dada no início do seminário para cada um dos seguintes itens:

1. Apresentação dos participantes;

2. O princípio do EKD;

3. A agenda do dia;

4. $\mathrm{O}(\mathrm{s})$ tópico(s) para discussão;

5. As regras para o máximo de produtividade:

Todos devem participar;

Tudo que for importante deve ser escrito em sentenças completas;

$>$ Todos devem ouvir o outro e pensar individualmente;

Todos devem se esforçar para balancear e ter consenso no resultado.

O objetivo do EKD não é apenas o Modelo Organizacional e sim obter um melhor entendimento para resolver problemas e desenvolver o conhecimento da organização. Para tanto, é necessário um estudo analítico e crítico do Modelo Organizacional e seus relacionamentos, baseado em um bom entendimento dos princípios da modelagem organizacional. Essa análise pode ser 
alcançada com a ajuda de questões. A lista de questões citadas a seguir não é completa, mas apenas exemplos que deverão ainda ser expandidos.

1. Cada objetivo é apoiado por um processo no Modelo de Processo? Se não, por que não?

2. Deveria ser introduzido o processo?

3. Quem é responsável por esse processo no Modelo de Atores e Recursos?

4. Deveria haver um investimento em um novo recurso para ajudar a execução desse processo?

5. Esse recurso precisa de um sistema de informação novo ou melhor?

6. Pode-se identificar no Modelo de Requisitos e Componentes Técnicos, os requisitos para o sistema de informação?

7. Existem regras do negócio que podem colocar restrições nos requisitos?

8. Existe uma definição comum da organização para essas restrições e requisitos no Modelo de Conceitos?

De acordo com BUBENKO et al. (1998), quando se procura por relacionamentos e inconsistências e se descobre lacunas, aumenta-se o conhecimento e entendimento da organização. O EKD torna o processo cognitivo de análise mais fácil através dos gráficos e das técnicas de representação estruturada na forma de Modelo Organizacional. Existem muitos perigos quando se envolve a comunicação de idéias entre humanos. No caso específico do EKD incluem-se:

1. Evitar iniciar a modelagem com longas explicações de conceitos abstratos.

2. Começar com atividades, objetivos ou processos práticos e bem conhecidos.

3. Evitar modelos desestruturados.

4. Conduzir a reestruturação e esclarecimento de atividades logo depois da sessão de modelagem, caso contrário, muitas informações inerentes no modelo desestruturado serão esquecidas.

5. Evitar descrições com poucas palavras que não são intuitivamente entendidas.

6. As descrições devem ser escritas cuidadosamente para que mais tarde elas possam ser facilmente entendidas.

7. Não colocar objetivos que não contribuem para a missão da organização.

8. Todos objetivos auxiliam uns aos outros. Não devem existir objetivos soltos. 
9. Evitar compor declarações que tenham muitos relacionamentos internos e externos, porque isso dificulta o entendimento e análise.

10. Evitar detalhar atributos antes que todo o contexto tenha sido estabelecido.

11. Os atributos não são todos relevantes.

12. Não verbalizar o que é aparente no modelo.

13. Evitar entidades duvidosas.

A primeira sessão é tipicamente uma atividade de brainstorming, sendo então necessária uma estrutura bem montada. Podem existir componentes redundantes, como dois objetivos que significam a mesma coisa, ou faltar componentes e relacionamentos importantes. A terminologia escrita pelos participantes pode ser ambígua. Depois do brainstorming vem a maior parte do trabalho, que é estruturar e analisar o resultado da primeira sessão, buscando torná-la apresentável para a próxima sessão. Para melhorar o primeiro modelo é necessário:

1. Introduzir relacionamentos. Os modelos começam a ter mais significado através dos relacionamentos entre os componentes. Os relacionamentos implícitos e indesejáveis devem ser descobertos e ajustados.

2. Uma classificação sistemática deve ser criada. A criação da estrutura depende do critério usado, da disponibilidade e uso de uma ferramenta computacional, do modelo a ser simplificado e se tem uma terminologia clara.

Antes da próxima sessão, os participantes devem ter em mãos todo o material da sessão anterior para que seja possível estudar o material e refletir sobre o conteúdo como uma introdução para a próxima sessão.

No seminário de Walkthrough os analistas apresentam para o grupo de aplicação o trabalho feito desde a primeira sessão. Durante o seminário os seguintes itens deverão ser realizados:

Revisão do trabalho na primeira sessão;

Realização de correções e/ou adição para modelos e descrições.

$>$ Estreitar o campo de discussão e especificar o domínio.

$>$ Criar novos modelos.

$>$ Expandir modelos anteriores.

Alocar tarefa para os participantes. 
Sugerir mais trabalho e direções futuras.

O estágio inicial da revisão deveria ser liderado pelos analistas que trabalharam com o modelo original e produziram o estado corrente. O segundo estágio deveria ser liderado pelos facilitadores que conduziram a primeira sessão de modelagem para assegurar a continuidade. Todas as modificações devem ser justificadas.

Procurar objetivos não é uma tarefa simples e por isso nem sempre é a melhor forma de resolver problemas. O EKD propõe organizar sessões de trabalho cooperativo, nas quais é utulizado brainstorming que, de acordo com ROLLAND et al. (1999), é melhor forma de exercer esse tipo de atividade que exige muita criatividade. Essa abordagem propõe modelar o conhecimento organizacional que fornece uma base para o entendimento da situação corrente e desse modo, estabelece uma visão do futuro sistema.

Uma característica interessante do EKD é sua natureza dinâmica. A principio o fluxo de decisão não é definido, mas construído dinamicamente. A confiabilidade do EKD depende da natureza do problema, da habilidade para medir o sucesso e a contribuição dos participantes. Julgar a confiabilidade não é uma tarefa fácil. Segundo BUBENKO et al. (1998), os problemas a serem atacados são geralmente mal-estruturados. Isso significa entre outras coisas que:

Não existe uma formulação definitiva para o problema;

$>$ Não é fácil saber como o trabalho é feito;

$>$ Não existe nenhuma forma de testar a solução;

Todo o problema é essencialmente único.

Não existe uma única solução correta para um problema e um ambiente particular. Adicionalmente, o ambiente e o problema que deverão ser atacados mudam continuamente. As soluções que serão escolhidas dependem dos seguintes fatores:

$>$ a estrutura conceitual e experiência dos participantes;

o grau de comunicação de sucesso entre os participantes;

a disponibilidade dos participantes;

a disponibilidade de recursos físicos;

o tempo gasto suficiente para o processo.

Ainda não existe nenhuma técnica sistemática para medidas quantitativas de sucesso. Percebe-se que alguns objetivos do EKD, que são conhecimento e percepção do domínio, não são facilmente quantificados. Por essa razão, o sucesso pode ser alcançado se a equipe acreditar que vai 
ganhar alguma coisa com EKD. O recurso mais importante no processo de modelagem são as pessoas que colaborarão para a tarefa e o nível do treinamento que elas possuem. O impacto do trabalho de modelagem não será maior do que a esfera da autoridade do mais alto gerente da companhia participante ou apoiando de forma ativa o processo de modelagem. A participação do gerente assegura que as estratégias do negócio sejam consideradas. Para obterem resultados corretos, os participantes devem coletivamente entender e ter conhecimento de todos os aspectos da organização. Esse domínio do conhecimento específico deve ser focado quando houver a decisão dos integrantes do grupo de modelagem (BUBENKO et al., 1998).

O foco principal do projeto ELEKTRA é provar a aplicabilidade da metodologia EKD nas companhias de eletricidade -PPC- Public Power Corporation da Grécia e Vattenfall da Suécia, nas quais o gerenciamento de mudança não era realizado de uma maneira controlada e estruturada. $\mathrm{O}$ setor de eletricidade na Europa passou por mudanças rápidas e turbulentas e o gerenciamento de mudança tornou-se um fator de sobrevivência nas companhias desse setor (ELEKTRA, 2000).

Em NURCAN et al. (1999) são relatados os benefícios da aplicação do EKD na ECOM European Electricity Company- a qual deveria se organizar de acordo com as regras da União Europeia (UE) que liberou concorrências. Assim não existiria o monopólio e a ECOM deveria se adequar para entrar no mercado competidor. Os benefícios para companhia ECOM por ter usado a abordagem EKD foram os seguintes:

> A aplicação da abordagem mostrou-se numa procura sistemática e conduzida por maneiras alternativas para atingir um objetivo de mudança, sendo no caso de melhoramento ou extensão do objetivo existente ou ainda na introdução de um novo objetivo. Ajudou também os stakeholders a apresentarem soluções inovadoras.

$>$ Devido à abordagem de desenvolvimento de objetivos usar como entrada o modelo de objetivo, os stakeholders foram capazes de apontar os impactos da mudança que eles estavam propondo nos processos existentes.

$>$ Os stakeholders foram capazes de realizar uma avaliação do cenário de alternativas de mudanças para selecionar a mais apropriada.

As versões mais antigas do EKD já foram aplicadas em algumas organizações como British Aerospace (Reino Unido), TELIA (Suécia), ERICSSON (Suécia), CESELSA (Espanha), Sweden Post (Suécia). Nessas organizações o método aplicado incluía: melhoramento de processos de negócio, planejamento de estratégia de negócio, definição de requisitos do sistema. Em ELEKTRA (2000) estão disponíveis grandes projetos que sistematicamente utilizaram a metodologia EKD e comprovaram grandes mudanças nas estruturas organizacionais e melhoras 
nos processos de negócio. Os resultados desses projetos são extensivamente apresentados em ELEKTRA $^{\mathrm{B}}(1999)$

O projeto ELEKTRA produziu uma base de conhecimento que contém modelos (padrões) de gerenciamento de mudança para o setor de eletricidade. O objetivo desses modelos é fornecer soluções nas áreas de Distribuição de Eletricidade e Gerenciamento de Recursos Humanos. Esse modelo consiste de uma linguagem para descrever o conhecimento embutido nos modelos e um método para descobrir as práticas e soluções potenciais e sua generalização de forma que eles possam ser aplicados em mais de uma organização. Em ROLLAND et al. (2000) avaliou-se esse modelo, criado pelos mesmos autores para capturar as melhores práticas do gerenciamento de mudança da abordagem EKD e as mais importantes conclusões foram:

Um alto nível de abstração deve ser evitado enquanto é descrita a solução para o problema organizacional. Os avaliadores freqüentemente expressaram que o nível de abstração era inapropriado para o tipo de problema a ser resolvido e na maioria das vezes o nível de abstração era muito alto.

$>$ Os modelos em grupo são mais fáceis de entender do que os isolados porque apresentam soluções mais completas. Assim os usuários podem entender mais rapidamente a idéia global de como as soluções propostas podem ser aplicadas naquelas situações.

> Os modelos deveriam descrever soluções concretas em vez de diretrizes e sugestões de como "agarrar" o problema em geral. As soluções propostas deveriam ser ilustradas pelas melhores práticas e ter referência para casos similares na vida real.

Os modelos deveriam descrever soluções alternativas com diretrizes para escolha de uma solução apropriada dependendo de uma situação particular da organização. Os avaliadores confirmaram que a base de conhecimento de uma determinada área é um parâmetro importante para resolver problemas no mesmo contexto.

\subsection{Considerações Finais}

A abordagem EKD propõe modelar o conhecimento organizacional para entender, analisar, melhorar e consertar algum sistema. Os componentes do EKD são modelos organizacionais que examinam a organização de um número de perspectivas inter-relacionadas. Esses modelos irão coletivamente constituir o Modelo Organizacional. 
O EKD direciona para a construção de modelos diferentes, representando o estado inicial da organização e o futuro estado, além da expressão das estratégias alternativas para mudanças, a avaliação dessas estratégias e outras atividades de brainstorming.

A metodologia fornece, de forma natural, uma possibilidade para os participantes entrarem em questões e fenômenos que são relacionados com sua parte do negócio e ver o impacto de suas decisões ou requisitos de todos os processos da organização. Os modelos proporcionam benefícios para a cultura e aprendizado organizacional. Os participantes devem explicitamente contribuir com seus conhecimentos do domínio, suas habilidades e experiências. Eles devem ser abertos, construtivos e ativamente participativos. O desenvolvimento do conhecimento organizacional é extremamente dependente dos participantes. 


\section{Conclusão}

Inicialmente este trabalho apresenta a prática tradicional de desenvolvimento de software, na qual a especificação de requisitos é muitas vezes o único documento com as informações do negócio. Essa atividade do ciclo de vida do sistema de informação é freqüentemente negligenciada. Quando realizada, geralmente é um documento longo e de difícil análise e validação. Para obter uma especificação livre de ambigüidade e inconsistência, em alguns casos acrescenta-se rigor matemático, reduzindo assim a linguagem natural, o que torna difícil a compreensão das pessoas do negócio, que por esse motivo, não participam da elaboração. Essa especificação deveria ser uma ponte que liga o negócio à tecnologia da informação, mas acaba formando um grande "vazio". Esse é o grande problema das organizações e sistemas.

Com base na literatura pesquisada, constata-se que a grande maioria dos métodos e linguagens, inclusive orientados a objetos, não considera a organização, o que leva a falhas na captura das necessidades do negócio. As notações gráficas são muito simples, como Diagrama de Fluxo de Dados e Diagrama de Entidade e Relacionamento, e não permitem análises precisas, avaliação de alternativas para os processos do negócio, entendimento de objetivos e estratégias, o que inviabiliza uma visão do contexto mais próxima da realidade da organização.

A linguagem UML, muito aceita pelos seguidores da linha $\mathrm{OO}$, não é direcionada para a definição de requisitos organizacionais, levando a falhas na captura das necessidades do negócio. O diagrama use case tem sido adotado com notável aceitação, é considerado como parte fundamental na Análise Orientada a Objeto e tem sido incorporado em várias metodologias recentes. Alguns autores o consideram um bom veículo para planejamento de projeto, porque controla o desenvolvimento interativo, o qual por si só é uma valiosa técnica para mostrar ao usuário o que o sistema deve fazer.

Por outro lado, alguns estudos foram apresentados, mostrando que não há captura de requisitos no diagrama use case. Esse diagrama é tratado por muitos como sendo uma forma de focar em como os usuários vêem as operações do sistema, mas na maioria das vezes o sistema ainda não existe e se existe não é satisfatório. Além disso, a visão do usuário está relacionada com os processos computadorizados existentes, que podem ser modos antiquados de operação.

A grande motivação deste trabalho está em mostrar soluções para os problemas de captura correta dos requisitos de software, principalmente com aspectos ligados à organização, que 
em geral não são considerados. Esses aspectos são fundamentais à compreensão das reais necessidades e intenções dessas organizações.

Nesse sentido, algumas abordagens de modelagem organizacional foram mostradas no presente trabalho, como forma de capturar requisitos organizacionais na tentativa de melhorar a compreensão do domínio, interagir com usuários para que eles entendam o que o sistema pode fazer para melhorar o negócio, e adquirir conhecimento da estrutura organizacional e estratégica para que o compartilhamento e o reuso de todo o ciclo de desenvolvimento sejam facilitados. $\mathrm{O}$ processo de modelagem organizacional deve trazer respostas a estas questões: por que, o que, quem, qual, quando, onde e como.

A modelagem organizacional foi considerada como um passo importante para se chegar a um conhecimento estruturado do negócio, para discutir mudanças e estruturar as regras do negócio, que representam requisitos que governam o sistema operacional da organização e determinam como o negócio é executado, podendo ser originadas dos objetivos organizacionais. Uma das primeiras técnicas de modelagem organizacional apresentadas neste trabalho foi a técnica de BUBENKO (1993) que mostrou-se viável por possuir uma linguagem mais natural, permitindo que pessoas do negócio participem da construção do modelo.

O modelo organizacional representa o "mundo" onde se aplicam as regras do negócio. Diferentes abordagens de regras do negócio foram apresentadas, mostrando que as organizações precisam ter um claro entendimento destas para serem flexíveis em um ambiente de crescente competitividade. Ao permitir que regras do negócio sejam definidas e gerenciadas separadamente, fazendo uma ligação com a Engenharia de Software, gerando e mantendo aplicações das regras do negócio, tem-se um excelente potencial para que o estado da arte de Sistemas de Informação evolua.

Em ambientes instáveis os desenvolvedores de software são desafiados a desenvolver sistemas que atendam aos requisitos das organizações modernas que passam por sucessivas mudanças. A mudança não é um processo simples, para realizá-lo a organização deve entender e conhecer a situação atual e a situação futura que se espera alcançar e como será alcançado esse estado.

As organizações devem criar novas formas de trabalhar para que sobrevivam no atual ambiente competitivo. Nesse contexto, foi apresentado que modelar o conhecimento organizacional contribui para o entendimento da situação corrente e se estabelece, assim, uma visão do futuro sistema. Portanto, modelar a organização torna-se um pré-requisito muito importante para o desenvolvimento de sistemas de informação. Poucas abordagens investigam o aspecto dinâmico da modelagem do conhecimento, focando na automação dos processos existentes 
(ROLLAND ${ }^{\mathrm{B}}$ et al., 1999). Nesse sentido, a abordagem EKD foi apresentada no presente trabalho por ser uma evolução da abordagem de BUBENKO (1993), pois proporciona uma forma estruturada de descrever o conhecimento organizacional. O EKD permite a realização de diferentes tipos de análises e discussões sobre o que tem sido dito e escrito sobre a organização. Em função dessas características, a metodologia foi apresentada em destaque no capítulo 4 mostrando que é possível chegar a um repositório de conhecimento, que pode ser usado para discutir mudanças no negócio e componentes do sistema de informação e traçar uma cadeia de componentes e decisões que leva a várias interpretações das decisões e dos componentes de informação. A abordagem auxilia os desenvolvedores de sistemas de informação e stakeholders na determinação dos requisitos e objetivos do sistema.

Os componentes do EKD são modelos conceituais que examinam a organização e seus requisitos a partir de um número de perspectivas inter-relacionadas. Esses modelos são abstrações do mundo físico. Para uma dada organização, esses modelos irão constituir coletivamente o Modelo Organizacional. Verifica-se que alguns desses modelos fornecem informações relevantes que apontam a necessidade de avaliação das alternativas de situações operacionais. Tais informações incluem critérios para avaliação, escolhas disponíveis, parâmetro de medidas e argumentos registrados a favor e contra escolhas. Para desenvolver um modelo organizacional completo é necessário fazer ligações entre os componentes de diferentes submodelos. Essas ligações mostraram executar uma tarefa essencial, tornando o conhecimento mais disponível e possibilitando ilustrar por que certos processos e requisitos do sistema de informação têm que ser introduzidos. A habilidade de traçar decisões, componentes e outros aspectos em todas as partes da organização depende do uso e entendimento dessas ligações. Toda ligação representa uma declaração feita sobre a organização e possivelmente seus requisitos do sistema de informação. A semântica de todas ligações deve ser analisada cuidadosamente. Existe, entretanto, um conjunto mínimo de ligações que deveria ser definido pela representação que fosse considerada completa.

Uma grande vantagem observada do EKD é a facilidade de uso. A notação utilizada tem como principal objetivo ser compreendida por todos usuários, sem requerer muito treinamento. $\mathrm{O}$ método ainda fornece um conjunto de diretrizes para sua introdução e aplicação, uma vez que o sucesso depende totalmente da forma em que a abordagem é introduzida e na forma que o processo de desenvolvimento é conduzido. Um outro fator importante considerado no EKD é o Modelo de Regras do Negócio que é usado para definir e manter regras do negócio formuladas explicitamente e consistentes com o modelo de objetivos. As regras do negócio estão relacionadas aos processos do negócio, porque condições diferentes vão requerer a invocação de processos diferentes. São as regras do negócio que determinam os estados permissíveis dos objetos do negócio e a interação 
entre tarefas diferentes. Essa foi a única abordagem dentre as encontradas na literatura a tratar explicitamente o Modelo de Regras do Negócio e suas ligações com outros modelos.

A modelagem de Regras do Negócio mostrou estar intimamente relacionada com o Modelo de Objetivos. As regras são definidas por objetivos ao mesmo tempo em que interferem na realização de outros objetivos. Elas disparam processos de negócio e têm conceitos definidos no Modelo de Conceitos. Atores do Modelo de Atores são responsáveis por alcançar e definir regras do negócio. Regras do negócio requerem funcionalidade do sistema de informação. Componentes do Modelo de Requisitos e Componentes Técnicos podem ser motivados por regras do negócio.

Por meio do Modelo de Regras do Negócio pode-se definir e manter explicitamente regras do negócio formuladas, consistentes com o Modelo de Objetivos. Regras do Negócio podem ser vistas como operacionalização ou limites dos objetivos. Elas controlam a organização na forma em que definem e restringem quais ações podem ser executadas em várias situações. Na abordagem EKD as regras do negócio são elementos simples para entendimento, sem rigor matemático, proporcionando uma grande evolução na fase de engenharia de requisitos.

No Modelo de Requisitos e Componentes Técnicos (MRCT) torna-se relevante definir os requisitos para o desenvolvimento de um sistema de informação. A atenção é centralizada no sistema técnico que é necessário para apoiar os objetivos, processos e atores da organização. Para tanto é desenvolvido um conjunto de requisitos de alto nível ou objetivos para o sistema de informação como um todo. Baseado nesses requisitos, o sistema de informação é estruturado em um número de subsistemas, ou componentes técnicos. O MRCT é uma tentativa inicial para definir toda a estrutura e propriedades do sistema de informação, além de apoiar as atividades do negócio, como definido no MPN. O MRCT normalmente esclarece questões como: quais requisitos são gerados pelos processos do negócio, qual o potencial da tecnologia da informação para melhoria do processo. Antes de desenvolver um sistema de informação, é necessário entender as influências que os objetivos terão na parte operacional do negócio. Os componentes desse submodelo devem estar intimamente relacionados aos componentes do Modelo do Processo de Negócio, Modelo de Objetivos ou Modelo de Regras do Negócio. Uma comparação entre as propriedades do atual sistema técnico MRCT e requisitos do futuro conjunto de sistema de informação fornece a base para análise das necessidades para mudanças.

$\mathrm{Na}$ abordagem EKD existe o cuidado de relacionar os componentes do Modelo de Objetivos através de ligações semânticas monodirecionais, das quais os principais tipos são: a) de apoio: é usado para refinar ou decompor objetivos e outros componentes; b) de impedimento: é usado para mostrar influências negativas entre componentes do Modelo de Objetivos; c) de 
conflito: é usado para definir situações em que ao atingir um objetivo, poderá haver um conflito com outro objetivo.

Para resolver essas ligações de conflitos a metodologia prevê o gerenciamento de conflito, que lida com duas questões chaves: conhecimento da trajetória do conflito e gravação das informações sobre esses conflitos, tais como as circunstâncias que levam a esses conflitos. Muito frequientemente, os objetivos de alto nível, os problemas, as regras do negócio, entre outros, adquiridos no estágio de aquisição, contêm um número de requisitos informais e imprecisos. É recomendado que a saída do Modelo de Objetivos inicial seja estruturada no estágio inicial. Para tanto é necessário realizar a classificação, priorização e correlação de objetivos. Na classificação dos objetivos é desenvolvida uma tabela matriz onde eles podem ser categorizados de acordo com origem, stakeholder, função, domínio, etc. Isso permitirá a comparação, a análise e, talvez a descoberta da necessidade de mais discussões baseadas na análise dos padrões dos objetivos. A correlação de objetivos é compreendida como interação positiva e negativa entre objetivos, sendo também desenvolvida uma tabela matriz a qual assegura que todas as interações possíveis serão descobertas.

No trabalho de ROSCA et al. (1997), também foi valorizada a importância da detecção de conflitos, uma vez que os objetivos de uma organização não são destituídos de conflitos. As redundâncias e conflitos devem ser eliminados, ou se não for possível, devem ser deixados visíveis aos projetistas, desenvolvedores e usuários do sistema de informação.

Um outro diferencial observado do EKD, é o fato de poder ser usado em situações diferentes e com propósitos diferentes, como nas seguintes situações:

Na engenharia de requisitos para definição e especificação de requisitos;

$>\mathrm{Na}$ análise do negócio para detecção do problema;

$>$ Na reengenharia de processos do negócio para definição de novos sistemas de negócio;

> No gerenciamento de conhecimento organizacional ou aprendizagem organizacional para formar a base de propagação e ampliação de conhecimento.

Com base na literatura pesquisada percebe-se que a aplicação de estratégias específicas no Desenvolvimento de Conhecimento Organizacional é muito afetada por vários fatores, incluindo:

$>$ Cultura organizacional: por exemplo, as pessoas que não trabalham em grupo de uma forma participativa não conseguem contribuir. 
Participação de pessoas "certas": a qualidade do conhecimento do modelo depende da participação de pessoas chaves em termos de especialista no negócio e no método.

Habilidade social e bom relacionamento entre os participantes: conflitos entre indivíduos e grupos dentro do projeto aumenta a complexidade da situação.

Uso de ferramentas para facilitar a execução do processo: o uso de ferramentas de apoio a sessões de reuniões aumenta a produtividade e a qualidade dos resultados obtidos

Familiaridade com as estratégias e tecnologia de apoio: o entendimento entre os participantes do projeto e a compreensão das capacidades e limitações das estratégias e das ferramentas aplicadas são vitais para fazer melhorar o uso e produzir bons resultados.

A falta desses fatores impede que o processo de gerenciamento de mudança seja totalmente prescrito. É interessante que o processo de mudança siga diretrizes flexíveis e não regras rígidas.

$\mathrm{O}$ uso do EKD e das abordagens que precederam em muitas aplicações diferentes durante os últimos dez anos, mostraram que a razão do sucesso não era apenas o Modelo Organizacional, mas também o gerenciamento apropriado do processo do negócio e engenharia de requisitos. Diferente de algumas abordagens que usam cenários apenas para a análise dos requisitos, na abordagem EKD, os cenários são usados apenas para representar uma série de eventos alternativos possíveis, processos, ou questões, os quais podem ser descritos ou elaborados no modelo.

Além disso, considera-se que o recurso mais importante no processo de modelagem são as pessoas que colaborarão para a tarefa e o nível do treinamento que elas possuem. O EKD propõe organizar sessões de trabalho cooperativo. A participação da alta gerência da companhia assegura que as estratégias do negócio sejam consideradas. Para obter resultados corretos, os participantes devem, coletivamente, entender e ter conhecimento de todos os aspectos da organização.

Finalmente, considera-se que a partir deste trabalho pode-se originar novos trabalhos, como a criação metodologias de treinamentos em Modelagem Organizacional e Regras do Negócio e aplicação do EKD em organizações visando buscar dados estatísticos que comprovem os resultados. 


\section{Referência Bibliográfica}

ACHOUR, B.; SOUVEYET, C.; TAWBI, M. (1999). Bridging the gap betwem users and requirements engineering: the scenario-based approach. International Journal of Computer Systems Science \& Engineering, v.14, n.6, p.112-122, Nov.

ALENCAR, F. M. R. (1999). Mapeando a modelagem organizacional em especificações precisas. Recife. 304p. Tese (Doutorado) - Centro de Informática, Universidade Federal de Pernambuco.

ALENCAR, F.M.R..; SOUZA, F..M.; CASTRO, J.F.B. (1999). Modelagem organizacional: análise comparativa das técnicas $i^{*}$. In: WORKSHOP IBEROAMERICANO DE ENGENHARIA DE REQUISITOS DE AMBIENTE DE SOFTWARE, San Jose, Costa Rica March 1999. Proceedings. p. 326- 337.

BERNUS, P.; NEMES, L.(1997). Requirements of the generic enterprise reference architecture and methodology. Annual Reviews in Control, v. 21, p. 125-136.

BERZTISS, A.T.; BUBENKO JR., J.A.(1995). A software process model for business reengineering. In: INFORMATIONS SYSTEMS DEVELOPMENT FOR DECENTRALIZED ORGANIZATIONS / IFIP WORKING CONFERENCE, Trondheim, 2123 August, Trondheim, Proceedings. Norway, Chapman \& Hall. Chapman \& Hall.

BUBENKO JR, J.A.; WANGLER, B. (1993). Objectives driven capture of business rules and information systems requirements. In: INTERNATIONAL CONFERENCE ON SYSTEMS, MAN AND CYBERNETICS, Le Touquet, France, Proceedings. s.n.t. p.670-677.

BUBENKO JR., J.A. (1993). Extending the scope of infomation modelling. In: INTERNATIONAL WORKSHOP ON THE DEDUCTIVE APPROACH TO INFORMATION SYSTEMS AND DATABASE, 4., Lloret-Costa Brava, Proceedings. Departament de Llenguatges i Sistemes Informatics of the Universitat Politecnica de Catalunya, Barcelona, Catelonia, A. Olivé (Ed.). p.73-98. 
BUBENKO JR., J.A.; KIRIKOVA, M. (1994). Enterprise modelling: improving the quality of requirements specification. In: IRIS-17 INFORMATION SYSTEMS RESEARCH SEMINAR IN SCANDINAVA, Oulu, Proceedings, s.n.t.

BUBENKO JR.; J. A., STIRNA, J.; BRASH, D. (1998). EKD user guide, Dpt of computer and systems sciences. Stockholm, Royal Institute of Technology.

BUHR, R. J. A. (1998). Use case maps as architectural entities for complex systems. IEEE Transactions on Software Engineering, v. 24, n.12, p.1131-1155, Dec.

CERI, S.; FRATEMALE, P. (1997). Designing database applications with objects and rules: the IDEA methodology. Reading, Mass Addison-Wesley.

CERVO, A.L.; BERVIAN, P.A. (1983). Metodologia Cientifica. São Paulo, Makron.

DALlAVAlLE, S.I.; CAZARINI, E.W. (2000). Regras do negócio: fator chave de sucesso no processo de desenvolvimento de sistemas de informações. ENEGEP - Encontro Nacional de Engenharia de Produção, 10., São Paulo, 31 out. CD ROM.

DOBSON, J. E.; STREMS, R. (1994). Organizational requirements definition for information technology. In: IEEE INTERNATIONAL CONFERENCE ON REQUERIMENTS ENGINEERING, Los Alamitos, Proceedings, s.1, IEEE Computer Society. p. 158 -165.

ELECTRICAL ENTERPRISE KNOWLEDGE FOR TRANSFORMING APPLICATIONS. (2000). The ELEKTRA project programme. www.singular .gr/elektra.ekd.htm. (27 Nov.)

FOWLER, M.; SCOTT, K. (1997). UML distilled - applying the standard object modelling language. Reading, Mass (Addison Wesley Object Technology Series).

FURLAN, J. D. (1997). Modelagem de negócio - uma abordagem integrada de modelagem estratégica funcional, de dados e a orientação a objetos. São Paulo, Makron Books.

FURLAN, J.D. (1998). Modelagem de objetos através da UML - the unified modeling language. São Paulo, Makron Books.

GOTTESDIENER, E. (1997). Business rules show power, promise. Application Development Trends, v. 4, n. 3, p. 36-43, March.

GOTTESDIENER, E. (1999). Capturing business rules. Software Developement, v.7, n. 12, p.72-76, Dec. 
GREENPAN, S.; FEBLOWITZ, M. (1993). Requirements engineering using the SOS paradigm. In: IEEE INTERNATIONAL SYMPOSIUM ON REQUERIMENTS ENGINEERING, San Diego, 1993. Proceedings. Los Alamitos, IEEE Computer Society.

HAUMER, P.; POHL, K.; WEIDENHAUPT, K. (1998). Requirements elicitation and validation with real word scenes. (CREWS Report 98-16).

HERBST, H.et al. (1994). The specification of business rules: a comparision of selected methodologies. In: IFIP WORKING CONFERENCE ON METHODS AND ASSOCIATED TOLLS FOR THE INFORMATION SYSTEMS LIFE CYCLE, Maastricht, 1994. Proceedings. Amsterdan, Elsevier. p.29-46.

HERBST, H. (1995). A meta-model for busines rules in systems analysis. In: CONFERENCE ON ADVANCED INFORMATION SYSTEMS ENGINEERING, 7., Jyvaskyla,1995. Proceedings. Berlin, Springer. p. 186-199.

HERBST, H. (1996). Business rules in system analysis: a meta-model and repository system. Information Systems, v. 21, n.2, p 147-166.

INTELLICORP. (1995). Livemodel user's guide, betaversion. s.n.t.

JACOBSON, I. (1995). A confused world of OOA and OOD. Journal Object-Oriented Programming, v.8, n.5, p.15-20, Sept.

JACOBSON, I.; BOOCH, G.; REUMBAUGH, J. (1999). The unified software development process. Reading, Mass, Addison Wesley.

KILOV, H.; SIMMONDS, I. (1997). Business rules: from business specification to design. In: BOSCH, J.; MITCHELL, S. Object oriented technology. Berlin, Springer. (Lectures Notes in Computer Sciences, 1357).

KIRIKOVA, M. (2000). Explanatory capability of enterprise models. Data \& Knowledge Engineering, n.33, p. 119-136.

KOTONYA, G.; SOMMERVILLE, L. (1996). Requirements engineering with viewpoints. Software Engineering Journal, v.11, n.1, p.5-18, Jan.

LARMAN, C. (1999). Appliyng UML and patterns: an introduction object-oriented and design. New Jersey, Prentice-Hall. 
LEE, W..J.; CHA, S. D.; KNON, Y.R. (1998). Integration and analysis of use cases using modular petri nets in requirements engineering. IEEE Transaction on Software Engineering, v.24, n.12, p.1115-1130.

LEITE, J.C.S.P.; PÁDUA, A.O.(1995). A client oriented requirements baseline. In: IEEE INTERNATIONAL SYMPOSIUM ON REQUERIMENTXS ENGINEERING, 2., York, 1995. Proceedings. Los Alamitos, IEEE Computer Society. p.108- 115.

LEITE, J.C.S.P.; LEONARDI, M.C. (1998). Business rules as organizational policies. In: INTERNATIONAL WORKSHOP ON SOFTWARE SPECIFICATION \& DESIGN, 9., Japan. Proceedings. Los Almitos, IEEE CSP. p. 68-76.

LILLY, S. (2000). How to avoid use-case pitfalls. Software Development, v.8, n.1, p.40-45, Jan.

LOUCOPOULOS, P. et al. (1998). Using the EKD approach: the modeling component. Manchester, UMIST.

MARTIN, J.; ODELL, J. J. (1995). Análise e projeto orientados a objeto. São Paulo, Makron Books.

MEYER, B. (1997). OOSC2: the use case principle. Journal Eiffel Liberty, v.1, n.2.

NISSEN, M.E. (1999). Knowledge-based knowledge management in the reengineering domain. Decision Support Systems, v.27, n 1-2., p.47-65 27, Nov.

PRADO, A. F. (1999). Desenvolvimento de software orientado a objetos na pós-graduação: nota de aula. http://www.dc.ufscar.br/ prado/ensinoepesquisa.html. (17 Maio).

PRESSMAN, R.S. (1994). Software engineering: practitioner's approach. 3.ed. England, McGraw-Hill.

ROLLAND, C.; NURCAN, S.; GROSZ, G. (1999). Enterprise knowledge development: the process view. Information and Management Journal, v.36, n.3, p. 165-184.

ROLLAND, C.; GROSZ, G.; KLA, R. (1999). Experience with goal-scenario coupling in RE. In: IEEE INTERNATIONAL SYMPOSIUM ON RE, 4., Limerich, Ireland, 7-19 June. Proceedings. Ireland, University of Limerich. 
ROLLAND, C.; NURCAN, S.; GROSZ, G. (2000). A decision making pattern for guiding the enterprise knowledge development process. Journal of Information and Software Technology, v.42, p. 313-331.

ROSCA, D. et al. (1995). Application of a decision support mechanism to the business rules lifecycle. In: KNOWLEDGE BASED SOFTWARE ENGINEERING CONFERENCE KBSE95, 10., Boston, 1995. Proceedings. IEEE Computer Society. p. 114-121.

ROSCA, D.; WILD, C. (1996). Business rules in the real world: a decision support approach. http://www.cs.odu.edu/ techrep/techreports/TR_97_07.os.Z. (03 June)

ROSCA D. et al. (1997). A decision making methodology in support of business rules lifecycle. In: IEEE INTERNATIONAL SYMPOSIUM ON REQUERIMENTS ENGINEERING,Annapolis, MD, 1997. Proceedings. s.l. IEEE Computer Society. p. 236 $-246$.

STERGIOU, M.; JOHNSON, L. (1998). The importance of business rules in the organizational transformation process. In: INTERNATIONAL CONFERENCE ON INFORMATIUON SYSTEMS, ANALYSIS AND SYNTHESIS, 4., Orlando, 1998. Proceedings. Orlando, International Institute of Informatics and Systemics. v.3, p.548-553.

SUTCLIFFE, A. G. et al. (1998). Supporting scenario-based requirements engineering. IEEE Transaction on Software Engineering, v.24, n.12, p. 1072-1088, Dec.

TAURION, C. (1999). Como alinhar tecnologia e negócio: opinião. http://www.uol.com.br/computerworld/news/opiniao/990913taurion.htm (09 jan)

YU, E. (1993). Modelling organizations for informations systems requirements engineering. In: IEEE INTERNATIONAL SYMPOSIUM ON REQUERIMENTS ENGINEERING, San Diego, 1993. Proceedings. Los Alamitos, IEEE Computer Society. p.34-41. 